\title{
A Comparison of the Effect of Outdoor Exposure on the Optical Properties of Solar Mirrors and Transparent Encapsulant Materials
}

\author{
L. S. Dake \\ M. A. Lind \\ C. R. Maag
}

September 1981

Prepared for the Solar Energy Research Institute under Related Services Agreement XP-9-8366-2 and the U.S. Department of Energy under Contract DE-AC06-76RLO 1830

Pacific Northwest Laboratory Operated for the U.S. Department of Energy by Battelle Memorial Institute 
NOTICE

This report was prepared as an account of work sponsored by the United States Government. Neither the United States nor the Department of Energy, nor any of their employees, nor any of their contractors, subcontractors, or their employees. makes any warranty, express or implied, or assumes any legal liability or responsibility for the accuracy. completeness or usefulness of any information, apparatus, product or process disclosed, or represents that its use would not infringe privately owned rights.

The views. opinions and conclusions contained in this report are those of the contractor and do not necessarily represent those of the United States Government or the United States Department of Energy.

\author{
PACIFIC NORTHWEST LABORATORY \\ operated by \\ BATTELLE \\ for the \\ UNITED STATES DEPARTMENT OF ENERGY \\ Under Contract DE-AC06-76RLO 1830
}
Printed in the United States of America
Available from
National Technical Information Service
United States Department of Commerce
5285 Port Royal Road
Springfield. Virginia 22151

Price: Printed Copy $\$$

$\therefore$ Microfiche $\$ 3.00$

NTIS

-Pages Selling Price

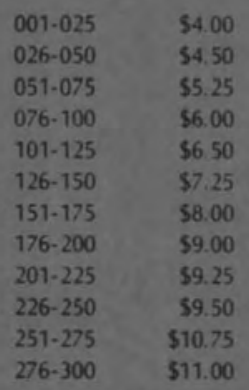




\section{A COMPARISON OF THE EFFECT OF OUTDOOR EXPOSURE ON THE OPTICAL PROPERTIES OF SOLAR MIRRORS AND TRANSPARENT ENCAPSULANT MATERIALS}
L. S. Dake
M. A. Lind
C. R. Maag (a)

September 1981

Prepared for the Solar Energy Research Institute under Re'lated Services Agreement XP-9-8366-2 and the U.S. Department of Energy under Contract DE-ACO6-76RLO 1830

Pacific Northwest Laboratory

Richland, Washington 99352

(a) Jet Proputsion Laboratory

Pasadena, CA. 91103 


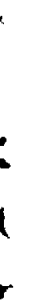




\section{ACKNOWLEDGEMENTS}

The authors wish to express their appreciation to $D$. Chaudiere, K. Mallory, D. Nelson, M. Nordmeyer and T. Stewart for their substantial contributions to the optical evaluations. The authors also wish to thank F. Morrelli and $W$. Neiderheiser of JPL for their assistance in the outdoor exposure testing. W. Neiderheiser was particularly helpful in forwarding samples and data and in assembling the characterizations of the California test sites. 


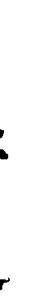




\section{EXECUTIVE SUMMARY}

This joint PNL and JPL study is an assessment and comparison of the effects of outdoor exposure on solar mirrors and transparent encapsulant materials. The encapsulant materials tested included glasses, polymers and silicones. Samples of the materials were placed on stationary exposure racks in six locations that represented urban, desert, oceanside and high altitude mountain areas. Samples were removed periodically and sent to PNL for optical characterizations. The spectral hemispherical and diffuse reflectance of the mirror samples was measured. The spectral hemispherical transmittance and diffuse reflectance of the encapsulant materials was measured. In addition JPL measured the "relative norma 1 hemispherical transmittance" of the encapsulant materials.

Correlations between the glass and mirror data showed that the average diffuse reflectance losses were six times larger for the mirrors than for the glass samples. The average specular reflectance losses for the mirror samples were seven times as large as the average hemispherical transmittance losses for the glass samples. These correlations may enable one to predict the performance of mirrors made using the other encapsulant materials for superstrates.

It was found that the urban and oceanside sites were the dirtiest, while the desert and mountain sites were the cleanest. Average specular reflectance losses varied from $4 \%$ at the cleanest site to $50 \%$ at the dirtiest site. The range in hemispherical transmittance losses for the encapsulant materials varied between $0 \%$ and $6 \%$. At one site, the average daily specular reflectance losses were $.04 \%$ for the mirror samples and average daily hemispherical transmittance losses were about .01\% for the glass samples. The polymer materials degraded somewhat more rapidly than the glasses, and the silicones irreversibly degraded too rapidly and severely to be useful for either photovoltaic or solar thermal applications. 


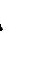

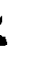

r 


\section{TABLE OF CONTENTS}

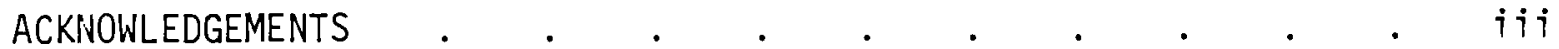

EXECUTIVE SUMMARY .

INTRODUCTION • . . . . . . . . . . . . . . 1

EXPERIMENTAL PROCEDURE $. \quad . \quad . \quad . \quad . \quad . \quad$. . . . . 1

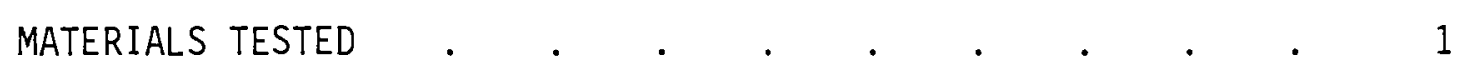

EXPOSURE RACKS . . . . . . . . . . . . . . 3

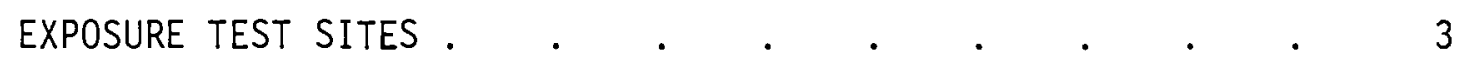

OPTICAL MEASUREMENTS $\quad$.

METHODS OF DATA ANALYSIS . . . . . . . . . . . 14

RESULTS AIID DISCUSSION

MIRROR AND GLASS DATA . . . . . . . . . . . 16

GLASS AND POLYMER DATA . . . . . . . . . . . 19

CONCLUSIONS

FEFERENCES . . . . . . . . . . . . . . . . . 28

APPENDIX A - DESCRIPTIONS OF OUTDOOR EXPOSURE TEST SITES

APPENDIX B - SODA LIME SILICATE GLASS MIRROR AND ENCAPSULANT DATA

APPENDIX C - GLASS AND POLYMER ENCAPSULANT DATA - SECOND YEAR STUDY

APPENDIX D - GLASS AND POLYMER ENCAPSULANT DATA - FIRST YEAR STUDY 


\section{LIST OF FIGURES}

1. Photograph Showing the JPL Exposure Rack . . . 4

2. Maps Showing Location of Exposure Sites . . . . 5

3. Spectral Reflectance Curves and Solar Weighted Values

for Second Surface Silvered Soda Lime Silicate Float

Glass Mirrors

4. Spectral Reflectance and Transmittance Curves and Solar Weighted Values for Soda Lime Silicate Float Glass

5. Spectral Reflectance and Transmittance Curves and Solar Weighted Values for Aluminosilicate Glass . $\quad .9$

6. Spectral Reflectance and Transmittance Curves and Solar Weighted Values for Borosilicate (7070)

Glass

7. Spectral Reflectance and Transmittance Curves and Solar Weighted Values for Borosilicate (7809)

Glass

8. Spectral Reflectance and Transmittance Curves and Solar Weighted Values for Polyvinylfluoride (Tediar) . 12

9. Spectral Reflectance and Transmittance Curves and Solar Weighted Values for Acrylic (Korad) . . . 13

B.1. Effects of Atmospheric Contamination on the Solar Weighted Optical Properties of Float Glass Mirrors Weathered at the Torrance Site, 1980-1981

B.1

B.2. Effects of Atmospheric Contamination on the Solar Weighted Optical Properties of Soda Lime Silicate Float Glass Weathered at the Torrance Site, 1980-1981 . B.2

B.3. Effects of Atmospheric Contamination on the Solar Weighted Optical Properties of Float Glass Mirrors Weathered at the Pasadena Site, 1980-1981

B.4. Effects of Atmospheric Contamination on the Solar Weighted Optical Properties of Soda Lime Silicate Float Glass Weathered at the Pasadena Site, 1980-1981 . B.4

B.5. Effects of Atmospheric Contamination on the Solar Weighted Optical Properties of Float Glass Mirrors Weathered at the Point Vicente Site, 1980-1981 . . B.5 
B.6. Effects of Atmospheric Contamination on the Solar Weighted Optical Properties of Soda Lime Silicate Float Glass Weathered at the Point Vicente Site, 1980-1981.

B.7. Effects of Atmospheric Contamination on the Solar Weighted 0ptical Properties of Float Glass Mirrors Weathered at the Richland Site, 1980-1981

B.8. Effects of Atmospheric Contamination on the Solar Weighted Optical Properties of Soda Lime Silicate Float Glass Weathered at the Richland Site, 1980-1981.

B.9. Effects of Atmospheric Contamination on the Solar Weighted 0ptical Properties of Float Glass Mirrors Weathered at the Goldstone Site, 1980-1981 . .

B.10. Effects of Atmospheric Contamination on the Solar Veighted Optical Properties of Soda Lime Silicate Float Glass Weathered at the Goldstone Site, 1980-1981

B.11. Effects of Atmospheric Contamination on the Solar Weighted 0ptical Properties of Float Glass Mirrors Weathered at the Table Mountain Site, 1980-1981

B.12. Effects of Atmospheric Contamination on the Solar Weighted Optical Properties of Soda Lime Silicate Glass Weathered at the Table Mountain Site, 1980-1981

C.1. Effects of Atmospheric Contamination on the Solar Weighted Transmittance $\left(\Delta T_{H}\right)$ of Glasses Weathered at the Torrance Site, 1980-1981

C.2. Effects of Atmospheric Contamination on the Solar Weighted Diffuse Reflectance $\left(-\Delta R_{D}\right)$ of Glasses Weathered at the Torrance Site, 1980-1981 . . . C.2

C.3. Effects of Atmospheric Contamination on the Solar Weighted Transmittance $\left(\Delta T_{H}\right)$ of Polymers Weathered at the Torrance Site, $1980-1981$

C.4. Effects of Atmospheric Contamination on the Solar Weighted Diffuse Reflectance $\left(-\Delta R_{0}\right)$ of Polymers Weathered at the Torrance Site, 1980-1981

C.5. Effects of Atmospheric Contamination on the Solar Weighted Transmittance $\left(\Delta T_{H}\right)$ of Glasses lleathered at the Pasadena Site, 1980-1981 
C.6. Effects of Atmospheric Contamination on the Solar Weighted Diffuse Reflectance $\left(-\Delta R_{R}\right)$ of Glasses

Weathered at the Pasadena Site, 1980-1981 . . . C.6

C.7. Effects of Atmospheric Contamination on the Solar Weighted Transmittance $\left(\Delta T_{H}\right)$ of Polymers

Weathered at the Pasadena Site, 1980-1981 . . . C.7

C.8. Effects of Atmospheric Contamination on the Solar Weighted Diffuse Reflectance $\left(-\Delta R_{D}\right)$ of Polymers

Weathered at the Pasadena Site, 1980-1981. . . C.8

C.9. Effects of Atmospheric Contamination on the Solar Weighted Transmittance $\left(\Delta T_{H}\right)$ of Glasses Weathered at the Point Vicente Site, 1980-1981. . . . C.9

C.10. Effects of Atmospheric Contamination on the Solar Weighted Diffuse Reflectance $\left(-\Delta R_{D}\right)$ of Glasses

Weathered at the Point Vicente Site, 1980-1981 . . C.10

C.11. Effects of Atmospheric Contamination on the Solar Weighted Transmittance $\left(\Delta T_{H}\right)$ of Polymers Weathered at the Point Vicente Site, 1980-1981. . . . C.11

C.12. Effects of Atmospheric Contamination on the Solar Weighted Diffuse Reflectance $\left(-\Delta R_{D}\right)$ of Polymers Weathered at the Point Vicente Site, 1980-1981 . . C.12

C.13. Effects of Atmospheric Contamination on the Solar Weighted Transmittance $\left(\Delta T_{H}\right)$ of Glasses Weathered at the Richland Site, $1980-1981$. . . . C.13

C.14. Effects of Atmospheric Contamination on the Solar Weighted Diffuse Reflectance $\left(-\Delta R_{D}\right)$ of Glasses Weathered at the Richland Site, 1980-1981. . . C.14

C.15. Effects of Atmospheric Contamination on the Solar Weighted Transmittance $\left(\Delta T_{H}\right)$ of Polymers Weathered at the Richland Site, 1980-1981. . . .

C.16. Effects of Atmospheric Contamination on the Solar Weighted Diffuse Reflectance $(-\Delta R)$ of Polymers Weathered at the Richland Site, 1980-1981. . . C.16

C.17. Effects of Atmospheric Contamination on the Solar Weighted Transmittance $\left(\Delta T_{H}\right)$ of Glasses Weathered at the Goldstone Site, $1980-1981$. . .

C.18. Effects of Atmospheric Contamination on the Solar Weighted Diffuse Reflectance $\left(-\Delta R_{D}\right)$ of Glasses Weathered at the Goldstone Site, 1980-1981 . . . C.18 
C.19. Effects of Atmospheric Contamination on the Solar Weighted Transmittance $\left(\Delta \mathrm{T}_{H}\right)$ of Polymers Weathered at the Goldstone Site, 1980-1981. . . . . C.19

C.20. Effects of Atmospheric Contamination on the Solar Weighted Diffuse Reflectance $\left(-\Delta R_{0}\right)$ of Polymers Weathered at the Goldstone Site, 1980-1981 . . . C.20

C.21. Effects of Atmospheric Contamination on the Solar Weighted Transmittance $\left(\Delta T_{H}\right)$ of Glasses Weathered at the Table Mountain Site, 1980-1981 . . .

C.22. Effects of Atmospheric Contamination on the Solar Weighted Diffuse Reflectance $\left(-\Delta R_{D}\right)$ of Glasses Weathered at the Table Mountain Site, 1980-1981

C.23. Effects of Atmospheric Contamination on the Solar Weighted Transmittance $\left(\Delta T_{H}\right)$ of Polymers Weathered at the Table Mountain Site, 1980-1981

C.24. Effects of Atmospheric Contamination on the Solar Weighted Diffuse Reflectance $\left(-\Delta R_{D}\right)$ of Polymers Weathered at the Table Mountain Site, 1980-1981

D.1. Effects of Atmospheric Contamination on the Solar Weighted Transmittance $\left(\Delta T_{H}\right)$ of Glasses Weathered at the Torrance Site, 1979-1980 . . . . . D.1

D.2. Effects of Atmospheric Contamination on the Solar Weighted Diffuse Reflectance $\left(-\Delta R_{D}\right)$ of Glasses Weathered at the Torrance Site, 1979-1980 . . . D.2

D.3. Effects of Atmospheric Contamination on the Solar Weighted Transmittance $\left(\Delta T_{H}\right)$ of Polymers Weathered at the Torrance Site, 1979-1980 . . . . . D.3

D.4. Effects of Atmospheric Contamination on the Solar Weighted Diffuse Reflectance $\left(-\Delta R_{D}\right)$ of Polymers Weathered at the Torrance Site, 1979-1980

D.5. Effects of Atmospheric Contamination on the Solar Weighted Transmittance $\left(\Delta T_{H}\right)$ of Glasses Weathered at the Pasadena Site, 1979-1980 . . . . . D.5

D.6. Effects of Atmospheric Contamination on the Solar Weighted Diffuse Reflectance $\left(-\Delta R_{R}\right)$ of Glasses Weathered at the Pasadena Site, 1979-1980 . . . 0.6 
D.7. Effects of Atmospheric Contamination on the Solar Weighted Diffuse Reflectance $\left(-\triangle R_{D}\right)$ of Polymers Weathered at the Pasadena Site, 1979-1980 . . . D.7

D.8. Effects of Atmospheric Contamination on the Solar Weighted Transmittance $\left(\Delta T_{H}\right)$ of Polymers Weathered at the Pasadena Site, $1979-1980$. . . .

D. 8

D.9. Effects of Atmospheric Contamination on the Solar Weighted Transmittance $\left(\Delta T_{H}\right)$ of Glasses Weathered at the Point Vicente Site, $1979-1980$. . . . D.9

D.10. Effects of Atmospheric Contamination on the Solar Weighted Diffuse Reflectance $\left(-\Delta R_{D}\right)$ of Glasses Weathered at the Point Vicente Site, 1979-1980 . . D.10

D.11. Effects of Atmospheric Contamination on the Solar Weighted Transmittance $\left(\Delta T_{H}\right)$ of Polymers Weathered at the Point Vicente Site, $1979-1980$. . . . D.11

D.12. Effects of Atmospheric Contamination on the Solar Weighted Diffuse Reflectance $\left(-\Delta R_{D}\right)$ of Polymers Weathered at the Point Vicente Site, 1979-1980 . . 0.12 


\section{LIST OF TABLES}

1. Materials Deployed at the Outdoor Exposure Test Sites . . 2

2. Average Solar Weighted Optical Losses at Each Site for Soda Lime Silicate Float Glass and Mirrors. Second Year Data (1980-1981). . . . . . . . . 17

3. Daily Degradation Rates and Correlation Coefficients (in parentheses) as Calculated by a Linear Regression Analys is for the Entire Exposure Period for Soda Lime Silicate Float Glass and Mirror Samples. Second Year Data (1980-1981).

4. Daily Degradation Rates and Correlation Coefficients (in parentheses) as Calculated by a Linear Regression Analys is After the First 45 Days of Exposure for Soda Lime Silicate Float Glass and Mirror Samples. Second Year Data (1980-1981)

5. Average Solar Weighted Optical Losses for Glasses. Second Year Data (1980-1981). . . . . . . . . 22

6. Average Solar Weighted Optical Losses for Glasses. First Year Data (1979-1980). . . . . . . . 23

7. Average Solar Weighted Optical Losses for Polymers. Second Year Data (1980-1981). . . . . . . . . 24

8. Average Solar Weighted Optical Losses for Polymers. First Year Data (1979-1980). . . . . . . . 25 


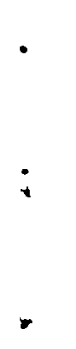




\section{INTRODUCTION}

The Pacific Northwest Laboratory (PNL) the and Jet Propulsion Laboratory (JPL) conducted a joint study on the effects of outdoor exposure on the optical properties of some transparent encapsulant and reflector materials. JPL performed exposure testing on stationary racks located at several different sites as part of their Low-Cost Solar Array (LSA) photovoltaic program. PNL provided the mirror samples and did the optical characterizations in support of the solar thermal Research and Advanced Development (RAD) program. Average degradation rates were calculated. Linear regression analysis was performed on the data to determine average daily degradation rates for each material at each site. The data was also analyzed to determine the range of degradation between the cleanest and dirtiest sites.

One purpose of the study was to determine correlations between the glass encapsulant materials and the mirror optical degradation data. If these correlations could be extended to the other encapsulant materials tested, predictions could be made about the performance of mirrors constructed using the different encapsulant materials as superstrates. Correlations were also sought between the different measurement techniques to determine which measurements were most useful in predicting the end use performance of the materials.

\section{EXPERIMENTAL PROCEDURE}

\section{MATERIALS TESTED}

The mirrors used in the exposure tests were standard industry wetchemistry second surface silvered float glass with PPG grey paint backing. The encapsulant materials tested included three different glasses, two polymers and two silicones. A detailed description of the materials is supplied in Table 1. Samples of each material were cut into $.05 \mathrm{~m} \times .05 \mathrm{~m}$ (2 in. $x 2$ in.) square coupons for deployment on the exposure racks. 
TABLE 1. Materials Deployed at the Outdoor Exposure Test Sites

Mirrors:

Second surface silvered soda lime

silicate float glass with grey paint

backing.

Glasses:

Soda lime silicate float glass

CGW 7070 and 7809 borosilicate glass

CGW 0317 aluminosilicate glass

Polymers:

DuPont Tedlar polyvinylfluoride

XCEL Korad 212 acrylic

Silicones:

G.E RTV-615 silicone rubber

D.C. Q1-2577 hardcoat silicone on

CGW 7070 borosilicate glass substrate 
It was quickly discovered that both of the silicone materials irreversibly degraded too rapidly to be useful for either photovoltaic or solar thermal applications. Therefore, no analysis of the silicone materials is presented in this report.

\section{EXPOSURE RACKS}

Special racks were constructed by JPL for sample deployment at all the sites. The racks were constructed of stainless steel coated with a black epoxy paint. Stainless steel strips were bolted to the racks. Samples were placed between the stainless steel strips, which were then tightened so that the samples were held securely in place. A sample rack containing coupons is shown in Figure 1 . The polymer samples were too thin to be held in place by the stainless steel strips. These samples were put in polymer slide holders, which could be secured in the racks. Rain channels were constructed between each row of samples to direct rain water to the side of the rack. In this manner, samples in lower rows were not contaminated by dirt washed off the samples above them.

The racks were deployed at each site so that the samples faced to the south. The racks were tilted at a $45^{\circ}$ angle. A sample of each material was removed periodically and sent to PNL and JPL for evaluation. Two studies were done at every site except Richland, Washington. In the first study, only encapsulant materials were expused, and samples were collected once a month. In the second study both encapsulant and reflector materials were deployed. Samples were collected about every three months and evaluated.

\section{EXPOSURE TEST SITES}

JPL deployed sample racks throughout the United States as a part of their LSA project. Six sites were chosen for consideration in this report. The map in Figure 2 shows the location of the sites. The sites chosen represented urban areas (Pasadena and Torrance, $C A$ ); desert regions (Richland, WA and Goldstone, $C A$ ); high altitude mountains (Table Mountain, $C A$ ); and an oceanside location (Point Vicente, $C A$ ). More complete descriptions of each site can be found in Appendix A. 


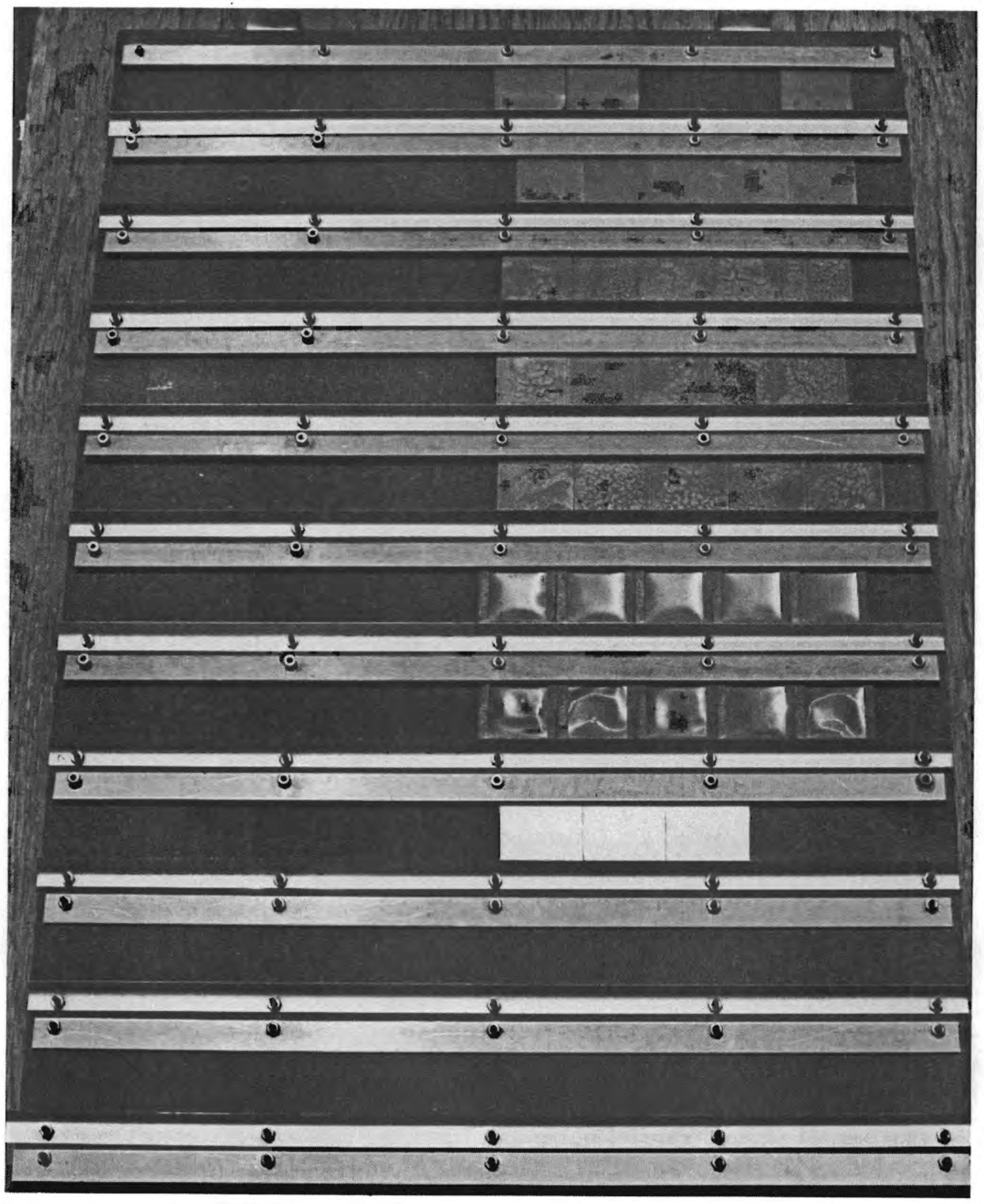

FIGURE 1. Photograph Showing the JPL Exposure Rack 


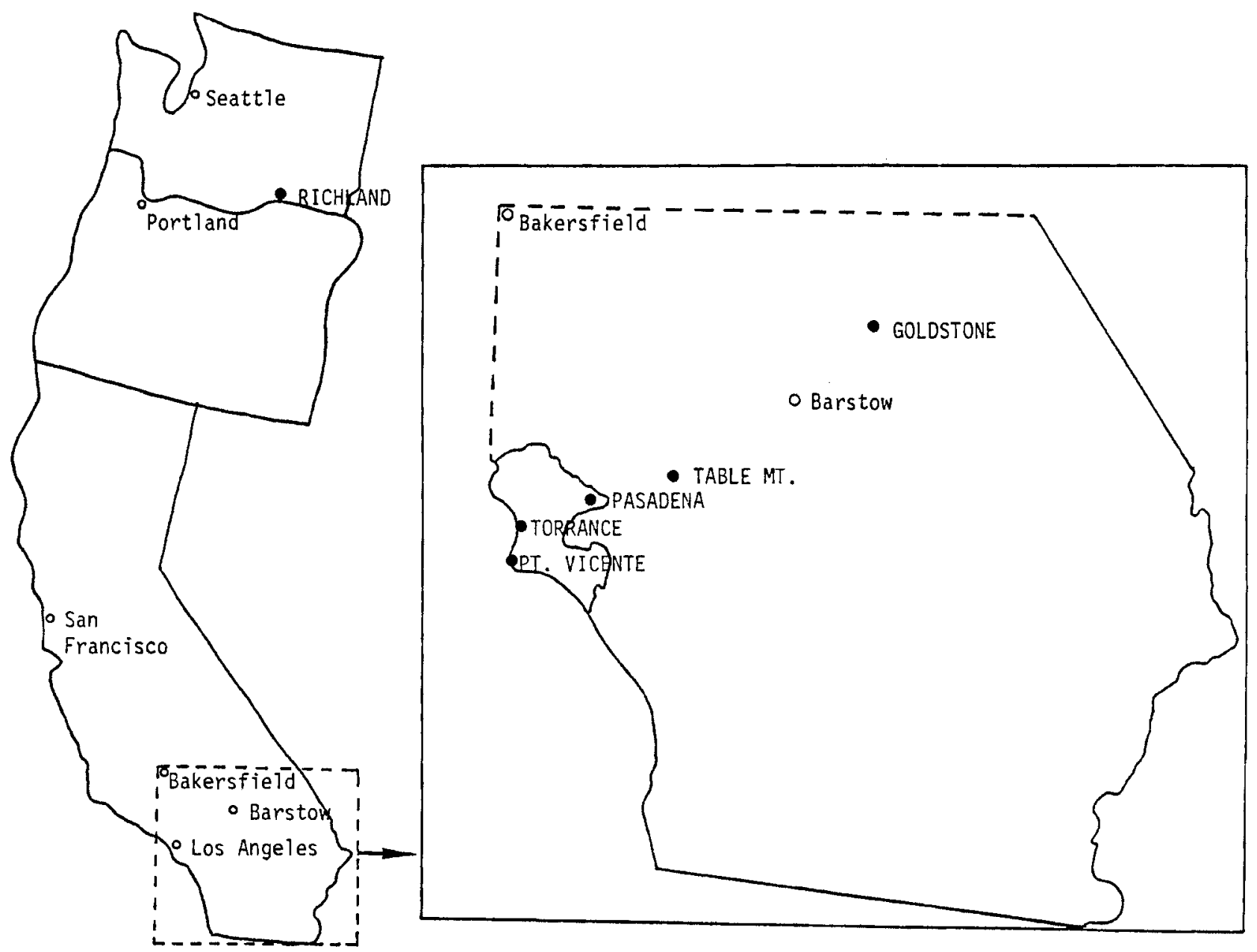

FIGURE 2. Maps Showing Location of Exposure Sites (solid circles). Reference cities are designated by the open circles. 


\section{OPTICAL MEASUREMENTS}

The sample coupons were sent to PNL for optical characterizations. Spectral hemispherical and diffuse reflectance measurements were performed on the mirror samples. Spectral hemispherical transmittance and diffuse reflectance measurements were performed on the encapsulant materials. A11 the measurements were done over the wavelength interval 300-2500 nm using a Beckman 5270 spectrophotometer with a $15 \mathrm{~cm}$ ( 6 in.) integrating sphere. The accuracy of the measurements is believed to be \pm .005 reflectance units and \pm .010 transmittance units. The spectral data was weighted to the NASA AM $1.5^{(1)}$ terrestrial solar spectral irradiance distribution (TSSID) using a best fit approximation routine to obtain the solar reflectance and transmittance. The result of this calculation is a single number between 0 and 1.000 (called the solar weighted reflectance or transmittance) that characterizes the entire spectral scan. The solar weighted value represents the fraction of solar energy reflected from or transmitted through the sample.

Typical spectral reflectance and transmittance curves are shown for each material in Figures 3 through 9 . In each figure, the curves for a clean, unweathered sample and a heavily soiled sample are plotted to illustrate some extreme changes in the optical performance that can occur. For all the materials, the hemispherical transmittances $\left(T_{H}\right)$ and reflectances $\left(R_{H}\right)$ decrease while the diffuse reflectances $\left(R_{D}\right)$ increase after weathering. The decreases in the hemispherical transmittances and reflectances are usually greatest in the ultraviolet-visible portion of the spectra $(300-750 \mathrm{~nm})$.

Samples were measured before $\left(R_{j}, T_{j}\right)$ and after $\left(R_{f}, T_{f}\right)$ outdoor exposure. For the encapsulant materials, the changes in the transmittance and diffuse reflectance values (i.e., the difference $\left(\Delta T_{H}\right.$ and $-\Delta R_{D}$ ) between the weathered sample and clean sample values) were plotted as a function of exposure time. In a similar manner, the changes in hemispherical, diffuse and specular reflectance were plotted for the mirror data. The change in hemispherical reflectance $\left(\Delta R_{H}\right)$ indicates the absorption of the dust layer. The change in diffuse reflectance $\left(-\Delta R_{D}\right)$ shows the losses due to scattering. The sum of the hemispherical and diffuse reflectance losses equals the total specular loss for the mirror samples $\left(\Delta R_{S}=\Delta R_{H}-\Delta R_{D}\right)$. 


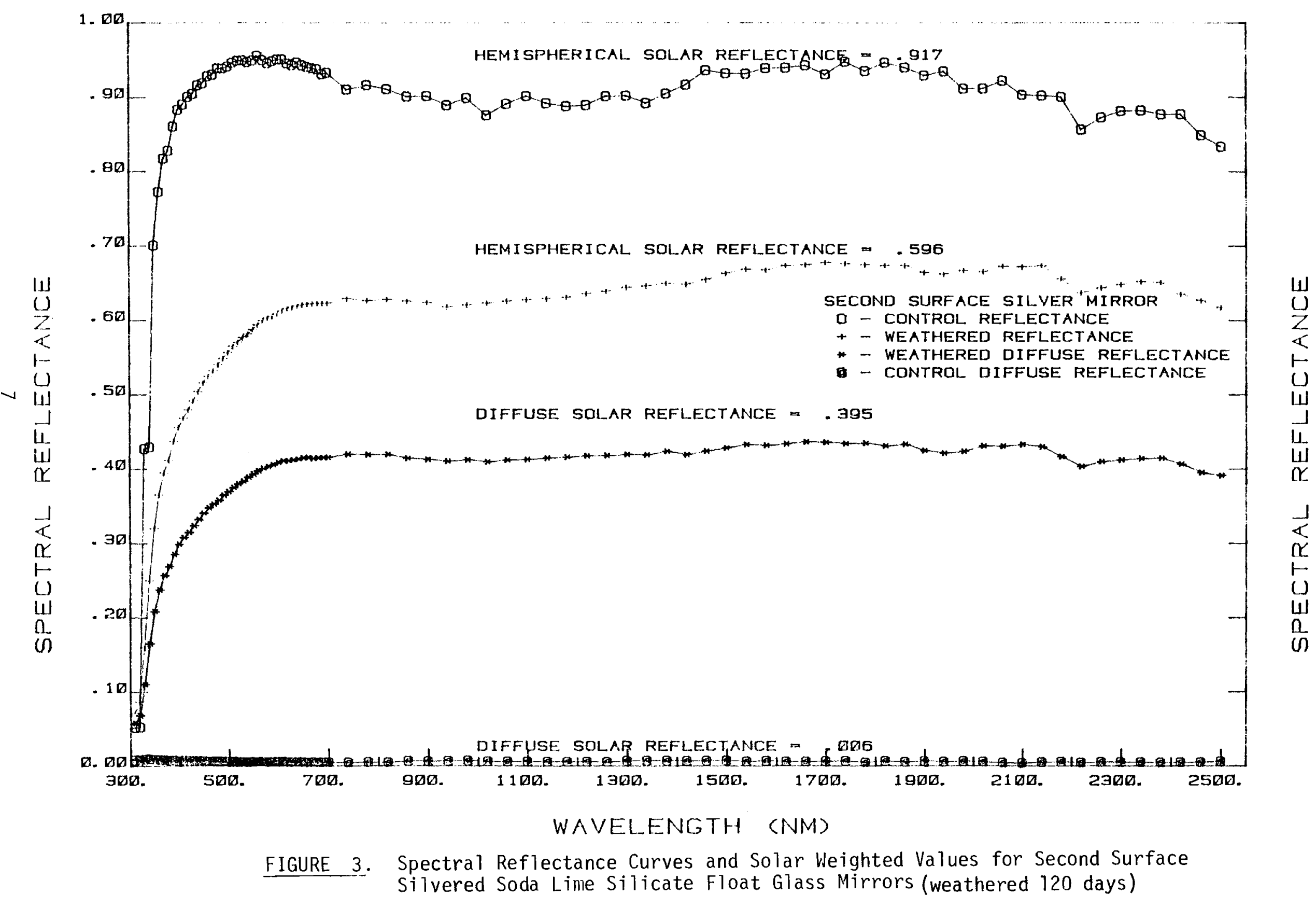




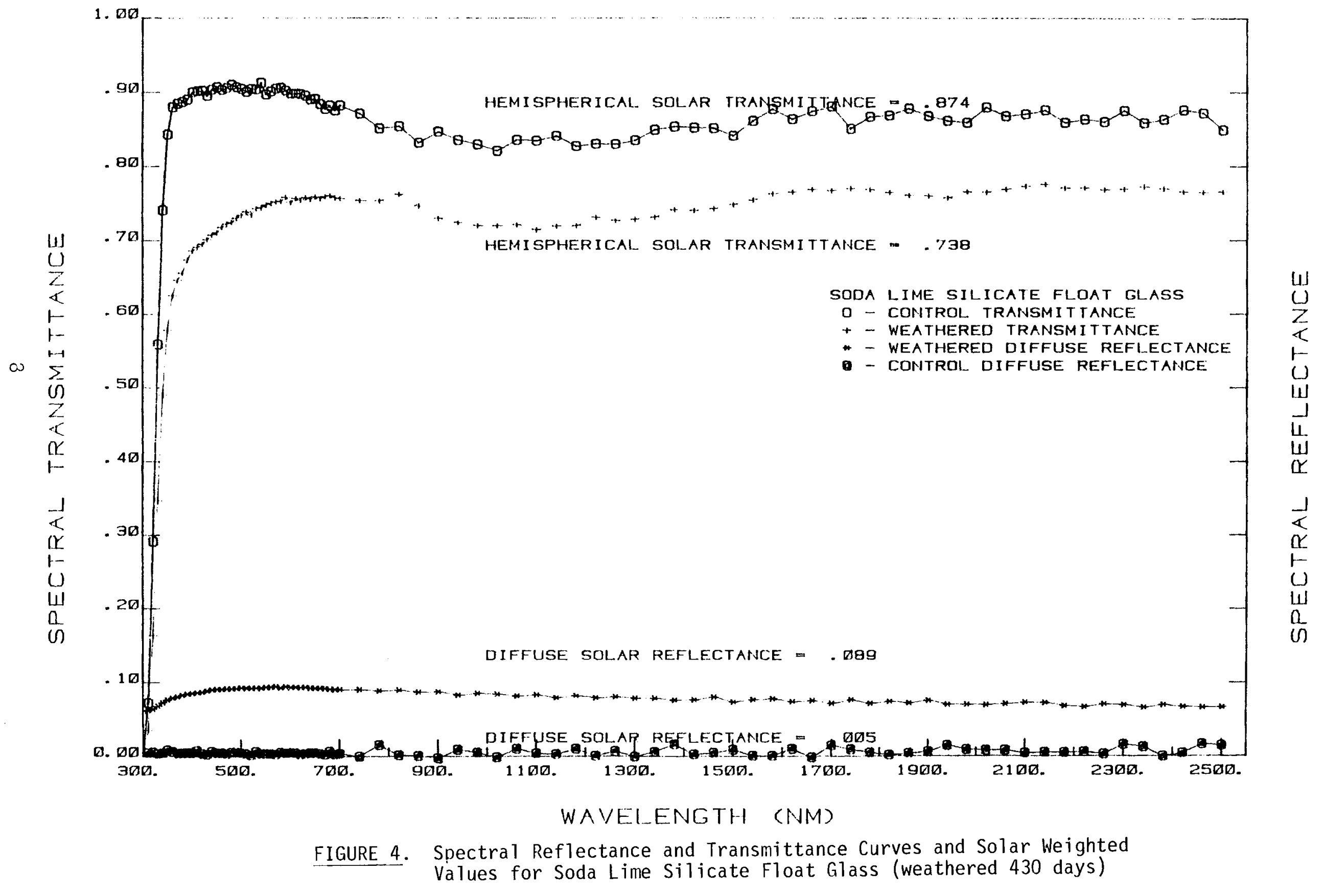




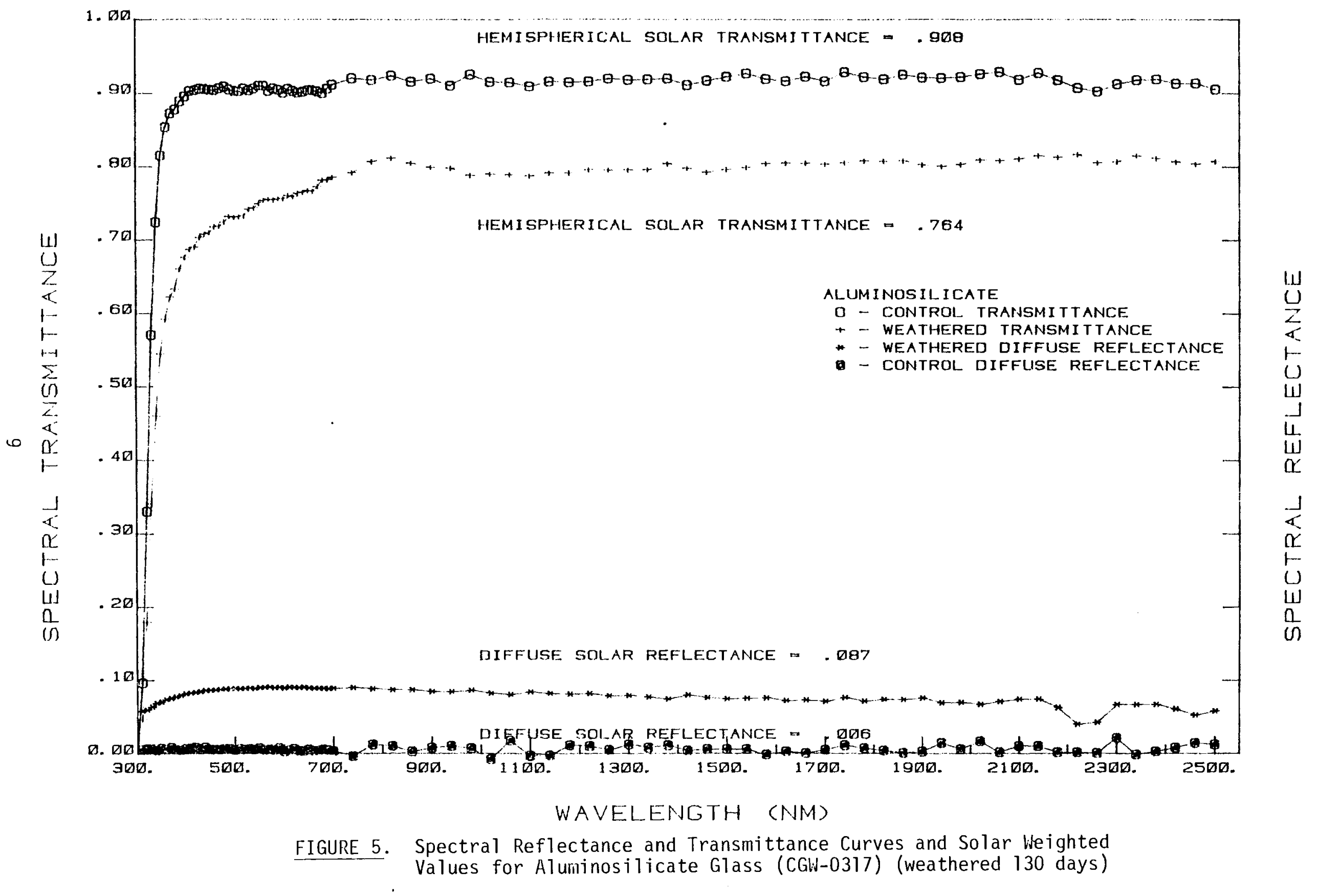




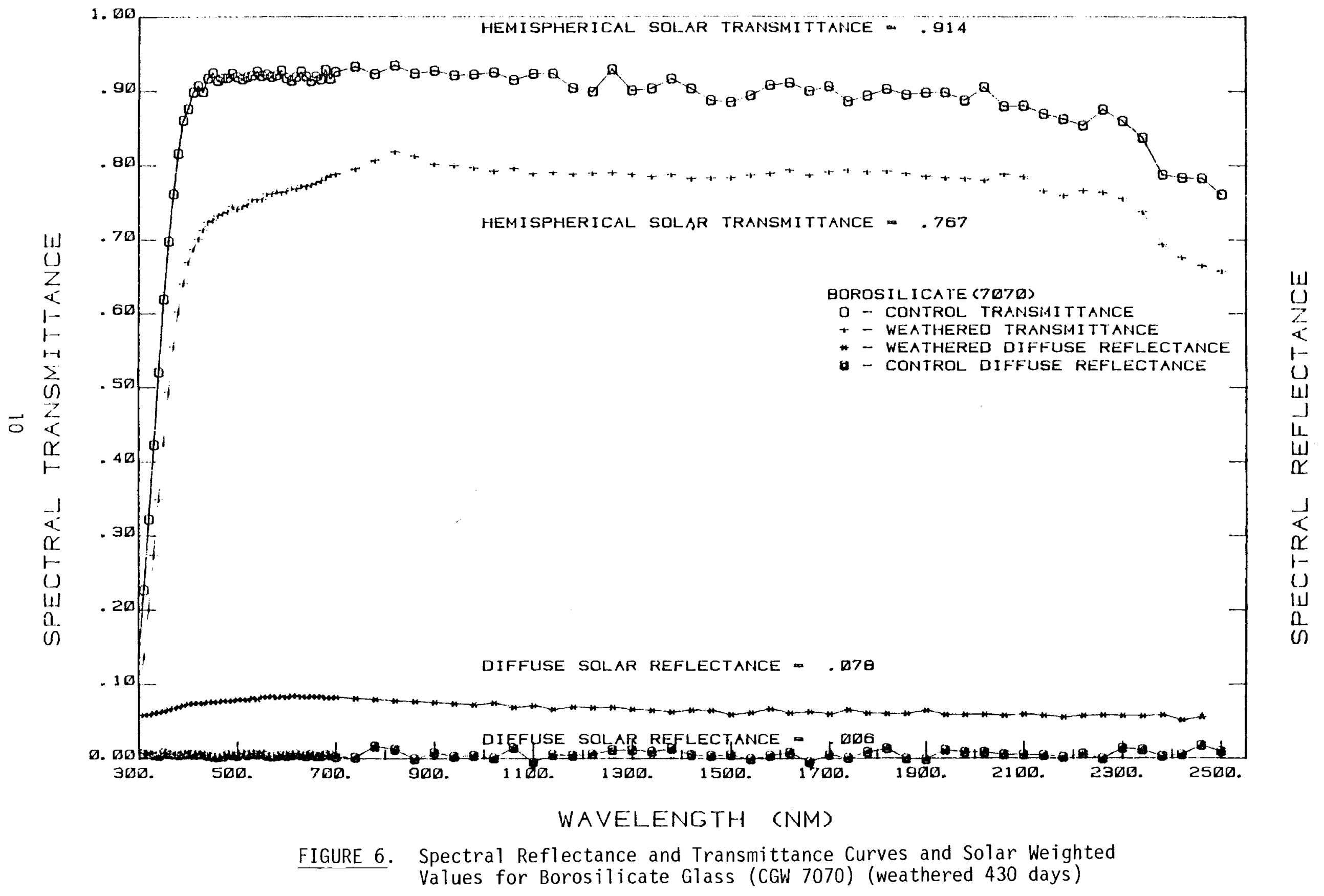




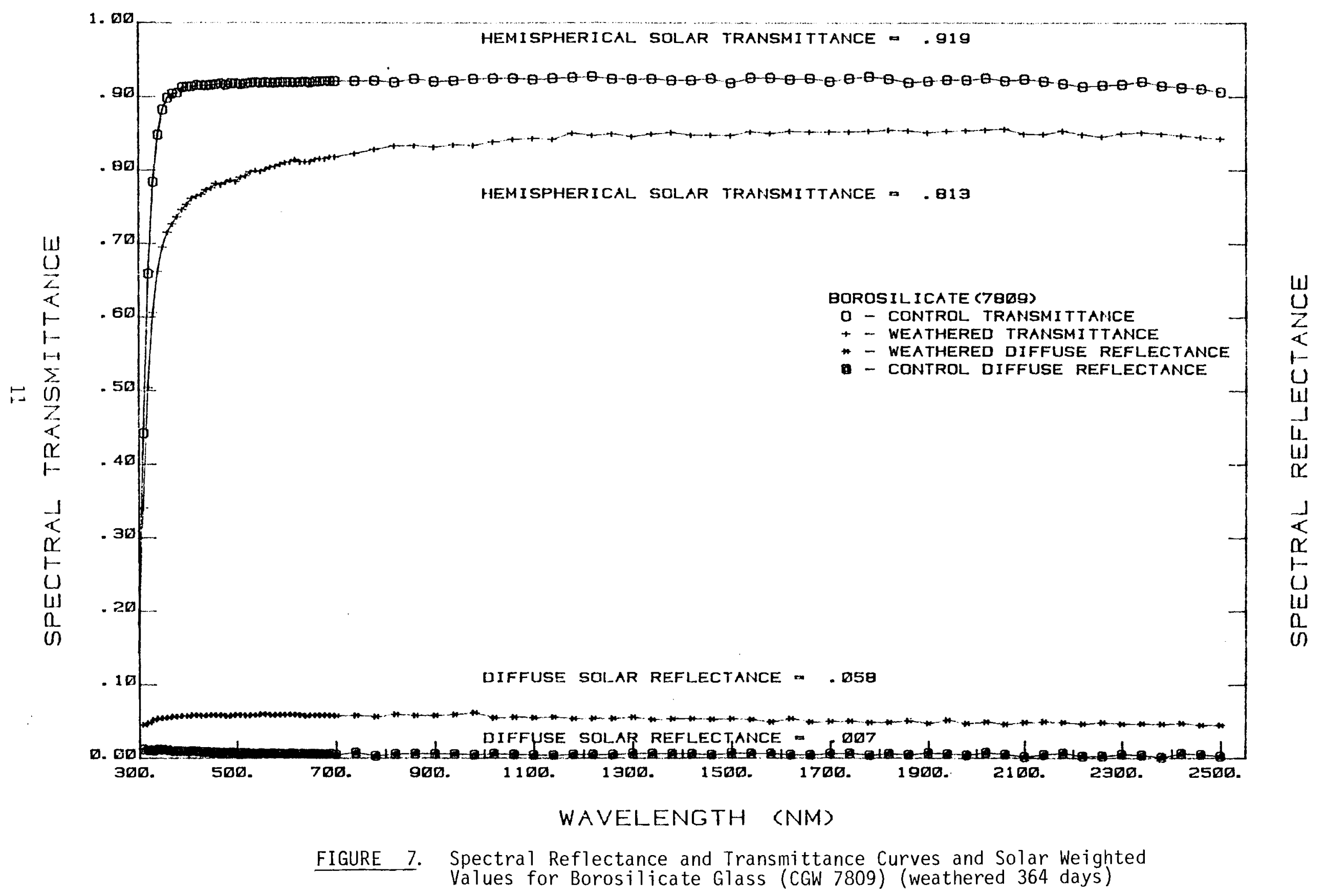




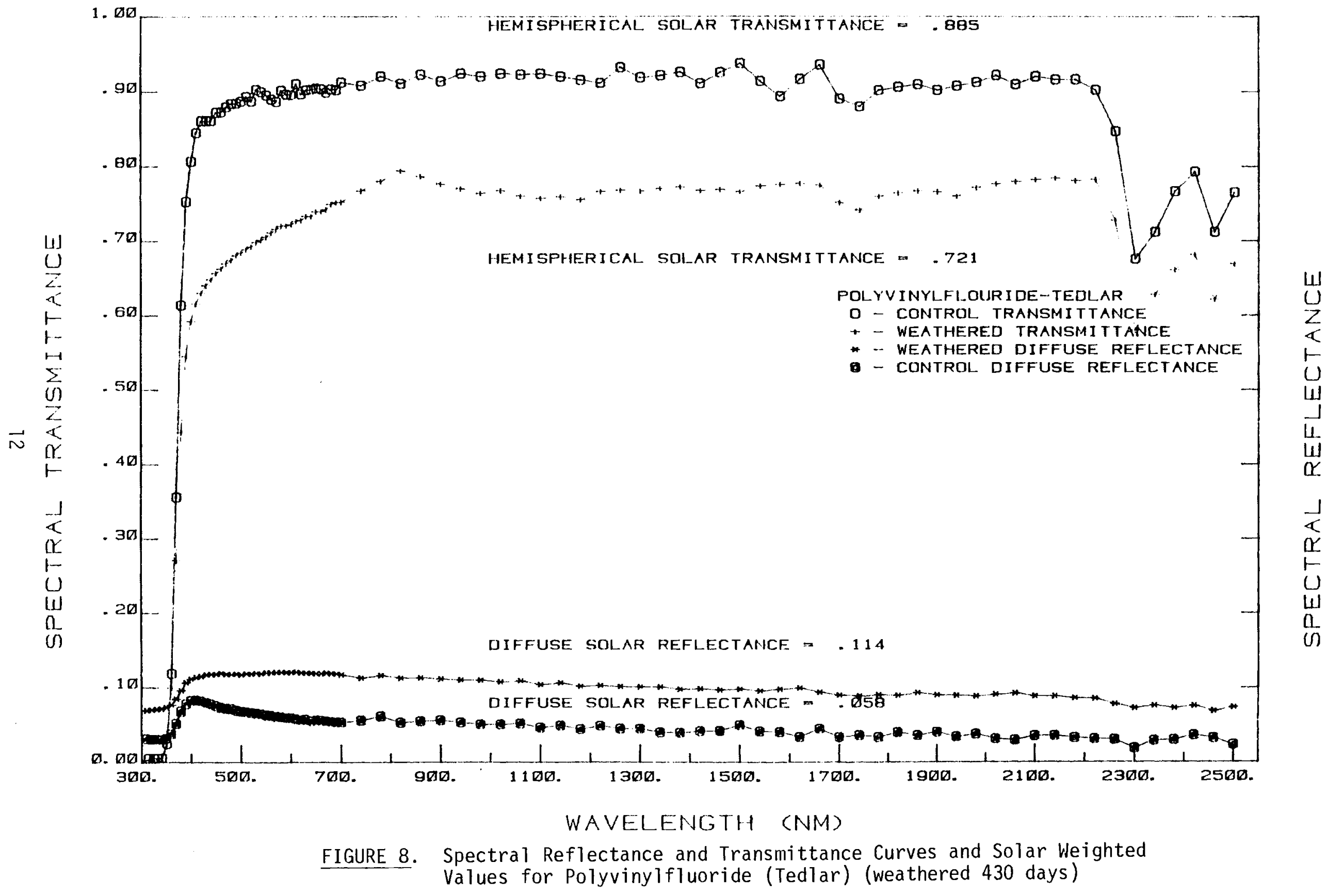




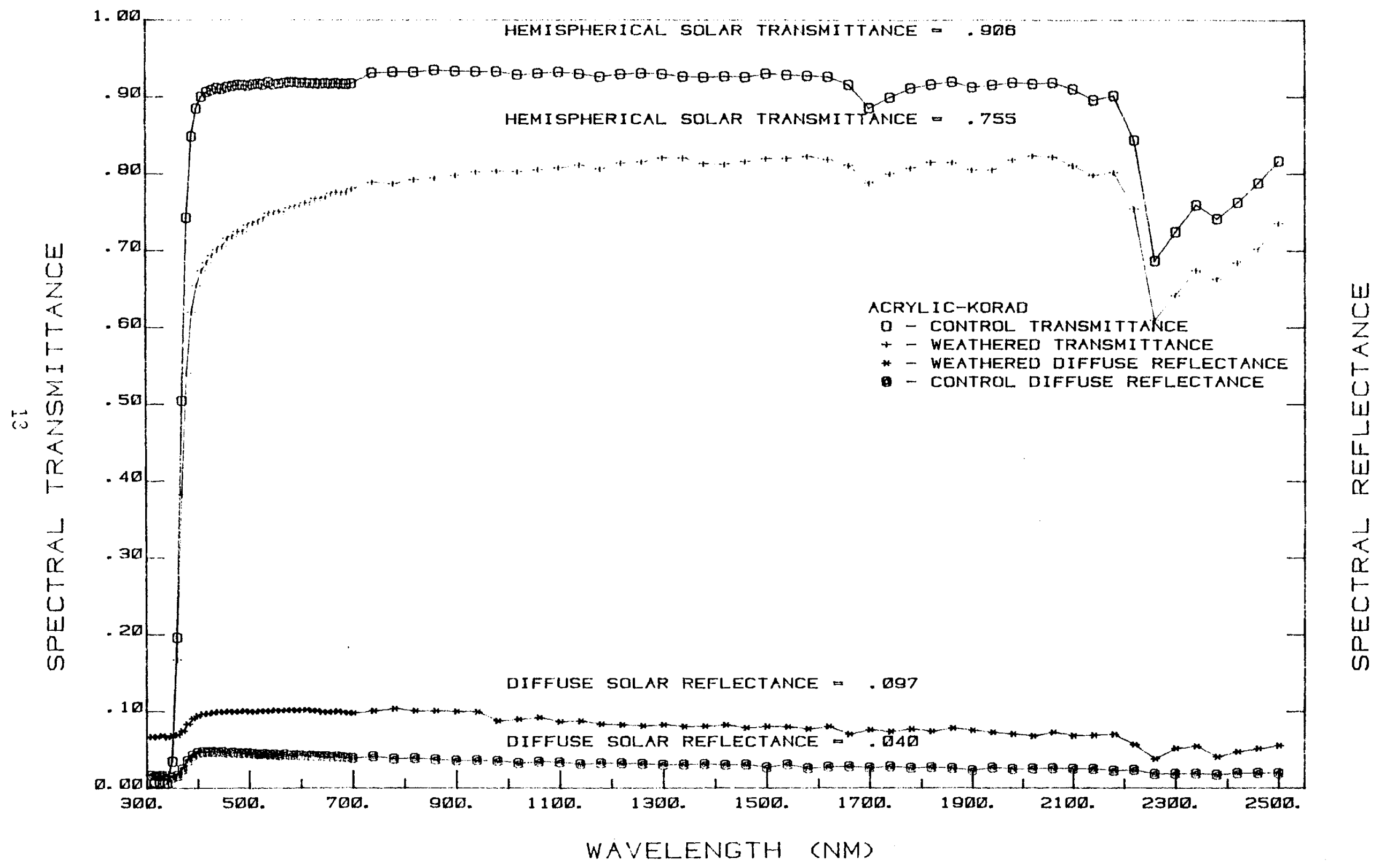

FIGURE 9. Spectral Reflectance and Transmittance Curves and Solar Weighted values for Acrylic (Korad) (weathered 430 days) 
In addition to the optical characterizations performed by PIIL, JPL monitored the optical transmission of the encapsulant materials using their "relative normal hemispherical transmittance" measurement apparatus. The weathered coupon and a coupon of the same material that has not been weathered are placed over two matched solar cells. The two cells are illuminated, and the ratio of the two short-circuit currents is recorded. This ratio is called the relative normal hemispherical transmittance (RNHT) and is a measure of the change in transmittance of the weathered material.

\section{METHODS OF DATA ANALYSIS}

For the mirror samples, changes in hemispherical, diffuse and specular reflectance data $\left(\Delta R_{H},-\Delta R_{D}\right.$, and $\left.\Delta R_{S}\right)$ were plotted as a function of exposure time for each site. For the encapsulant materials, changes in transmittance $\left(\Delta T_{H}\right)$ and diffuse reflectance $\left(-\Delta R_{D}\right)$ were plotted. The average losses $\left(\overline{\Delta R_{S}}, \overline{\Delta T_{H}}\right.$, etc. $)$ were calculated for each site and are presented in tabular form. For the glass and mirror data, ratios of the average losses (i.e., $\overline{\Delta R_{S}} / \overline{\Delta R_{H}}, \overline{\Delta T_{H}} / \overline{\Delta R_{D}}$ etc.) were calculated to determine if correlations existed between the glass and mirror data. These correlations could be used to predict the performance of the other encapsulatnt materials used as superstrates for mirrors.

A linear regression analysis was performed to calculate the average daily losses for each material at each site. The analysis calculates the best fit straight line through the data. This line is represented by the equation:

$$
y=a x+b
$$

where the slope is given by 


$$
a=\frac{\Sigma x_{i} y_{i}-\frac{\Sigma x_{i} \Sigma y_{i}}{n}}{\Sigma x_{i}^{2}-\frac{\left(\Sigma x_{i}\right)^{2}}{n}}
$$

and the intercept is given by

$$
b=\frac{\Sigma y_{i}}{n}-\frac{a \Sigma x_{i}}{n}
$$

Here the slope represents the average degradation rate. Since other studies have shown that the degradation rates may be significantly larger for the initial exposure period, the analys is was performed over the entire data set and over the data set after the first 45 days of exposure.

Correlation coefficients can be calculated using the following relationship:

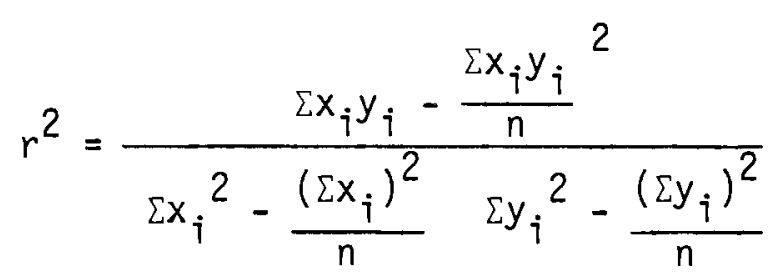

The correlation coefficient is a number between 0 and 1 . It is a measure of how closely the experimental data fits the line generated by the linear regression analysis. If $r^{2}=1$, the data is a perfect fit to the regression 1 ine. For the purposes of this study, the average daily degradation rates are considered reliable if the associated correlation coefficient is greater than 0.5 .

The data was examined for site specific variations that would help distinguish between the cleanest and dirtiest sites. Results for each measurement were analyzed to determine which specific measurements gave the most representative information about the material performance. Data from the first-year study was used to confirm trends noted in the second-year study. 


\section{RESULTS AND DISCUSSION}

MIRROR AND GLASS DATA

The solar weighted optical loss data is plotted as a function of exposure time for the soda lime silicate glass and mirrors in Appendix $B$. In many cases, the variation between successive data points is large. The widely scattered data swamps any readily discernible average trends.

The average optical losses and the standard deviation in the data for each site are summarized in Table 2. For the mirror coupons, the average specular reflectance losses varied between 4\% (Table Mountain site) and 50\% (Torrance site). For the glass samples, the average hemispherical transmittance losses varied between $0 \%$ (Table Mountain site) and 5\% (Torrance site). Similar average losses occurred in the diffuse reflectance measuremets. The average RNHT losses varied between $1 \%$ (Table Mountain) and $9 \%$ (Pasadena).

It is easy to differentiate between the sites on the basis of the mirror data since the range in average optical losses was large. It is more difficult to distinguish between the sites on the basis of the glass data, since the $\Delta \mathrm{T}_{H}$ data varied at most between 0 and $10 \%$. The standard deviations were large enough to make absolute determinations of cleanest and dirtiest sites difficult, but some generalizations can be made. The urban and oceanside sites were the dirtiest (Torrance, Pasadena and Point Vicente). The Richland Desert site appeared to be somewhat cleaner. The Goldstone desert site and the Table Mountain site were by far the cleanest locations.

The ratios of the various optical losses were calculated for each site and then averaged to determine if any meaningful correlations between the measurements existed. With the exception of Table Mountain, these ratios were surprisingly consistent. The ratios for the Table Mountain site often varied wildly from the other sites. Since this was a very clean site, changes in the optical losses were small. These small differences impact greatly the calculated ratios. 
TABLE 2. Average Solar Weighted Optical Losses at Each Site for Soda Lime Silicate Float Glass and Mirrors.

Second Year Data (1980-1981).

\begin{tabular}{|c|c|c|c|c|c|c|}
\hline \multirow{2}{*}{ Site } & \multicolumn{3}{|c|}{$\begin{array}{l}\text { Mirrors } \\
\text { (Absolute Units) }\end{array}$} & \multicolumn{3}{|c|}{$\begin{array}{c}\text { Soda Lime Silicate Float Glass } \\
\text { (Absolute Units) }\end{array}$} \\
\hline & $\Delta \mathrm{R}_{\mathrm{H}}$ & $-\Delta R_{D}$ & $\Delta \mathrm{R}_{\mathrm{S}}$ & $\Delta \mathrm{T}_{\mathrm{H}}$ & $-\Delta \mathrm{R}_{\mathrm{D}}$ & $\triangle \mathrm{RNHT}^{\star}$ \\
\hline Torrance & $-.2 \pm .1$ & $-.3 \pm .1$ & $-.5 \pm .2$ & $-.05 \pm .03$ & $-.04 \pm .02$ & $-.08 \pm .05$ \\
\hline Pasadena & $-.10 \pm .03$ & $-.18 \pm .04$ & $-.3 \pm .1$ & $-.06 \pm .02$ & $-.03 \pm .01$ & $-.09 \pm .03$ \\
\hline Point Vicente & $-.07 \pm .03$ & $-.19 \pm .09$ & $-.3 \pm .1$ & $-.05 \pm .02$ & $-.04 \pm .02$ & $-.02 \pm .02$ \\
\hline Richland & $-.04 \pm .02$ & $-.16 \pm .08$ & $-.2 \pm .1$ & $-.03 \pm .03$ & $-.03 \pm .02$ & $-.02 \pm .01$ \\
\hline Goldstone & $-.02 \pm .01$ & $-.06 \pm .03$ & $-.08 \pm .04$ & $-.01 \pm .01$ & $-.01 \pm .003$ & $-.02 \pm .01$ \\
\hline Table Mountain & $-.01 \pm .01$ & $-.03 \pm .01$ & $-.04 \pm .02$ & $-.002 \pm .002$ & $-.01 \pm .01$ & $-.01 \pm .01$ \\
\hline
\end{tabular}

* Relative normal hemispherical transmittance 
It was discovered that average diffuse reflectance losses in the mirror samples were about six times as great as the average diffuse reflectance losses for the glass samples:

$$
\frac{\overline{-\Delta R_{D}} \text { (mirror) }}{\overline{-\Delta R_{D}} \text { (glass) }}=6 \pm 1 \text { (Table Mounta in data excluded) }
$$

It was also found that the average specular reflectance losses for the mirror samples were about seven times as large as the average hemispherical transmittance losses for the glass samples:

$$
\frac{\Delta \mathrm{R}_{\mathrm{S}} \text { (mirror) }}{\Delta \mathrm{T}_{H} \text { (glass) }}=7 \pm 2 \text { (Table Mountain data excluded) }
$$

For all the other mirror/glass ratios, standard deviations were so large that no meaningful relationships could be determined.

For the mirror data alone, it was found that the ratio of specular to hemispherical reflectance losses was approximately $4: 1$, and the ratio of diffuse to hemispherical reflectance losses was about $3: 1$.

$$
\begin{aligned}
& \frac{\Delta R_{S} \text { (mirror) }}{\Delta R_{H} \text { (mirror) }}=4 \pm 1 \\
& \frac{-\Delta R_{D} \text { (mirror) }}{\Delta R_{H} \text { (mirror) }}=3 \pm 1
\end{aligned}
$$

For the glass data the ratio of hemispherical transmittance losses to diffuse reflectance losses was nearly $1: 1$.

$$
\frac{\Delta T_{H}(g l a s s)}{-\Delta R_{D}(g l a s s)}=1.3 \pm .4
$$

No meaningful relationships were found between the RNHT losses and any of the other measurements. 
The results from linear regression analys is of the second year data are shown in Tables 3 and 4 . Since the correlation coefficients were small in most cases, the degradation rates are not very useful. An exception was the data from the Richland site. This data had correlation coefficients of .8 and .9. Specular reflectance degradation rates were .04\%/day for the mirror samples. For the glass samples, hemispherical transmittance and diffuse reflectance degradation rates were approximately $.01 \% /$ day.

\section{GLASS AND POLYMER DATA}

Optical loss curves for the first and second year studies of the glass and polymer samples are shown in Appendix $C$ and $D$. The average solar weighted optical losses are shown for each site in Tables 5 through 8.

Looking at the second year data for the glass samples in Table 5, it is difficult to discern meaningful differences between the four glass types. From site to site, the average hemispherical transmittance losses varied between 0 and $7 \%$, and the average diffuse reflectance losses varied between 0 and $4 \%$. The large standard deviations make any differences between the glasses ambiguous. The borosilicate (CGW-7070) glass may have performed slightly better on the average. The first year data in Table 6 shows the same general trends as the second year data. The magnitude of the losses was comparable for the two studies.

Again, the correlation coefficients were very small for most of the linear regression analysis. The Richland data was again the exception, with correlation coefficients of 0.6 to 0.9 . For all the glasses, the daily degradation rates for both transmittance and diffuse reflectance was approximately .01\%/day (calculated over the entire curve). Similar rates were found when the analysis was done on the data after the first 45 days of exposure.

It was difficult to distinguish between the two polymer materials on the basis of the hemispherical transmittance losses. But the diffuse reflectance losses are smaller for the polyvinylfluoride (Tedlar) samples, as seen in Tables 7 and 8 . Of more significance is the fact that the ratio of the average hemispherical transmittance to diffuse reflectance 
TABLE 3. Daily Degradation Rates and Correlation Coefficients (in parentheses) as Calculated by a Linear Regression Analysis for the Entire Expcsure Period for Soda Lime Silicate Float Glass and Mirror Samples. Second Year Data (1980-1981).

\begin{tabular}{|c|c|c|c|c|c|}
\hline \multicolumn{3}{|c|}{$\begin{array}{l}\text { Mirrors } \\
\text { (Absolute Units) } \\
\end{array}$} & \multicolumn{3}{|c|}{$\begin{array}{c}\text { Soda Lime Silicate Float Glass } \\
\text { Absolute Units) }\end{array}$} \\
\hline$\Delta \mathrm{R}_{\mathrm{H} / \mathrm{day}}$ & $-\Delta \mathrm{R}_{\mathrm{D} / \mathrm{day}}$ & $\Delta \mathrm{R}_{\mathrm{S} / \text { day }}$ & $\Delta \mathrm{T}_{\mathrm{H} / \mathrm{day}}$ & $-\Delta R_{D / d a y}$ & $\triangle \mathrm{RNHT} / \mathrm{day}$ \\
\hline $\begin{array}{r}-.00002 \\
(.001)\end{array}$ & -.00004 & $\begin{array}{c}-.00002 \\
(0)\end{array}$ & $-i 0001$ & -.00007 & -.00006 \\
\hline $\begin{array}{r}-.0002 \\
(.16)\end{array}$ & $\begin{array}{r}-.0002 \\
(.14)\end{array}$ & $\begin{array}{c}-.0004 \\
(.2)\end{array}$ & $\begin{array}{c}-.0001 \\
(.2)\end{array}$ & $\begin{array}{c}-.00005 \\
(.2)\end{array}$ & -.00009 \\
\hline-.00005 & -.00007 & $\begin{array}{r}-.0001 \\
(.02)\end{array}$ & -.0002 & $\begin{array}{l}-.0001 \\
(.6)\end{array}$ & -.00008 \\
\hline $\begin{array}{c}-.0001 \\
(.9)\end{array}$ & -.0004 & $\begin{array}{c}-.0004 \\
(.8)\end{array}$ & -.0001 & $\begin{array}{c}-.00008 \\
(.9)\end{array}$ & -.00006 \\
\hline-.00003 & $\begin{array}{c}0 \\
(0)\end{array}$ & -.00003 & -.00004 & $\begin{array}{c}-.00003 \\
(.7)\end{array}$ & $\begin{array}{l}-.00009 \\
(.9)\end{array}$ \\
\hline-.00002 & -.00007 & -.0001 & $\begin{array}{l}0 \\
(.004)\end{array}$ & -.00001 & $-i 00005$ \\
\hline
\end{tabular}


TABLE 4. Daily Degradation Rates and Correlation Coefficients (in parentheses) as Calculated by a Linear Regression Analysis After the First 45 Days of Exposure for Soda Lime Silicate Float Glass and Mirror Samples. Second Year Data (1980-1981).

\begin{tabular}{|c|c|c|c|c|c|c|}
\hline & & $\begin{array}{l}\text { Mirrors } \\
\text { solute Un }\end{array}$ & & Soda & $\begin{array}{l}\text { Silicate } \\
\text { solute Uni }\end{array}$ & at Glass \\
\hline Site & $\Delta \mathrm{R}_{\mathrm{H} / \text { day }}$ & $-\Delta \mathrm{R}_{\mathrm{D} / \mathrm{day}}$ & $\Delta \mathrm{R}_{\mathrm{S} / \text { day }}$ & $\Delta \bar{T}_{H / \text { day }}$ & $-\Delta \bar{R}_{D / d a y}$ & $\triangle \mathrm{RNHT} /$ day* \\
\hline Torrance & $\begin{array}{c}+.0007 \\
(.6)\end{array}$ & $\begin{array}{c}+.0006 \\
(.4)\end{array}$ & $\begin{array}{r}+.001 \\
(.5)\end{array}$ & $\begin{array}{r}-.00001 \\
(.001)\end{array}$ & $\begin{array}{r}-.00001 \\
(.004)\end{array}$ & $\begin{array}{c}+.0002 \\
(.2)\end{array}$ \\
\hline Pasadena & $\begin{array}{c}+.0002 \\
(.3)\end{array}$ & $\begin{array}{c}+.0003 \\
(.9)\end{array}$ & $\begin{array}{c}+.0005 \\
(.7)\end{array}$ & -.0001 & $-i^{.00006}$ & $\begin{array}{c}-.0001 \\
(.3)\end{array}$ \\
\hline Point Vicente & $\begin{array}{c}+.00002 \\
(.05)\end{array}$ & $\begin{array}{r}+.0001 \\
(.03)\end{array}$ & $\begin{array}{r}+.0001 \\
(.02)\end{array}$ & -.0001 & -.00007 & -.00004 \\
\hline Richland & -.00008 & $\begin{array}{c}-.0003 \\
(.8)\end{array}$ & -.0003 & $\begin{array}{c}-.0001 \\
(.3)\end{array}$ & $\begin{array}{c}-.00007 \\
(.8)\end{array}$ & -.00005 \\
\hline Goldstone & $\begin{array}{c}-.00003 \\
(.5)\end{array}$ & +.00003 & $\begin{array}{c}+.00004 \\
(0)\end{array}$ & -.00002 & $\begin{array}{c}-.00002 \\
(.4)\end{array}$ & $\begin{array}{c}-.00009 \\
(.8)\end{array}$ \\
\hline Table Mountain & -.00001 & -.00003 & $\begin{array}{c}-.00004 \\
(.06)\end{array}$ & $\begin{array}{c}+.00001 \\
(.7)\end{array}$ & $\begin{array}{c}+.00005 \\
(.9)\end{array}$ & $\begin{array}{c}-.00005 \\
(.8)\end{array}$ \\
\hline
\end{tabular}

*Relative normal hemispherical transmittance 


\section{TABLE 5. Average Solar Weighted Optical Losses for Glasses}

Second Year Data (1980-1981)

\begin{tabular}{|c|c|c|c|c|c|c|c|c|}
\hline \multirow[b]{2}{*}{ Site } & \multicolumn{2}{|c|}{ Soda Lime Silicate } & \multicolumn{2}{|c|}{ Aluminosilicate } & \multicolumn{2}{|c|}{ Borosilicate $(7070)$} & \multicolumn{2}{|c|}{ Borosilicate (7809) } \\
\hline & $\Delta T_{H}$ & $-\Delta R_{D}$ & $\Delta T_{H}$ & $-\Delta R_{D}$ & $\Delta T_{H}$ & $-\Delta R_{D}$ & $\Delta T_{H}$ & $-\Delta R_{D}$ \\
\hline Torrance & $-.05 \pm .03$ & $-.04 \pm .02$ & $-.07 \pm .04$ & $-.03 \pm .02$ & $-.05 \pm .03$ & $-.03 \pm .01$ & $-.06 \pm .03$ & $-.04 \pm .01$ \\
\hline Pasadena & $-.06 \pm .02$ & $-.03 \pm .01$ & $-.05 \pm .01$ & $-.03 \pm .01$ & $-.03 \pm .02$ & $-.02 \pm .01$ & $-.03 \pm .01$ & $-.02 \pm .001$ \\
\hline Point Vicente & $-.05 \pm .02$ & $-.04 \pm .02$ & $-.04 \pm .02$ & $-.03 \pm .01$ & $-.03 \pm .02$ & $-.02 \pm .01$ & $-.04 \pm .02$ & $-.03 \pm .01$ \\
\hline Richland & $-.03 \pm .03$ & $-.03 \pm .02$ & $-.05 \pm .05$ & $-.03 \pm .02$ & $-.03 \pm .04$ & $-.03 \pm .02$ & --- & --- \\
\hline Goldstone & $-.01 \pm .01$ & $-.01 \pm .003$ & $-.02 \pm .004$ & $-.01 \pm .004$ & $-.004 \pm .003$ & $-.007 \pm .001$ & $-.01 \pm .01$ & $-.007 \pm .003$ \\
\hline Table Mountain & $-.002 \pm .002$ & $-.01 \pm .01$ & $-.01 \pm .01$ & $-.009 \pm .005$ & $-.002 \pm .002$ & $-.009 \pm .004$ & $-.01 \pm .01$ & $-.009 \pm .004$ \\
\hline
\end{tabular}


TABLE 6. Average Solar Weighted Optical Losses for Glasses First Year Data (1979-1980)

$\tilde{\omega}$
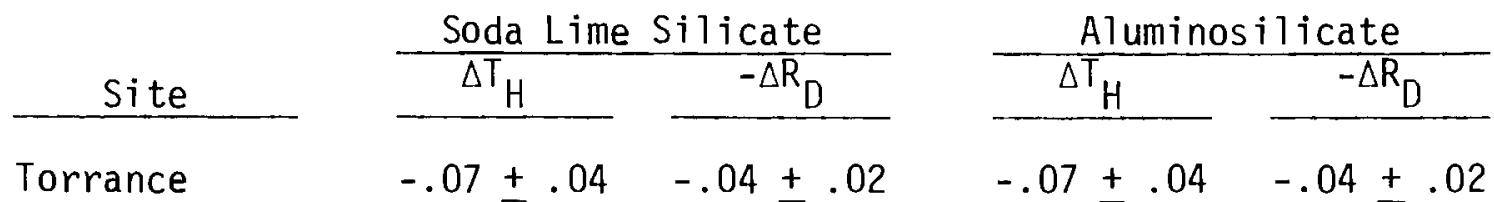

$$
\begin{array}{cc}
\frac{\text { Borosilicate }(7070)}{\Delta T_{H}}-\frac{-\Delta R_{D}}{-.07 \pm .06}-.03 \pm .02 \\
-.04 \pm .02 & -.03 \pm .02 \\
-.03 \pm .02 & -.03 \pm .02
\end{array}
$$$$
-.06 \pm .03-.04 \pm .01 \quad-.05 \pm .02-.04 \pm .02
$$$$
-.04 \pm .02-.04 \pm .02-.06 \pm .03-.03 \pm .02
$$ 
TABLE 7. Average Solar Weighted Optical Losses for Polymer"s Second Year Data (1980-1981)

\begin{tabular}{|c|c|c|c|c|}
\hline \multirow{2}{*}{ Site } & \multicolumn{2}{|c|}{$\begin{array}{c}\text { Polyvinylfluoride } \\
\text { (Tedlar) }\end{array}$} & \multicolumn{2}{|c|}{$\begin{array}{l}\text { Acryl ic } \\
\text { (Korad) }\end{array}$} \\
\hline & $\Delta T_{H}$ & $-\Delta R_{D}$ & $\Delta \bar{T}_{H}$ & $-\Delta \mathrm{R}_{\mathrm{D}}$ \\
\hline Torrance & $-.09 \pm .04$ & $-.03 \pm .01$ & $-.11 \pm .04$ & $-.06 \pm .02$ \\
\hline Pasadena & $-.11 \pm .04$ & $-.02 \pm .01$ & $-.11 \pm .02$ & $-.04 \pm .01$ \\
\hline Point Vicente & $-.05 \pm .02$ & $-.02 \pm .01$ & $-.06 \pm .03$ & $-.06 \pm .02$ \\
\hline Richland & $-.02 \pm .002$ & $-.004 \pm .003$ & $-.03 \pm .01$ & $-.03 \pm .02$ \\
\hline Goldstone & $-.02 \pm .002$ & $-.004 \pm .003$ & $-.03 \pm .01$ & $-.03 \pm .02$ \\
\hline Table Mountain & $-.03 \pm .001$ & $-.009 \pm .002$ & $-.03 \pm .01$ & $-.03 \pm .02$ \\
\hline
\end{tabular}


TABLE 8. Average Solar Weighted Optical Losses for Polymers First Year Data (1979-1980)

\begin{tabular}{|c|c|c|c|c|}
\hline \multirow[b]{2}{*}{ Site } & \multicolumn{2}{|c|}{$\begin{array}{l}\text { Polyvinylfluoride } \\
\text { (Tedlar) }\end{array}$} & \multicolumn{2}{|c|}{$\begin{array}{l}\text { Acrylic } \\
\text { (Korad) }\end{array}$} \\
\hline & $\Delta \mathrm{T}_{\mathrm{H}}$ & $-\Delta R_{D}$ & $\Delta \mathrm{T}_{\mathrm{H}}$ & $-\Delta R_{D}$ \\
\hline Torrance & $-.11 \pm .06$ & $-.03 \pm .02$ & $-.10 \pm .05$ & $-.05 \pm .02$ \\
\hline Pasadena & $-.09 \pm .04$ & $-.02 \pm .01$ & $-.07 \pm .03$ & $-.06 \pm .02$ \\
\hline Point Vicente & $-.06 \pm .03$ & $-.03+.01$ & $-.05 \pm .03$ & $-.05 \pm .02$ \\
\hline
\end{tabular}


losses is quite different for the two polymers. For both the first and second year data, the ratio is approximately $4: 1$ for the polyvinylfluoride, but is only about $1: 1$ for the acrylic.

$$
\begin{aligned}
& \begin{array}{l}
\text { Polyvinylfluoride: } \\
\text { (Tedlar) }
\end{array} \quad \frac{\Delta T_{H}}{-\Delta R_{D}}=4 \pm 1 \\
& \text { Acrylic: } \\
& \text { (Korad) } \\
& \frac{\Delta T_{H}}{-\Delta R_{D}}=1.4 \pm .7
\end{aligned}
$$

This ratio for the acrylic material is about the same magnitude as the same ratio for the glass data, but this ratio for the polyvinylfluoride material is much larger. The reason for this is unknown.

Again, the linear regression analysis was only meaningful for the Richland data. Daily degradation rates for the acrylic (Korad) material were approximately .01\%/day for both the diffuse reflectance and hemispherical transmittance losses. The daily degradation rate for the hemispherical transmittance of the polyvinylfluoride (Tedlar) was also about $.01 \% /$ day. But, the diffuse reflectance for the polyvinylfluoride was an exception; having a much smaller daily degradation rate of $.003 \% /$ day.

\section{CONCLUSIONS}

Analysis of the glass and mirror data revealed some interesting correlations. The average diffuse reflectance losses for the mirrors were six times larger than the average diffuse reflectance losses for the glass samples. The average specular reflectance losses for the mirror samples were seven times as large as the average hemispherical transmittance losses for the corresponding glass samples.

In addition to correlations between the mirror and glass data, several correlations were found within the glass and mirror measurements. Average specular reflectance losses were four times as large as average hemispherical reflectance losses for the mirrors. Average diffuse reflectance 
losses were three times as large as the average hemispherical reflectance losses for the mirror samples. For the glass samples, average hemispherical transmittance losses were slightly greater than average diffuse reflectance losses. No strong correlations were found between the RINHT measurements and any of the other measurements performed.

Average daily degradation rates were calculated using linear regression analysis for all the sites, but only the data from the Richland site had high enough correlation coefficients to be considered predictable. For the Richland site, the average daily specular reflectance loss was .04\% for the mirror samples. The average daily diffuse reflectance and hemispherical transmittance losses were $.01 \%$ for the glass samples.

The range of average specular reflectance losses for the mirrors varied from $4 \%$ at the Table Mountain site, to $50 \%$ at the Torrance site. The range of hemispherical transmittance losses varied between $0 \%$ for the Table Mountain site, and $6 \%$ at the Pasadena site. Because of the magnitude of the standard deviation in the average loss data, it was difficult to determine an absolute ranking from dirtiest to cleanest for the sites. In general, the Torrance and Pasadena urban sites and the Point Vicente oceanside site were the dirtiest. The Goldstone desert site and the Table Mountain mountain site were cleanest. The Richland site was in between.

Comparisons between the glass and polymer data were also performed. It was difficult to distinguish between the performance of the glasses, again due to the scatter in the average loss data. The borosilicate (CGW-7070) glass may have shown slightly less degradation. The site to site range in average hemispherical transmittance losses for the glasses was $0-7 \%$, while the range for average losses in diffuse reflectance was between 0 and $4 \%$. Again, only the Richland data provided valid daily degradation rates. Average daily losses at Richland for both hemispherical transmittance and diffuse reflectance were $.01 \% /$ day. 
In general, the polymer materials were dirtier than the glass materials. The average hemispherical transmittance losses were about the same for the polyvinylfluoride and the acrylic. But the diffuse reflectance losses were smaller for the polyvinylfluoride material. The ratio of average hemispherical transmittance loss to average diffuse reflectance loss was approximately 1:1 for the acrylic, but was nearly $4: 1$ for the polyvinylfluoride. From the Richland data, average daily degradation rates were approximately .01\%/day for all the polymer measurements except the average change in diffuse reflectance for the polyvinylfluoride, whose daily degradation rate was $.003 \%$. The first year data verified the second year data in both general trends and absolute magnitude of the losses.

One recommendation for future studies of this type would be to take data more frequently--at least once a week. It has been found that daily degradation rates are much larger for the initial weathering period at some sites. By taking more frequent data, information about short term degradation rates can also be determined.

\section{REFERENCES}

1. H.W. Brandhorst, Jr., et al. 1977. "Terrestrial Photovoltaic Measurement Procedures." NASA TM 73702. ERDA/NASA/1022-77116, IAASA Lewis Research Center, Cleveland, $\mathrm{OH}$.

2. A.R. Hoffman and C.R. Maag. 1980. "Photovoltaic Module Soiling Studies May 1978 - October 1980." DOE/JPL-1012-49. Jet Propulsion Laboratory, Pasadena, CA.

3. L.S. Dake and M.A. Lind. 1981. "The Optical Losses of Solar Mirrors Due to Atmospheric Contamination at Liberal, Kansas and 0ologah, Oklahoma." PNL-4073. Pacific Northwest Laboratory, Richland, Washington. 


\section{APPENDIX A}

DESCRIPTIONS OF OUTDOOR

EXPOSURE TEST SITES 
APPENDIX A

\section{DESCRIPTIONS OF EXPOSURE TEST SITES}

Torrance: Located on corner of Imperial Highway and La Cienega Boulevard in metropolitan Los Angeles.

Rack is mounted on top of one story building facing South to a parking lot near the flight path of LAX Airport to the North and the San Diego Freeway (405) $1 / 2$ block to the East.

Plant life: Several large trees in the area but not within 75 feet of panel.

Soil: Parking lot to the South, asphait streets to the West and North. Buildings and Freeway to the East.

Elevation: $75 \mathrm{ft}$. above sea level.

Weather conditions: Moderate to heavy rains (winter season), moderate winds.

Pasadena: Located in Pasadena, CA, 2 blocks South of 210 (Foothi11) Freeway, Central Pasadena. South facing rack mounted on top of one story building facing parking lot and three story apartment building about $100 \mathrm{ft}$. away.

Plant life: Several large trees, general industrial area and business offices.

Soil: Parking lot to South, streets to the Horth, East and West.

Elevation: $867 \mathrm{ft}$. above sea level.

Weather: Moderate rains (winter season), occassional light to heavy winds.

Point Vicente: Located in Palos Verdes at U.S. Coast Guard station. Rack is 10 feet from edge of 100 foot cliff facing South to Pacific Ocean.

Plant life: Iceplant, wild grass, weeds.

Soil: Rocks, loamy, moving soil condition.

Elevation: $100 \mathrm{ft}$. above sea level.

Weather conditions: High winds, heavy rains (winter season). 
Richland: Located on the Hanford reservation 5 miles north of Richland, WA. Rack is in desert location facing South.

Plant life: Tumbleweeds, sagebrush and grasses.

Soil: Sand, smali rocks.

Elevation: $400 \mathrm{ft}$. above sea level.

Weather conditions: Hot, dry summers, high winds, dust storms.

Goldstone: Located in Central Mojave desert of California 58 miles

north of Barstow. Rack is in desert locale facing South to gradual

up hil1 slope.

Plant 1ife: Tumbleweeds, coyote bush, Yucca trees.

So i1: Sand, rocks, sma 11 stones.

Elevation: $2200 \mathrm{ft}$. above sea level.

Weather conditions: Flash flooding, heavy rains, high winds, occassional snow.

Table Mountain: Located near the city of Hrightwood in Big Pines area U.S. Forestry service property. Rack is $15 \mathrm{ft}$. from edge of $200 \mathrm{ft}$. South facing cliff (sloping).

Plant 1ife: Pine trees, wild shrub, weeds.

Soil: Rocks, sand, sliding soit.

Elevation: $7500 \mathrm{ft}$. above sea level.

Weather conditions: Snow, high winds, heavy rains.

NOTE: California site descriptions courtesy of $W$. Neiderheiser, JPL. 
APPENDIX B

SODA LIME SILICATE GLASS

MIRROR AND ENCAPSULANT DATA 


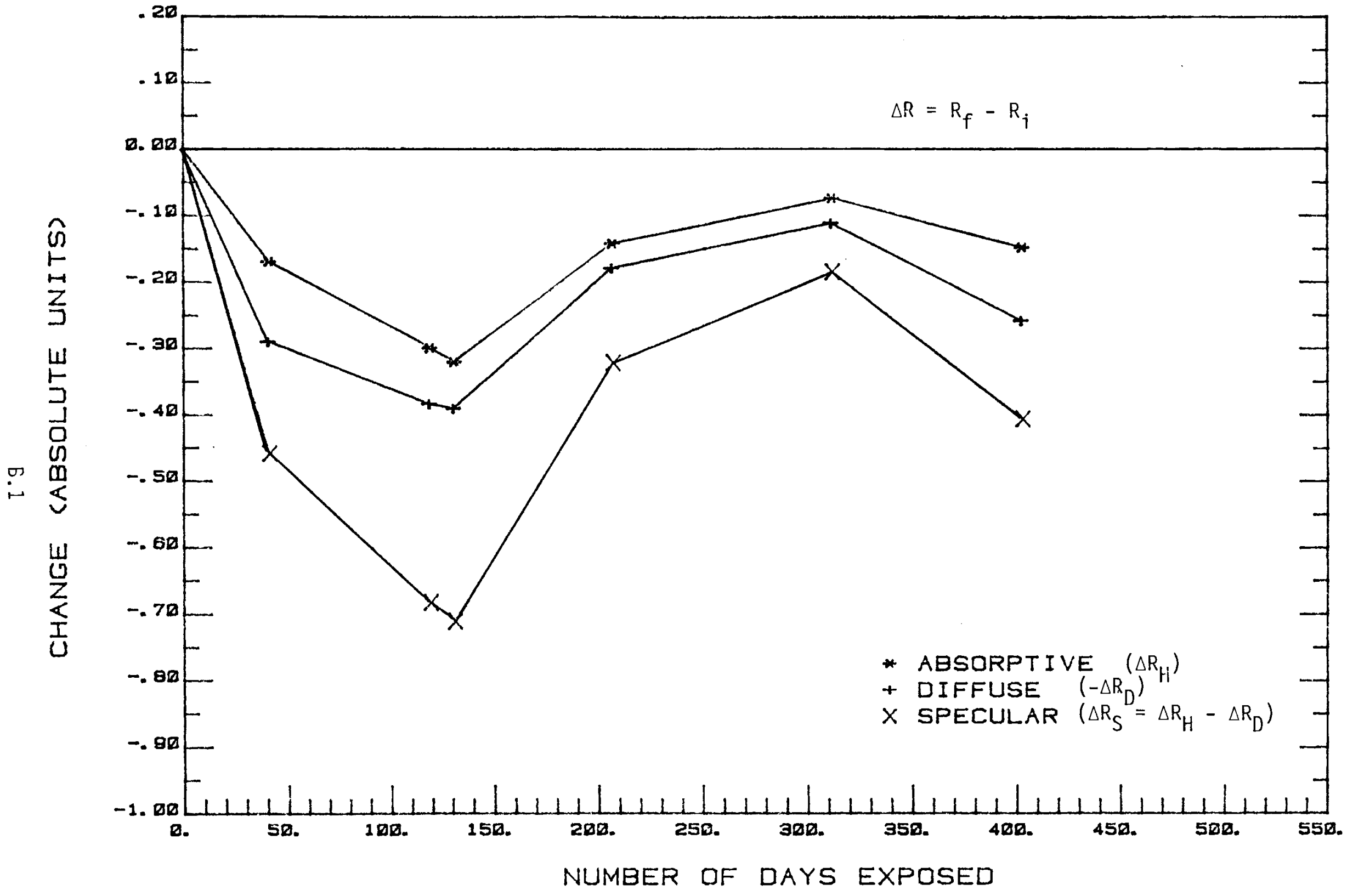

FIGURE B.1. Effects of Atmospheric Contamination on the Solar Weighted Optical Properties of Float Glass Mirrors Weathered at the Torrance Site, 1980-1981 


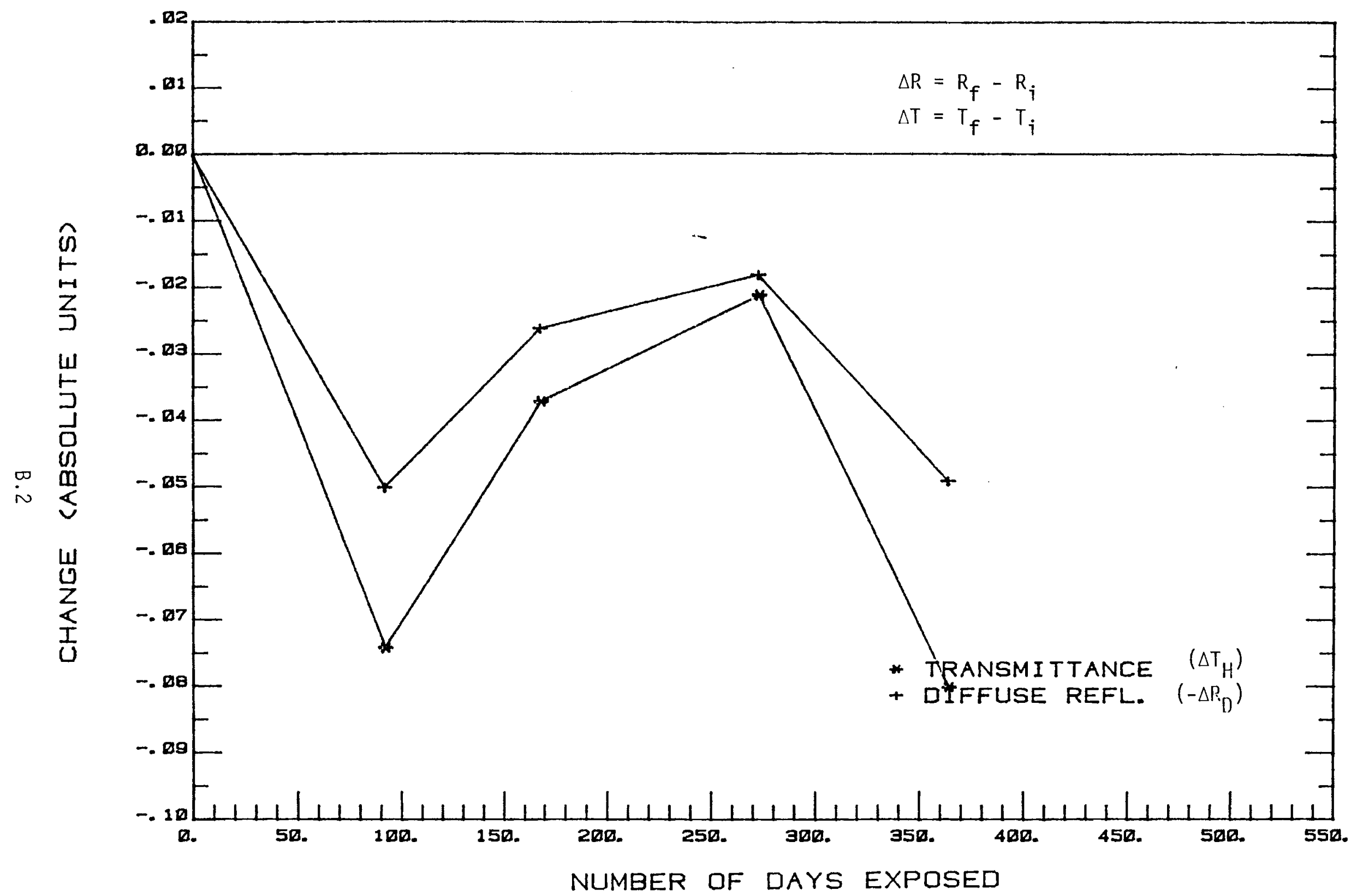

FIGURE B.2. Effects of Atmospheric Contamination on the Solar Weighted 0ptical Properties of Soda Lime Silicate Float Glass Weathered at the Torrance Site, 1980-1981 


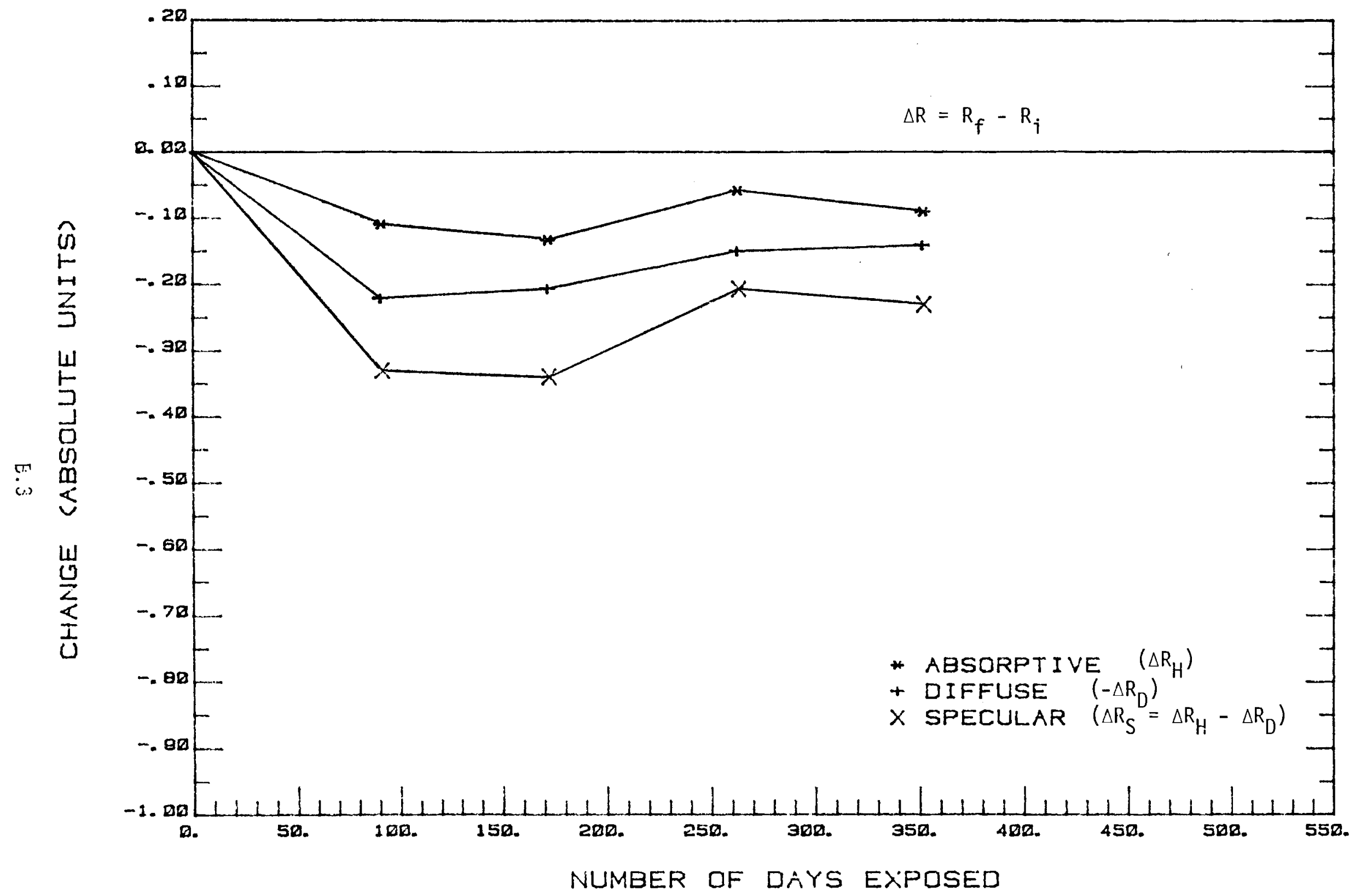

FIGURE B.3. Effects of Atmospheric Contamination on the Solar Weighted Optical Properties of Float Glass Mirrors Weathered at the Pasadena Site, 1980-1981 


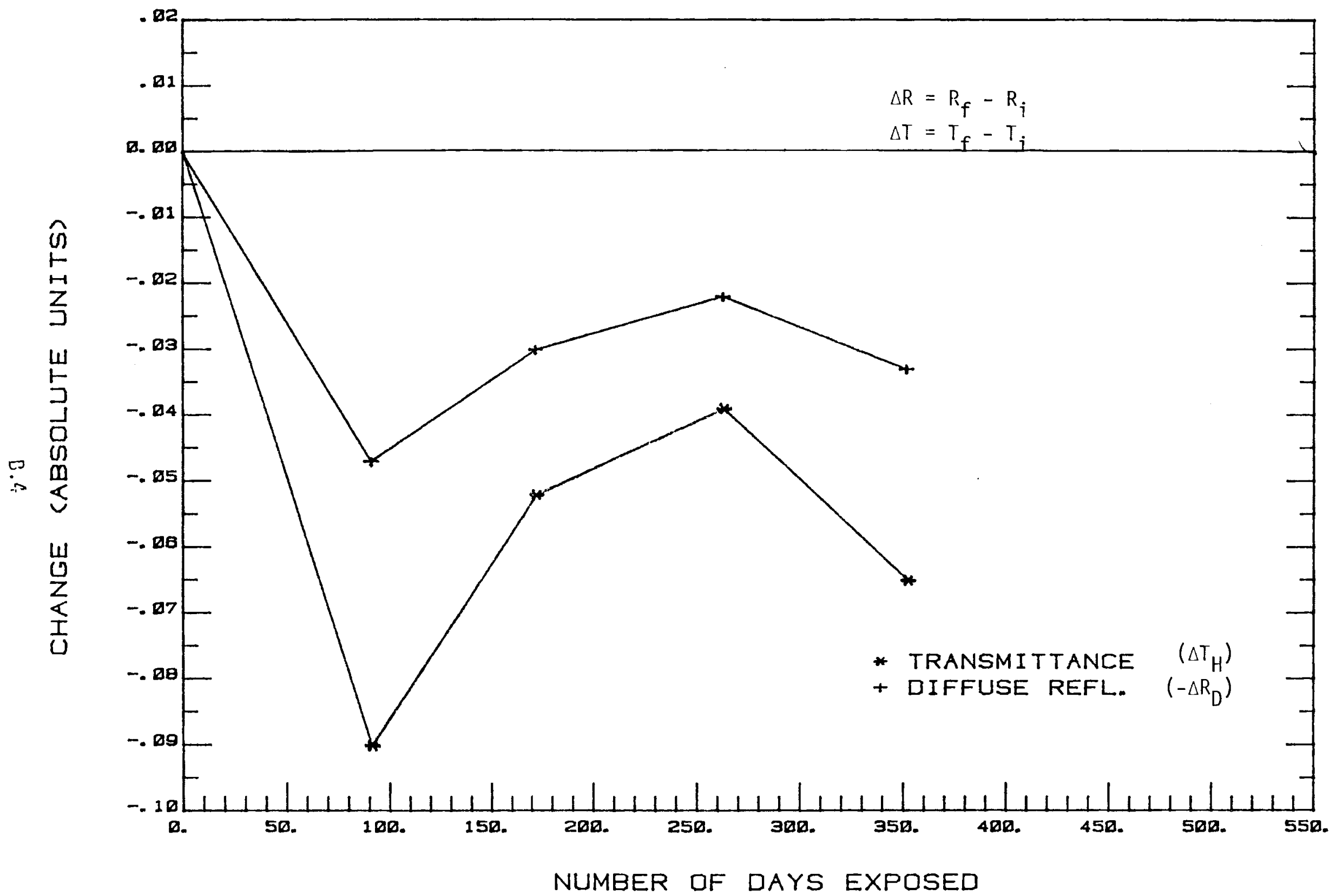

FIGURE B.4. Effects of Atmospheric Contamination on the Solar Weighted Optical Properties of Soda Lime Silicate Float Glass Weathered at the Pasadena Site, 1980-1981 


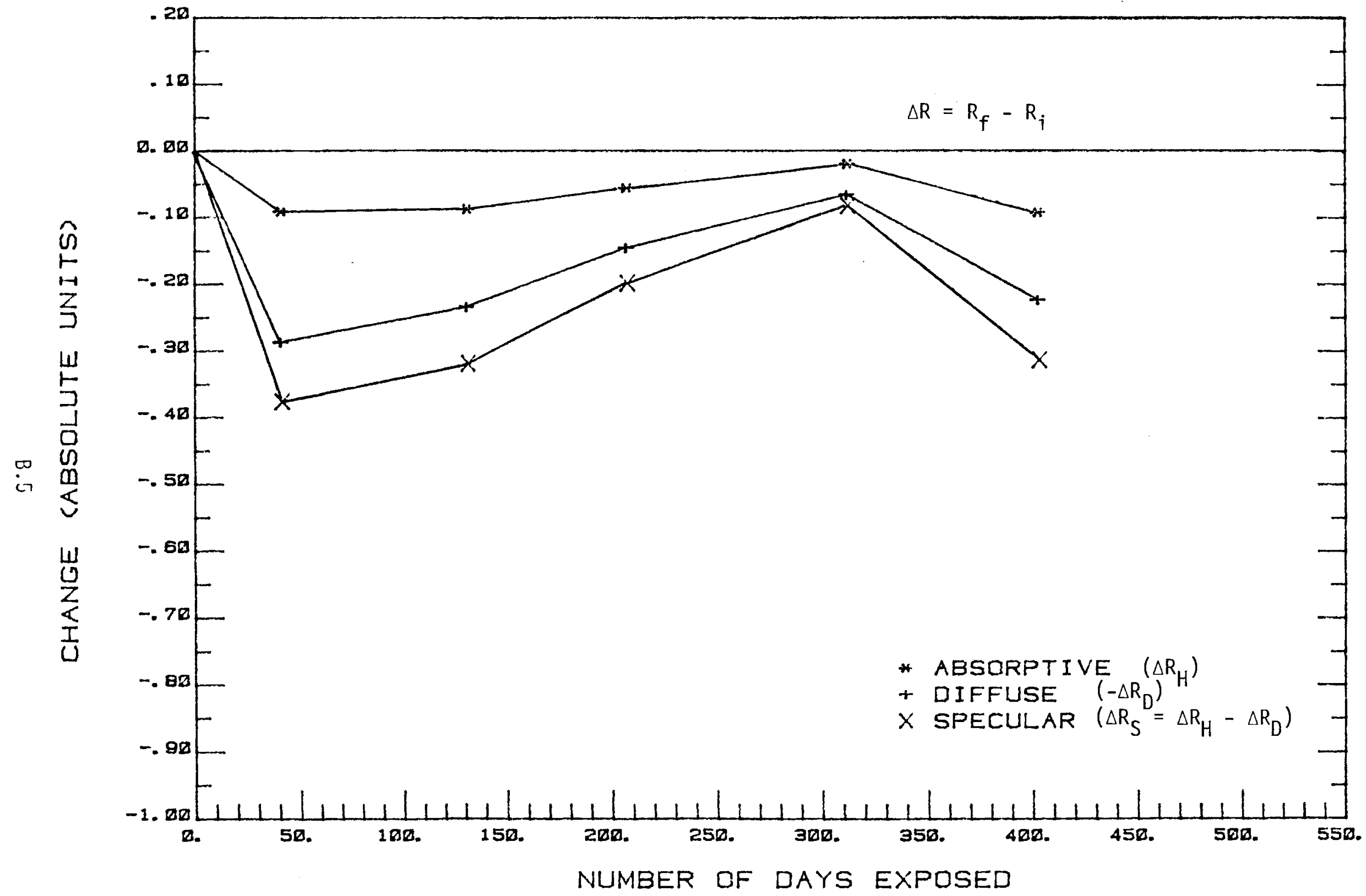

FIGURE B.5. Effects of Atmospheric Contamination on the Solar Weighted Optical Properties of Float Glass Mirrors Weathered at the Point Vicente Site, 1980-1981 


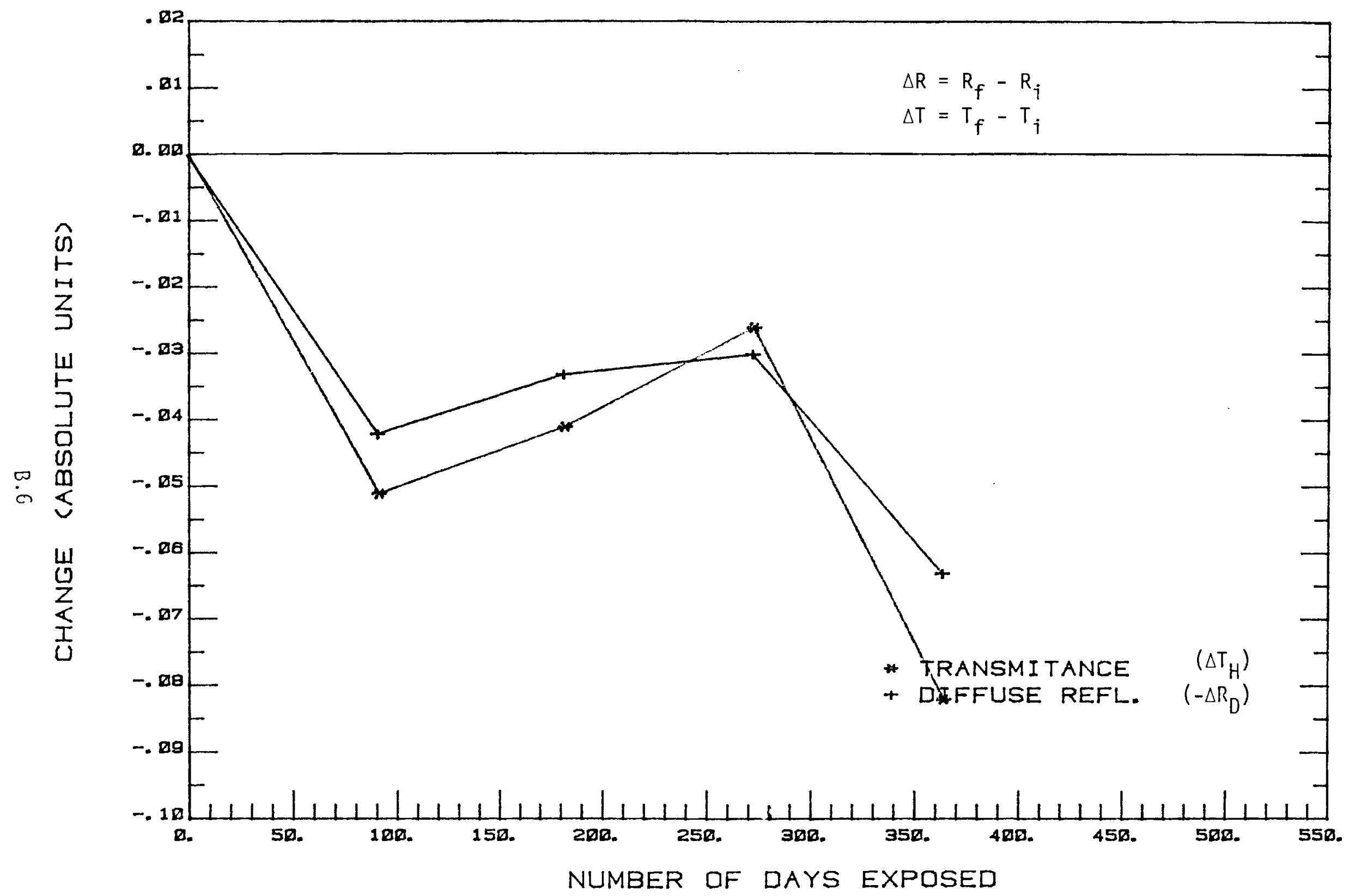

FIGURE B.6. Effects of Atmospheric Contamination on the Solar Weighted Optical Properties of Soda Lime Silicate Float Glass Weathered at the Point Vicente Site, 1980-1981 


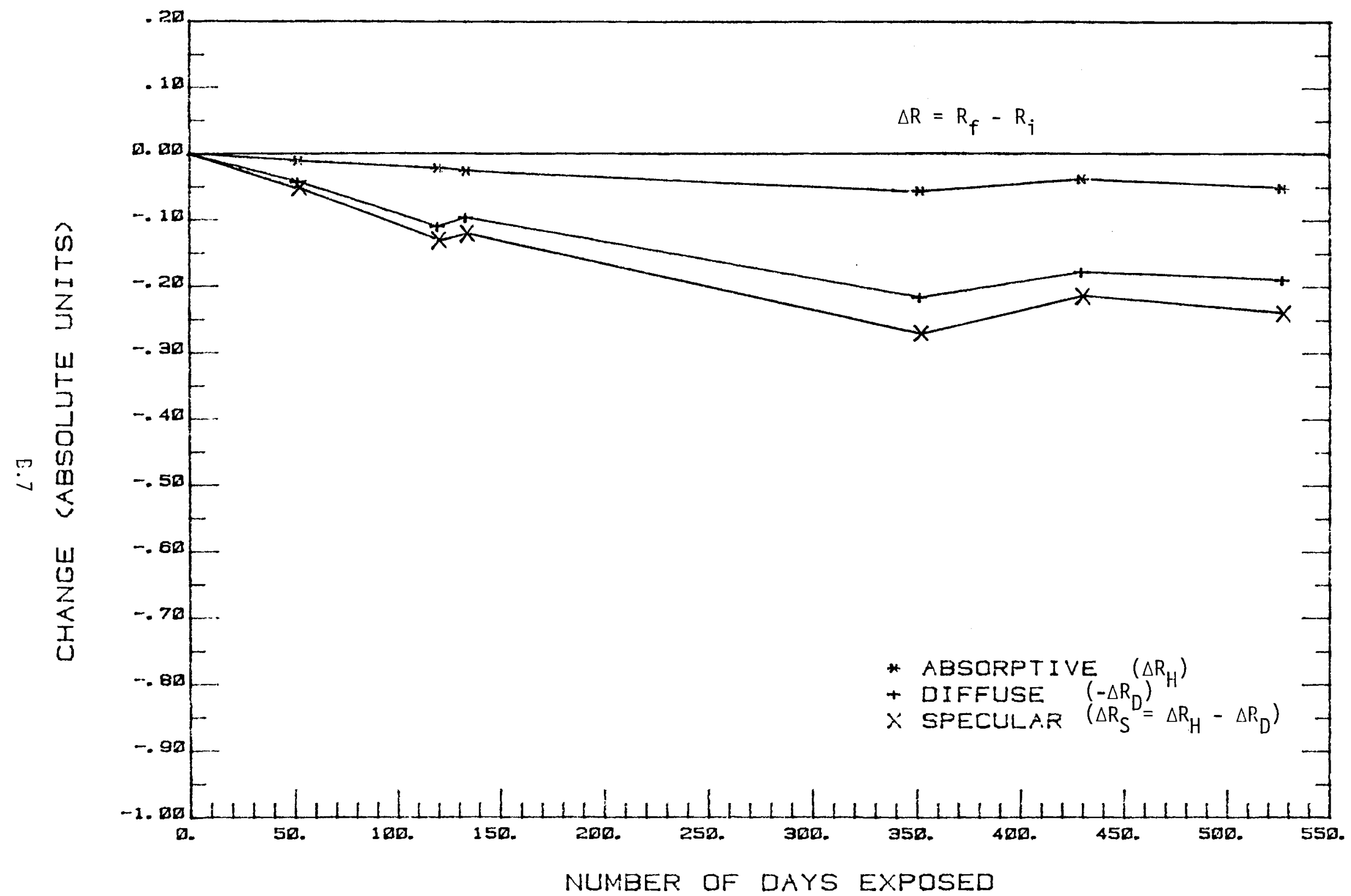

FIGURE B.7. Effects of Atmospheric Contamination on the Solar Weighted Optical Properties of Float Glass Mirrors Weathered at the Richland Site, 1980-1981 


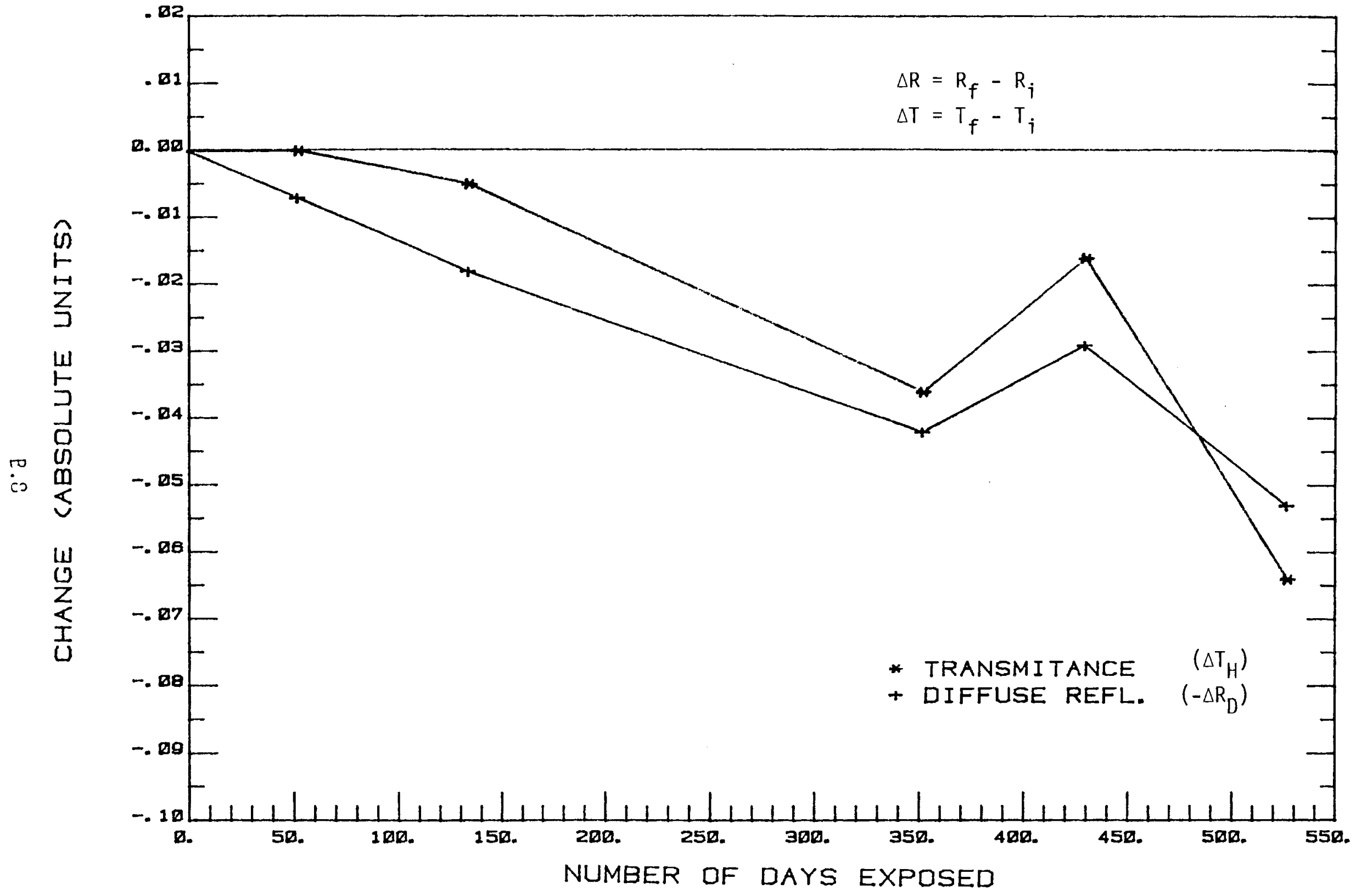

FIGURE B.8. Effects of Atmospheric Contamination on the Solar Weighted Optical Properties of Soda Lime Silicate Float Glass Weathered at the Richland Site, 1980-1981 


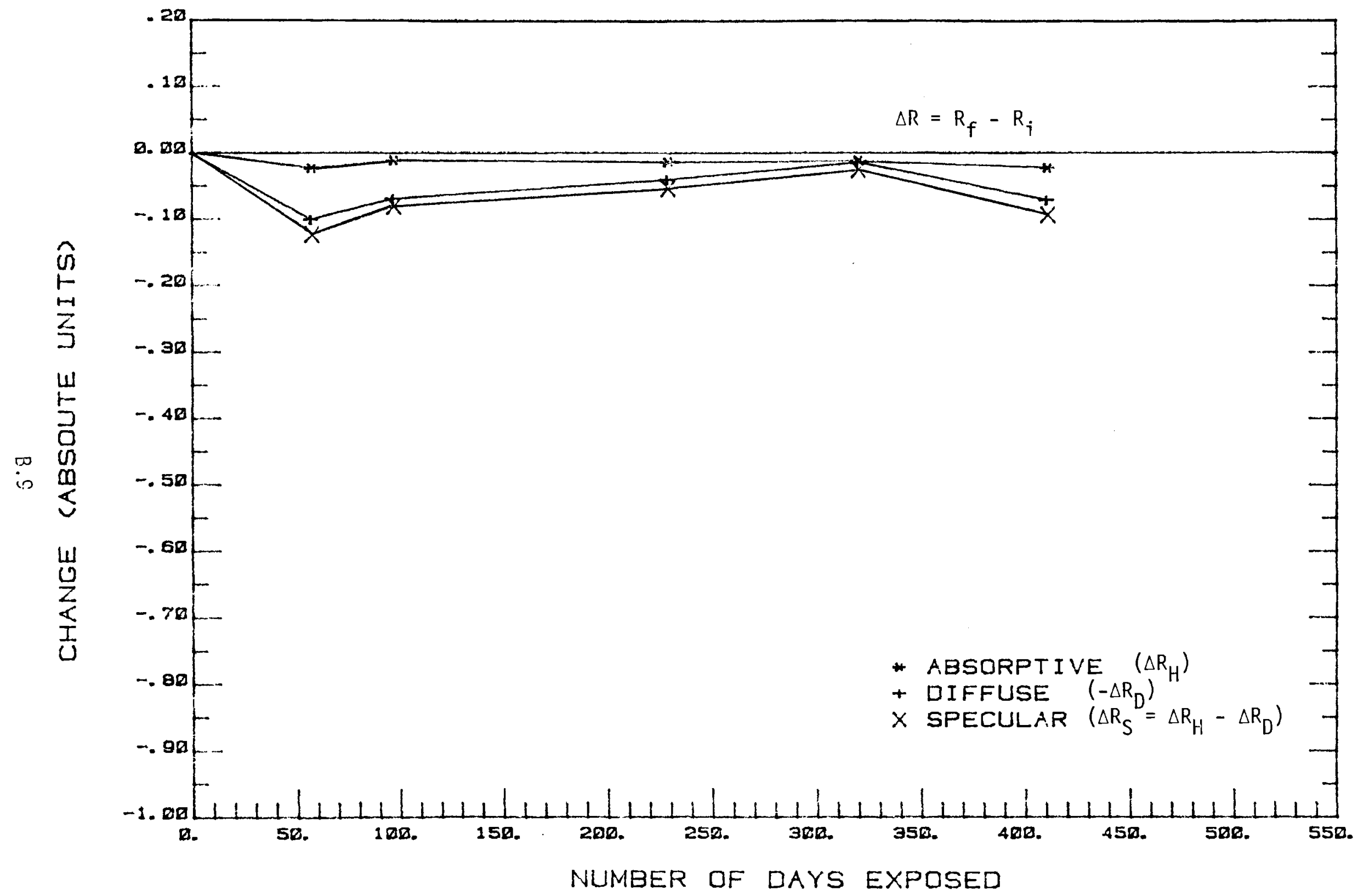

FIGURE B.9. Effects of Atmospheric Contamination on the Solar Weighted Optical Properties of Float Glass Mirrors Weathered at the Goldstone Site, 1980-1981 


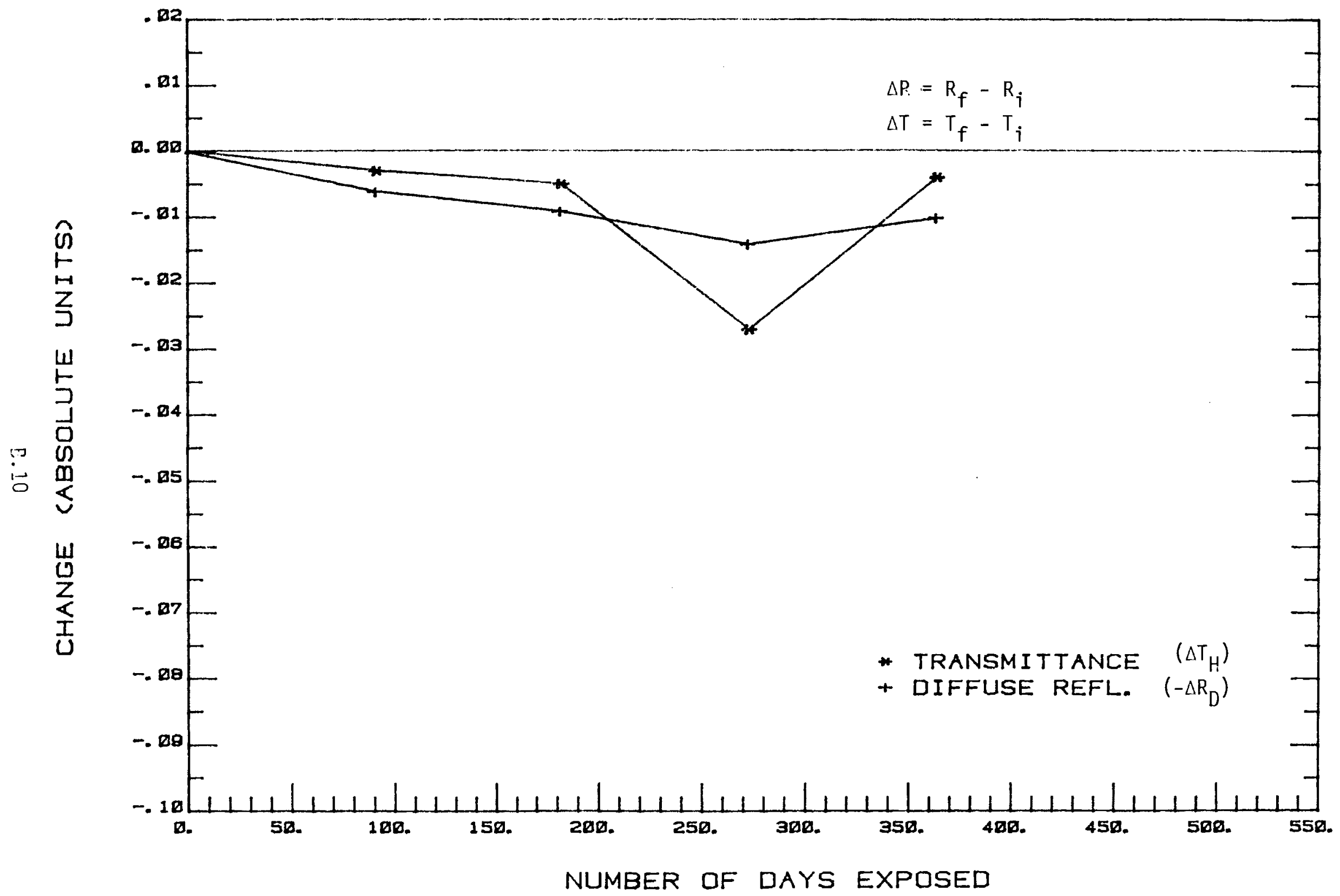

FIGURE B.10. Effects of Atmospheric Contamination on the Solar Weighted Optical Properties of Soda Lime Silicate Float Glass Weathered at the Goldstone Site, 1980-1981 


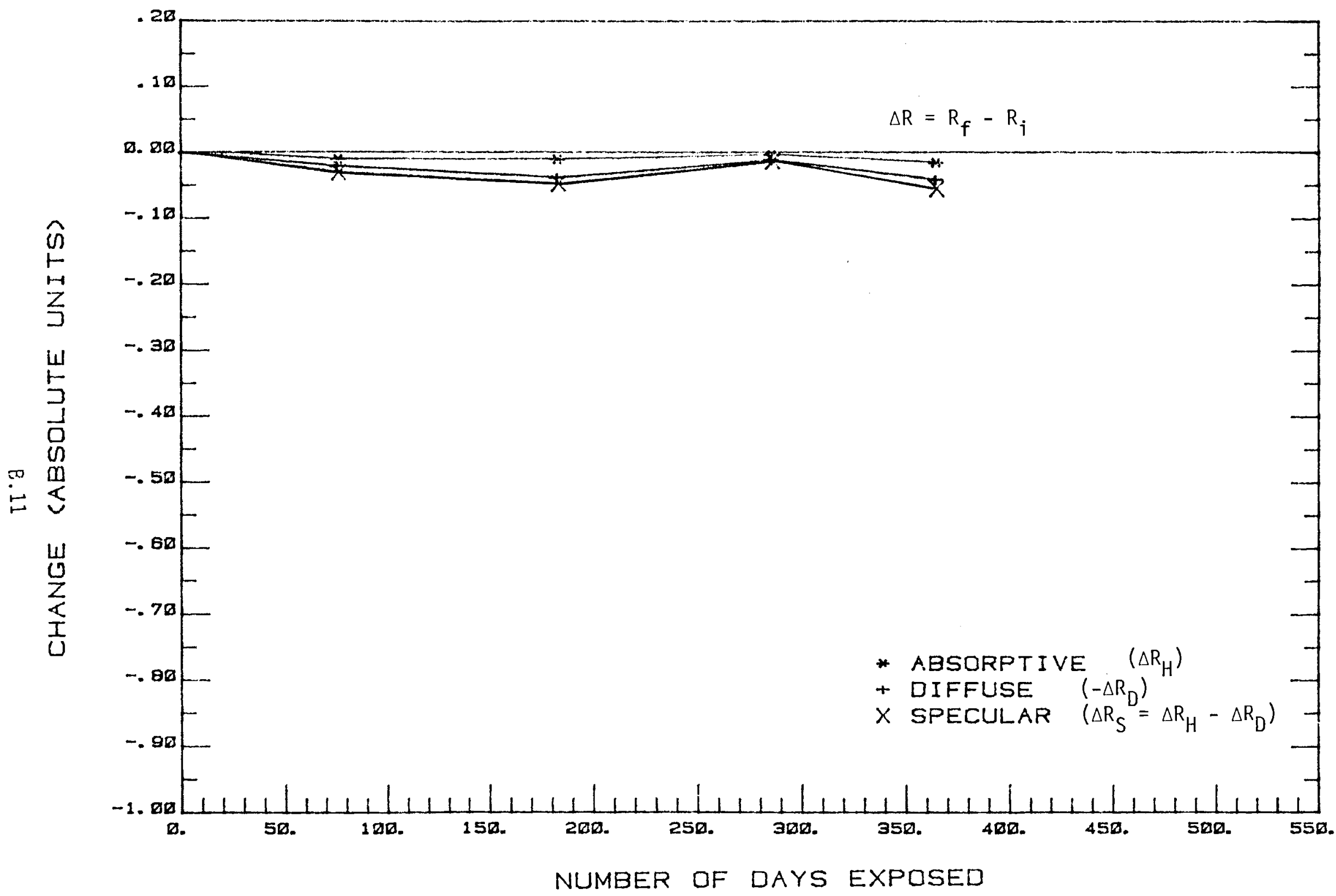

FIGURE B.11. Effects of Atmospheric Contamination on the Solar Weighted Optical Properties of Float Glass Mirrors Weathered at the Table Mountain Site, 1980-1981 


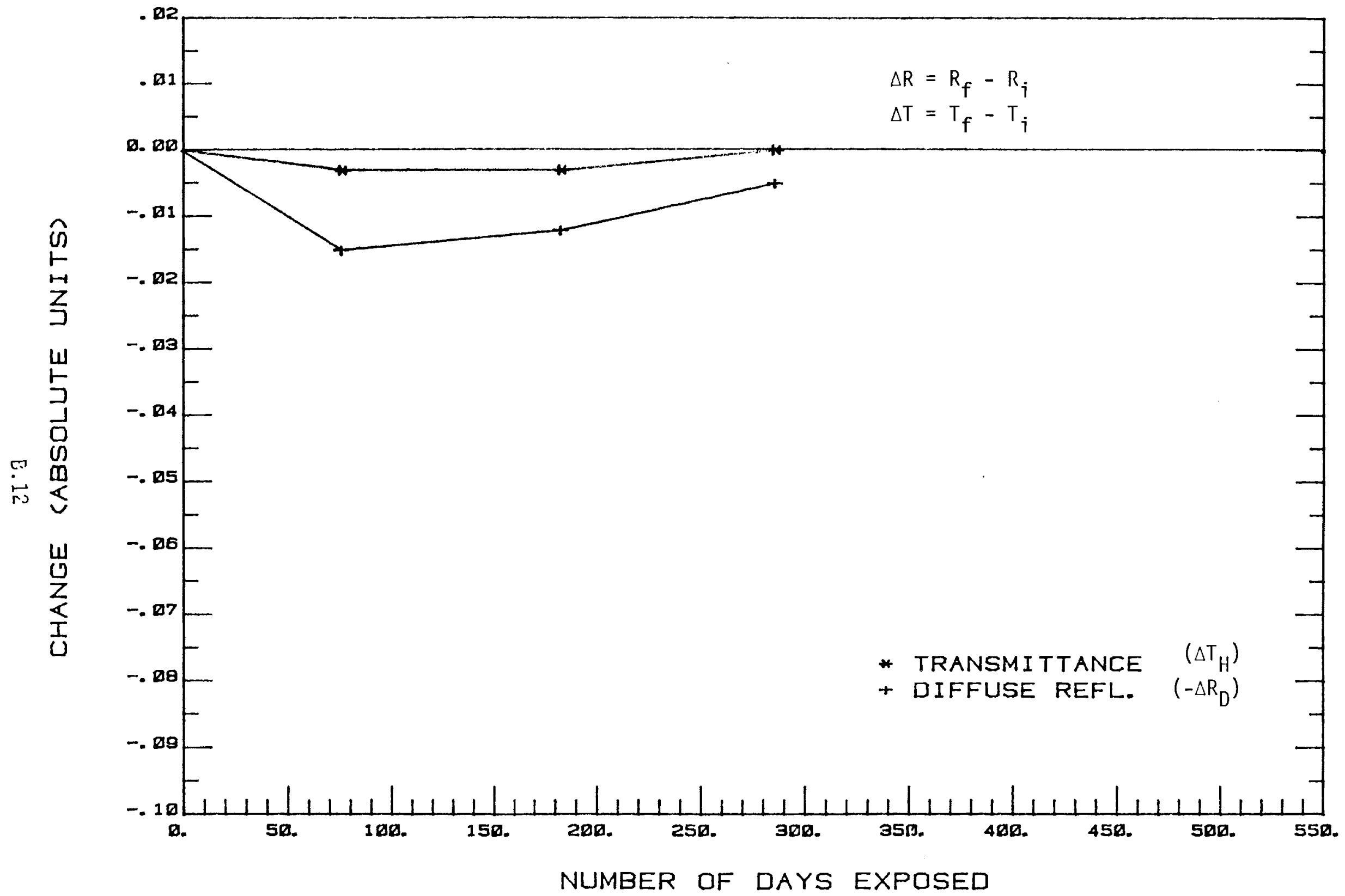

FIGURE B.12. Effects of Atmospheric Contamination on the Solar Weighted Optical Properties of Soda Lime Silicate Glass Weathered at the Table Mountain Site, 1980-1981 


\section{ÄPPENDIX C}

GLASS AND POLYMER ENCAPSULANT DATA

SECOND YEAR STUDY 


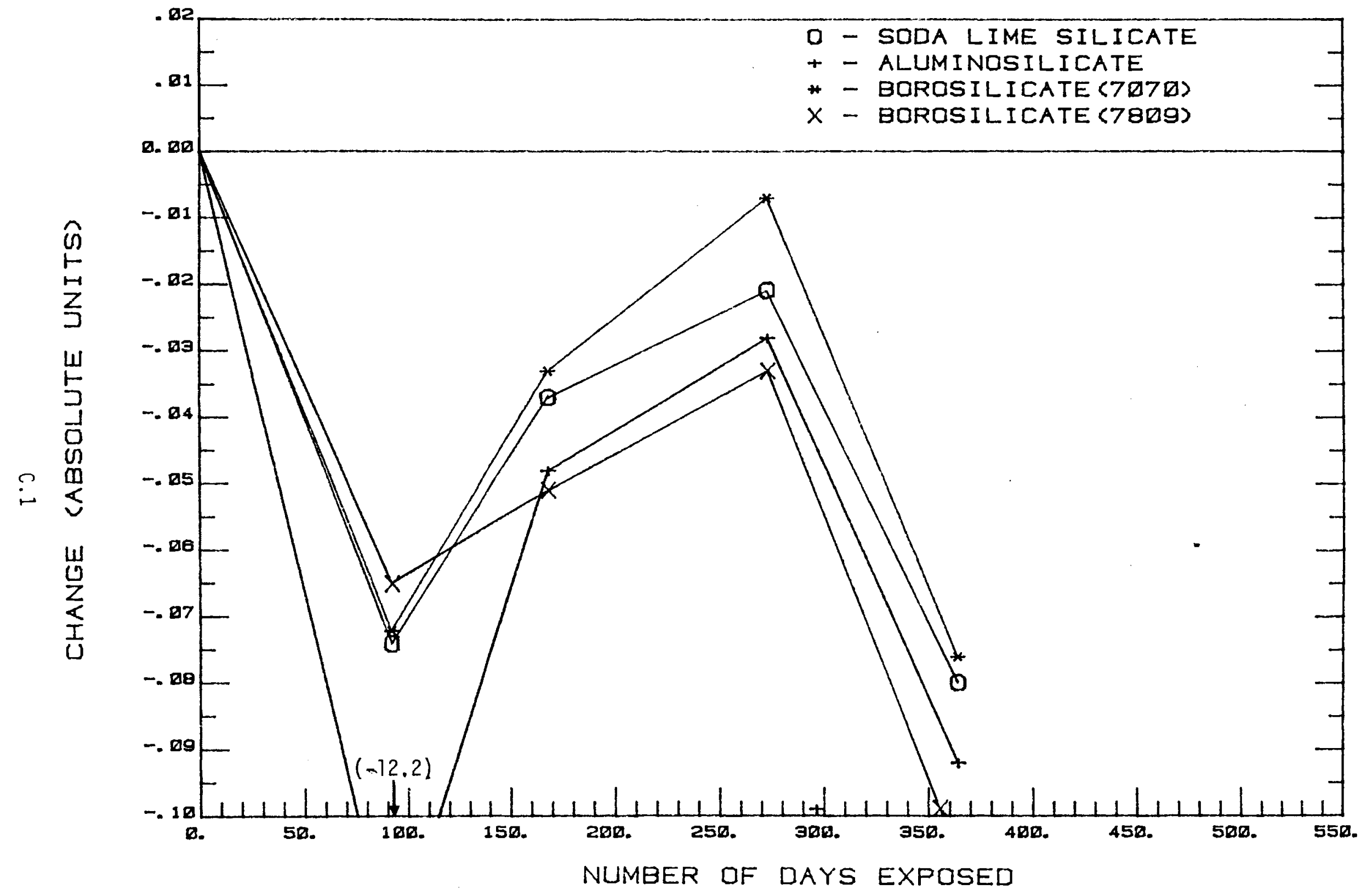
FIGURE C.1. Effects of Atmospheric Contamination on the Solar Weighted Transmittance $\left(\Delta T_{H}\right)$ of Glasses
Weathered at the Torrance Site, 1980-1981 


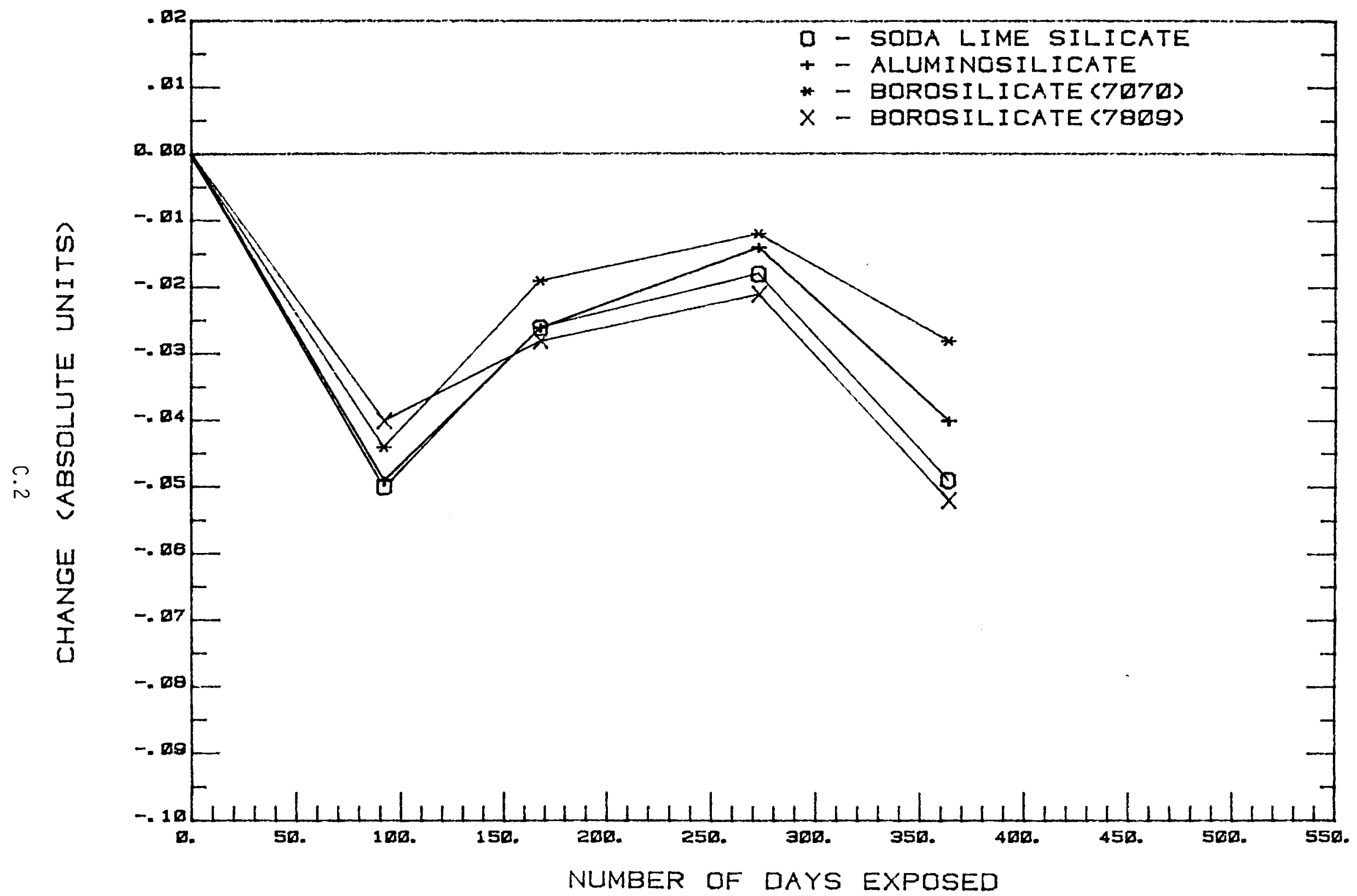
FIGURE C.2. Effects of Atmospheric Contamination on the Solar Weighted Diffuse Reflectance (- $\left.\triangle R_{D}\right)$ of Glasses
Weathered at the Torrance Site, 1980-1981 


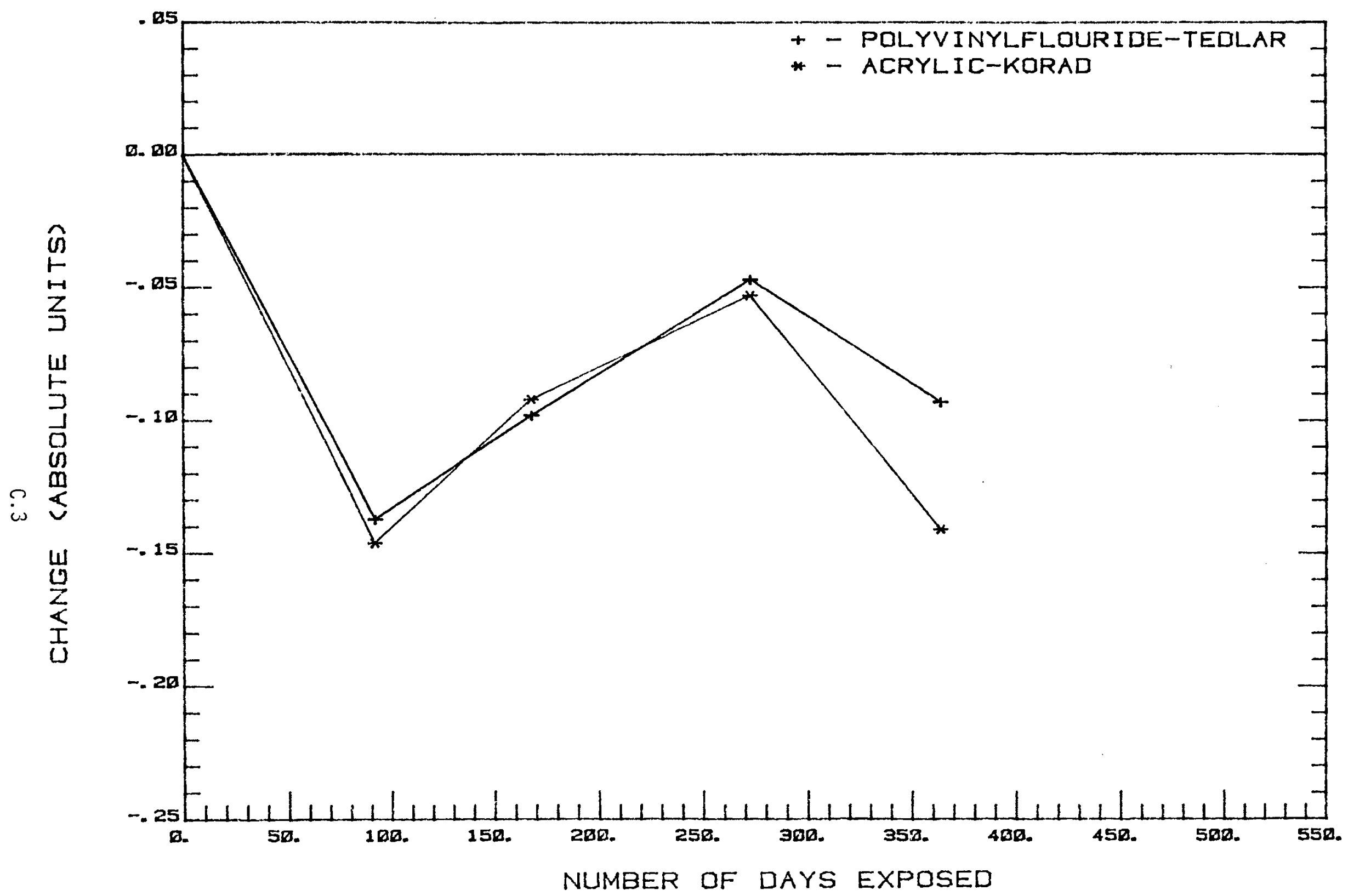

FIGURE C.3. Effects of Atmospheric Contamination on the Solar Weighted Transmittance $\left(\Delta T_{H}\right)$ of Polymers Weathered at the Torrance Site, 1980-1981 


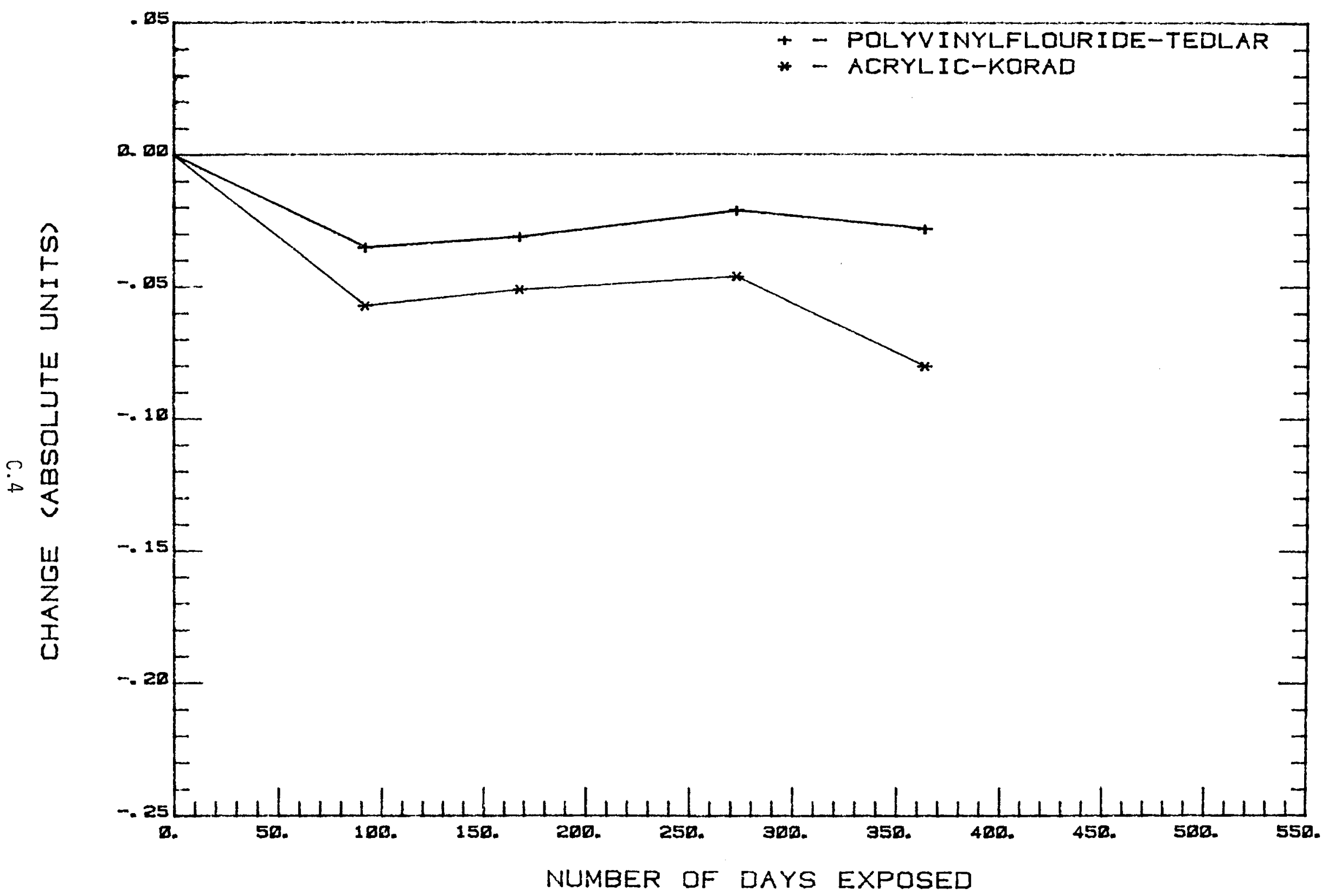
FIGURE C.4. Effects of Atmospheric Contamination on the Solar Weighted Diffuse Reflectance (- $\left.\Delta R_{D}\right)$ of
Polymers Weathered at the Torrance Site, 1980-1981 


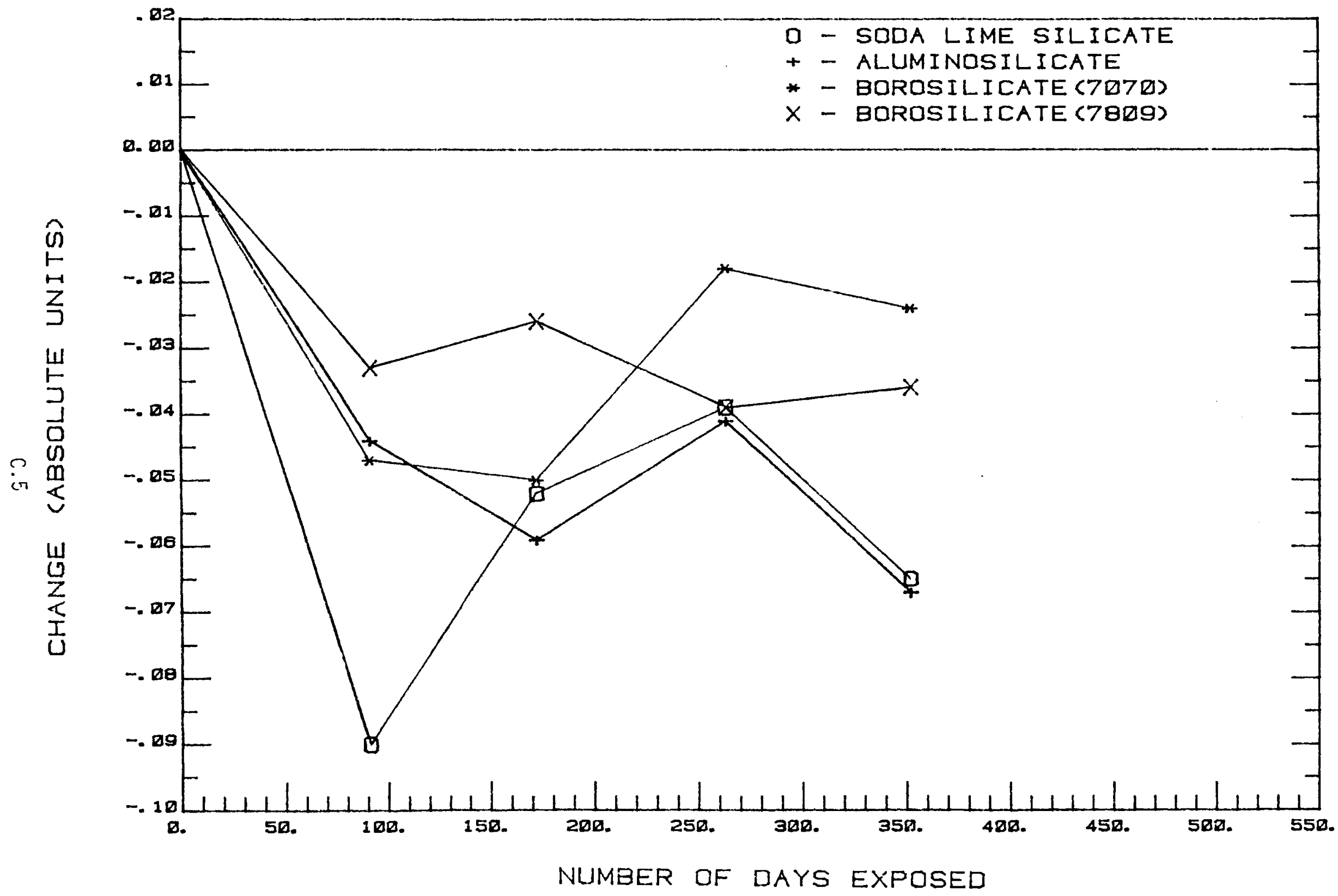

FIGURE C.5. Effects of Atmospheric Contamination on the Solar Weighted Transmittance $\left(\Delta T_{H}\right)$ of $G 1$ asses Weathered at the Pasadena Site, 1980-1981 


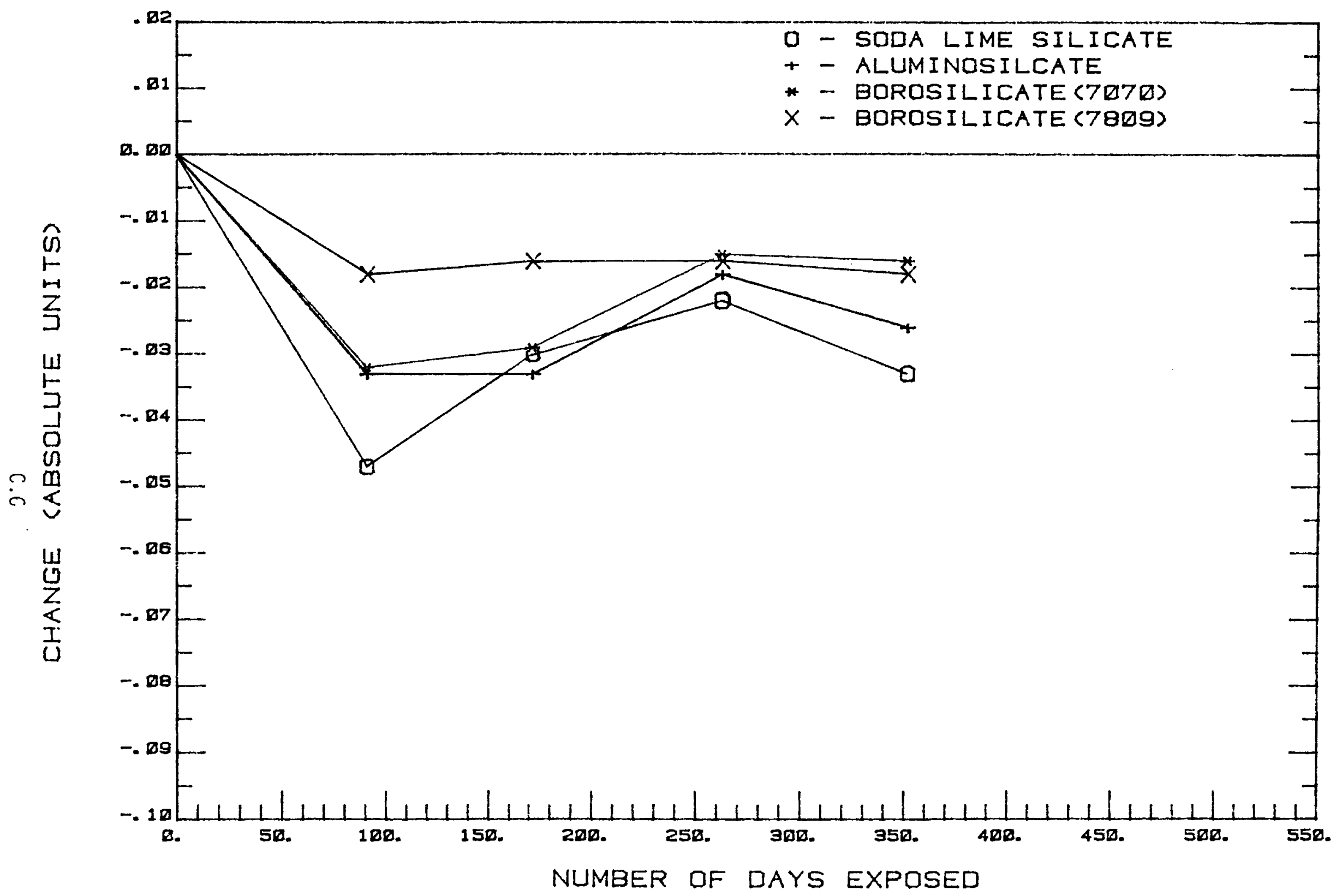
FIGURE C.6. Effects of Atmospheric Contamination on the Solar Weighted Diffuse Reflectance $\left(-\Delta R_{D}\right)$ of Glasses
Weathered at the Pasadena Site, 1980-1981 


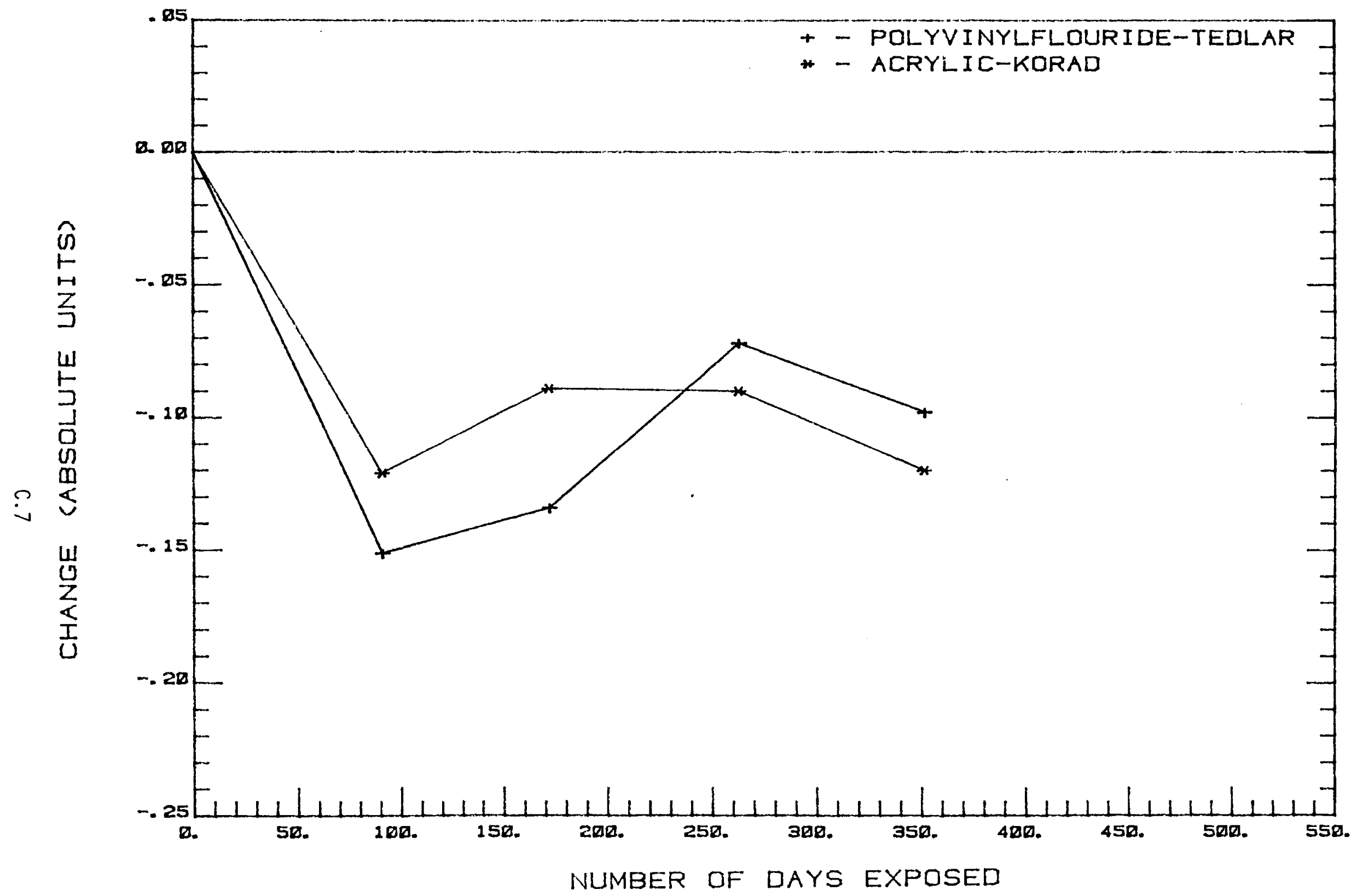
FIGURE C.7. Effects of Atmospheric Contamination on the Solar Weighted Transmittance $\left(\Delta \mathrm{T}_{H}\right)$ of Polymers
Weathered at the Pasadena Site, 1980-1981 


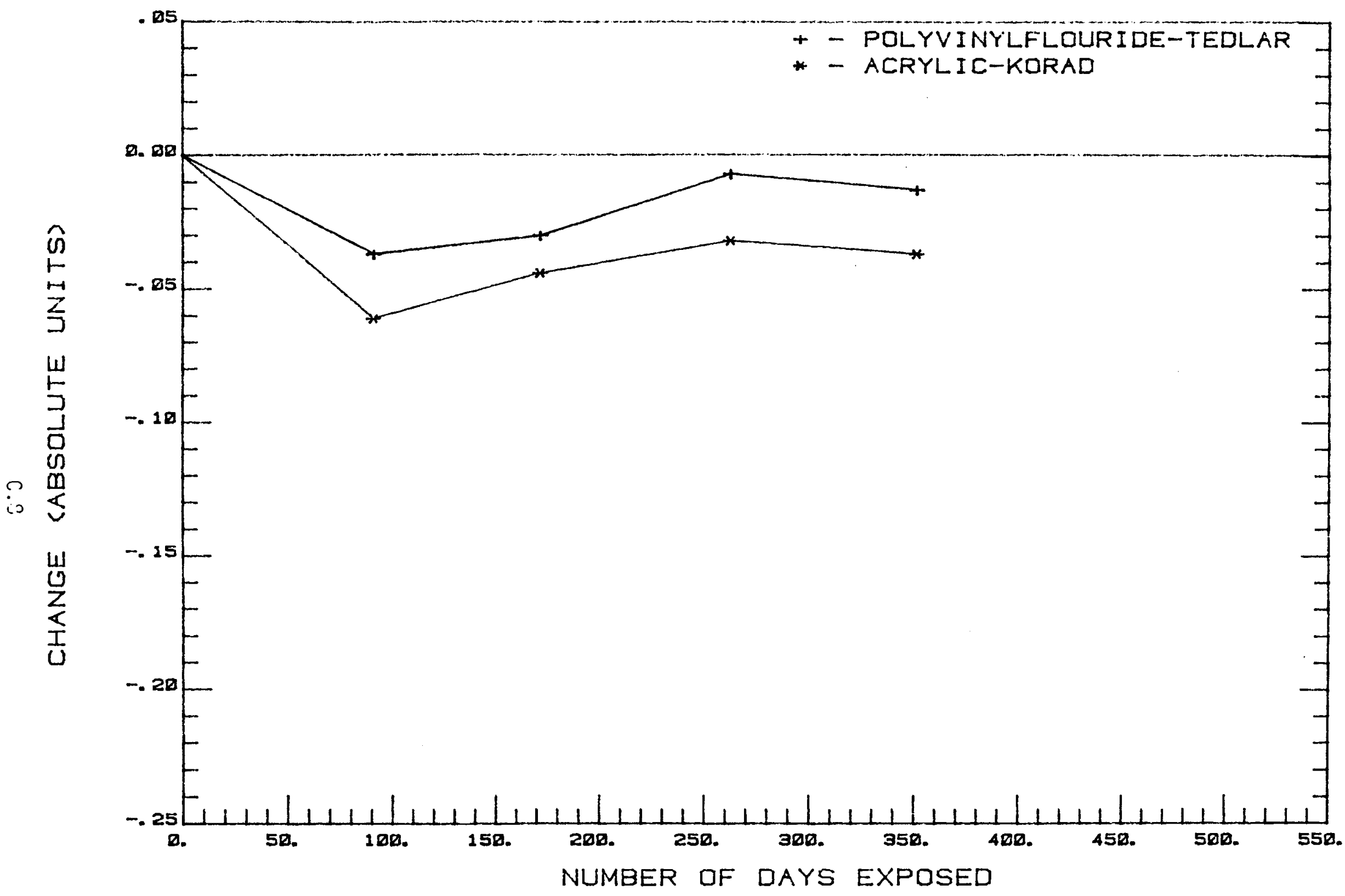
FIGURE C.8. Effects of Atmospheric Contamination on the Solar Weighted Diffuse Reflectance $\left(-\Delta R_{D}\right)$ of
Polymers Weathered at the Pasadena Site, 1980-1981 


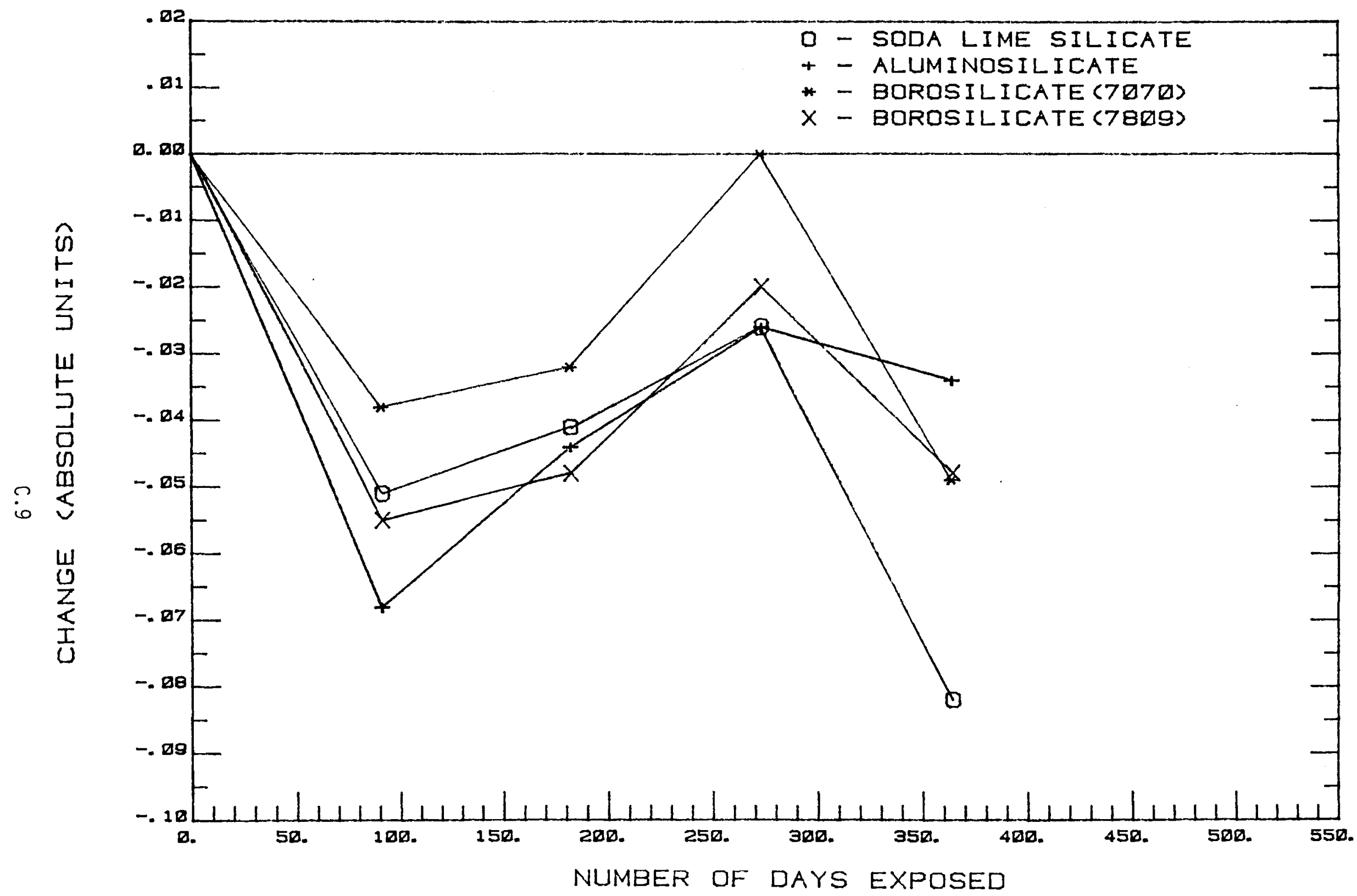

FIGURE C.9. Effects of Atmospheric Contamination on the Solar Weighted Transmittance ( $\Delta \mathrm{T}_{H}$ ) of Glasses Weathered at the Point Vicente Site, 1980-1981 


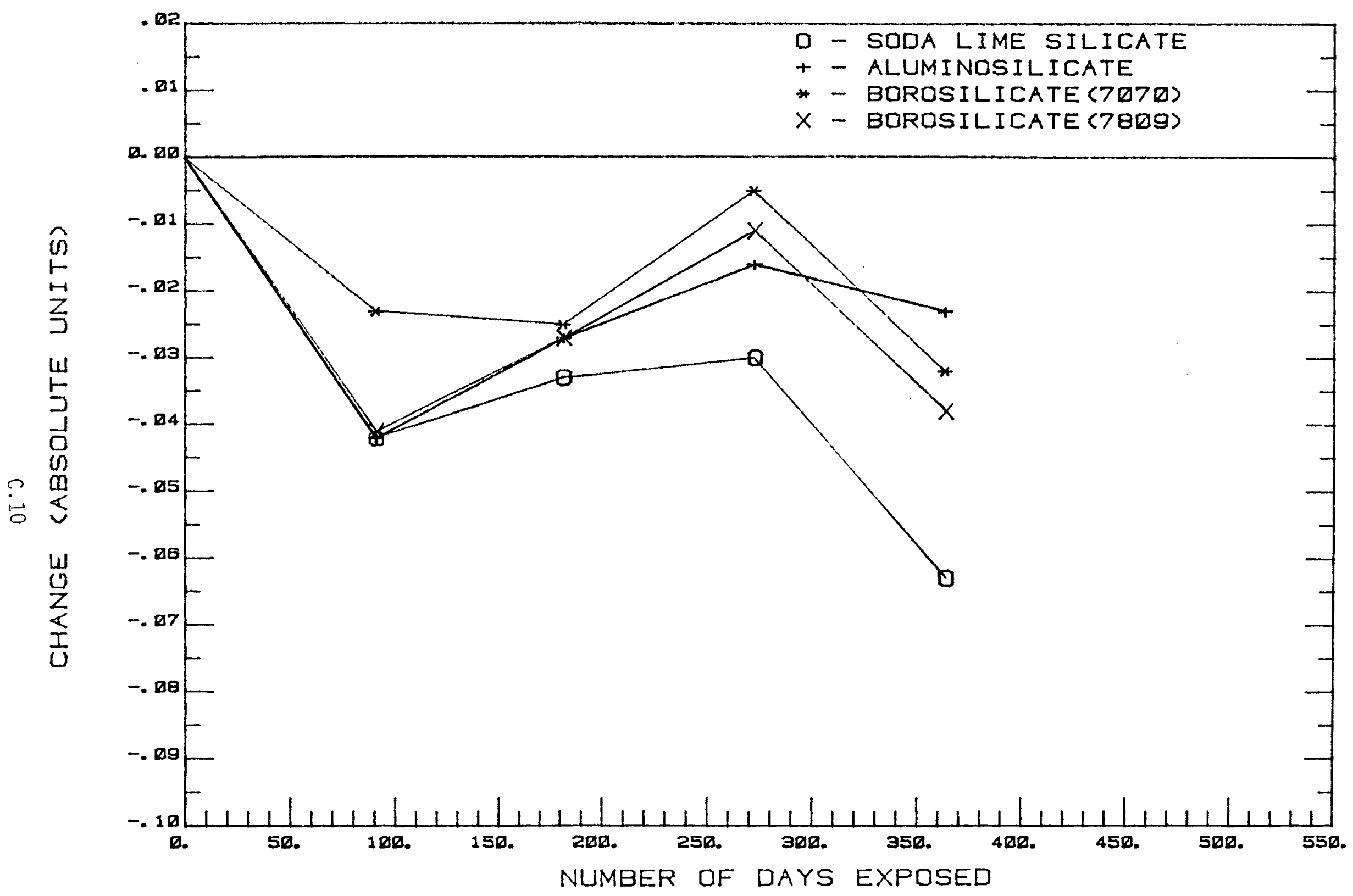
FIGURE C.10. Effects of Atmospheric Contamination on the Solar Weighted Diffuse Reflectance $\left(-\triangle R_{D}\right)$ of Glasses
Weathered at the Point Vicente Site, 1980-1981 


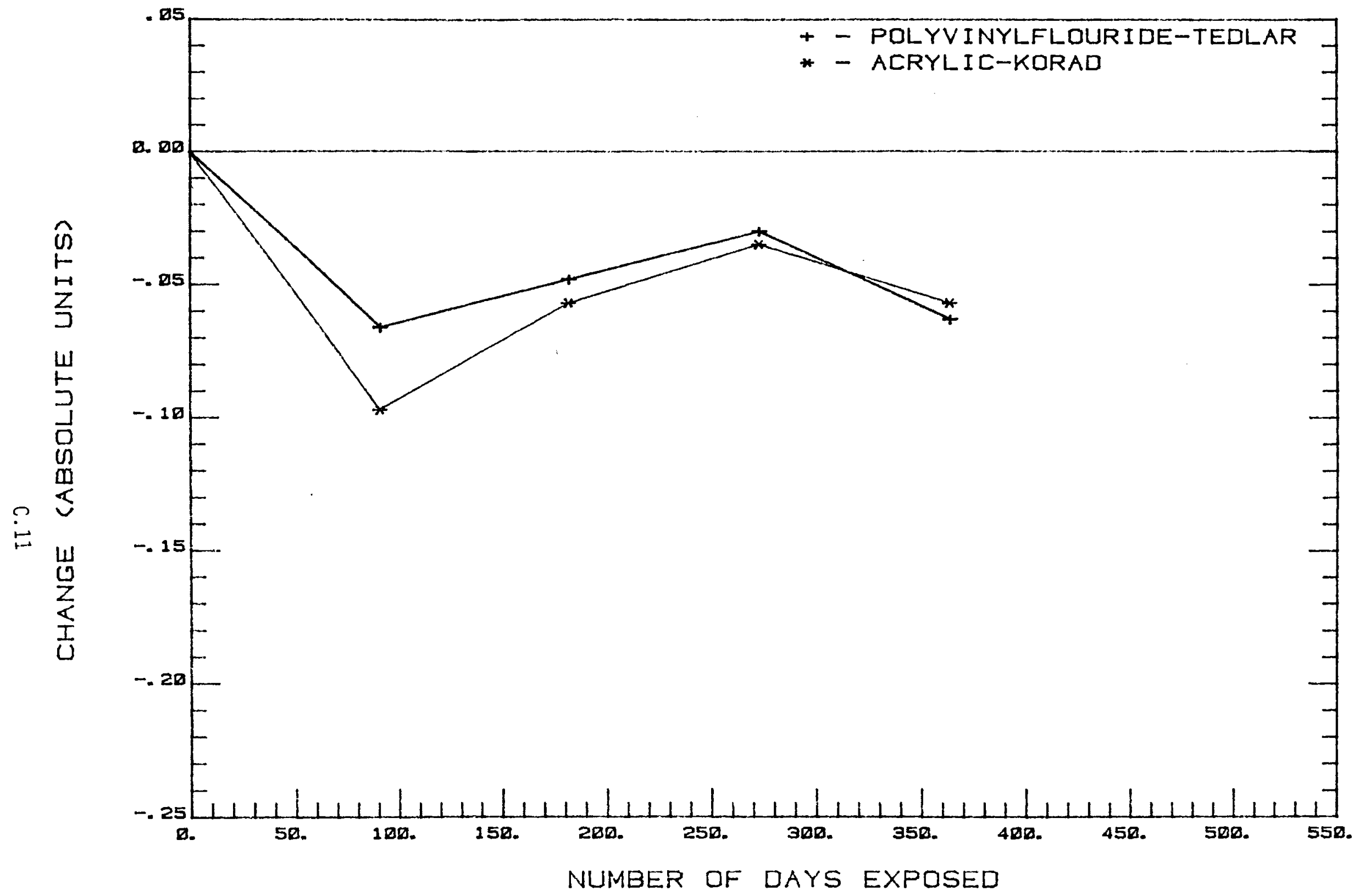

FIGURE C.11. Effects of Atmospheric Contamination on the Solar Weighted Transmittance $\left(\Delta T_{H}\right)$ of Polymers Weathered at the Point Vicente Site, 1980-1981 


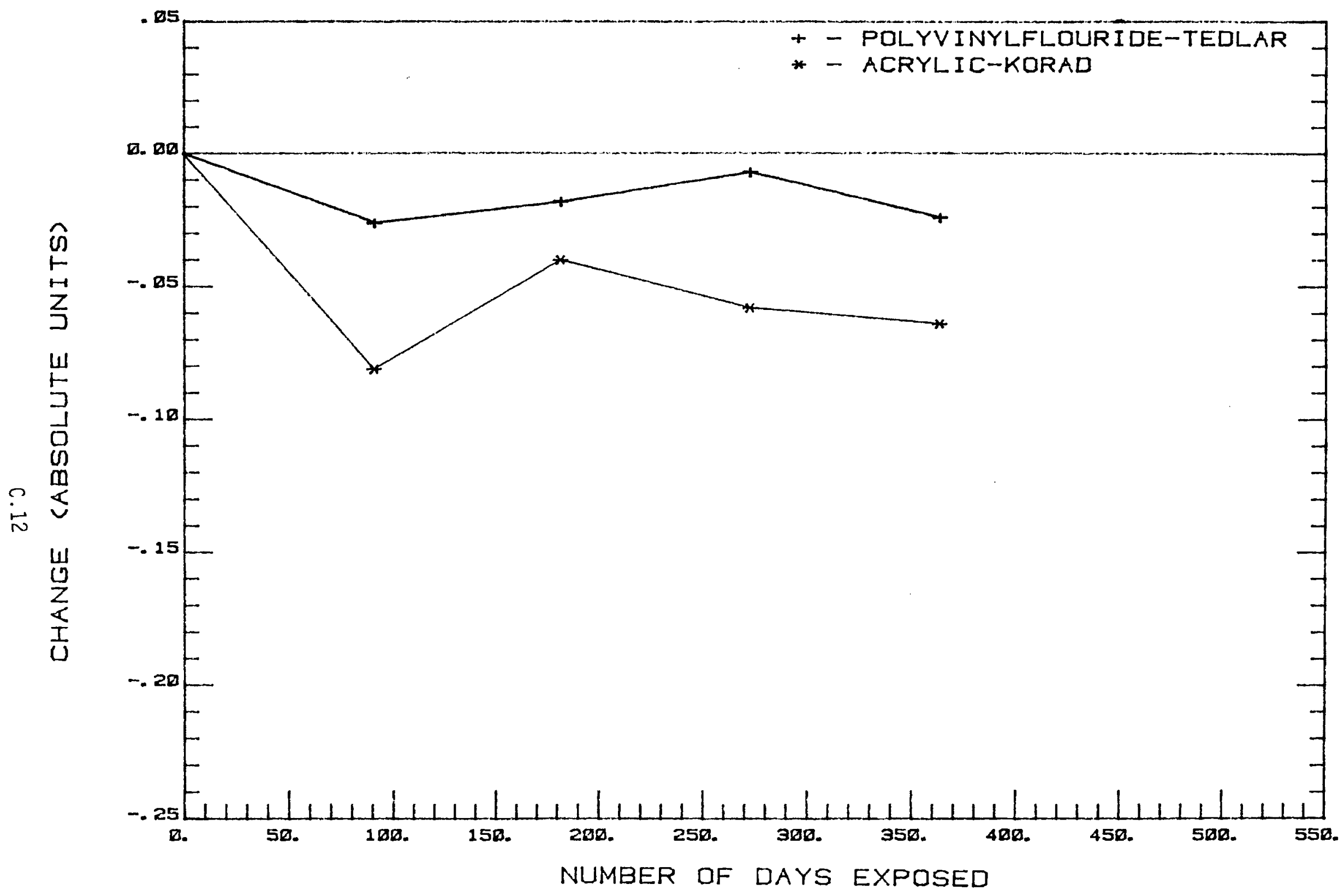

FIGURE C.12. Effects of Atmospheric Contamination on the Solar Weighted Diffuse Reflectance (- $\left.\Delta \mathrm{R}_{\mathrm{D}}\right)$ of Polymers Weathered at the Point Vicente Site, 1980-1981 


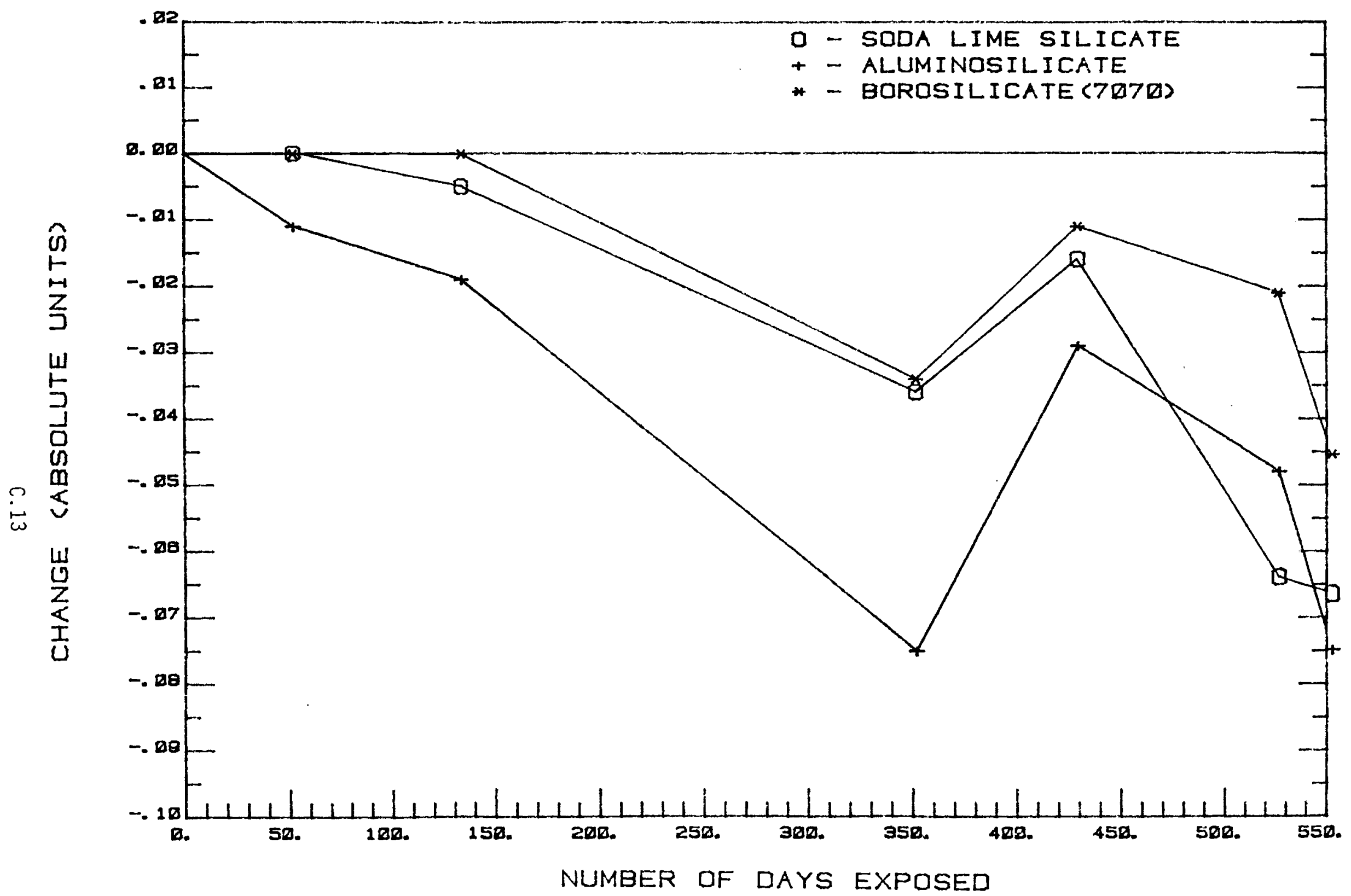

FIGURE C.13. Effects of Atmospheric Contamination on the Solar Weighted Transmittance $\left(\Delta T_{H}\right)$ of Glasses
Weathered at the Richland Site, 1980-1981 


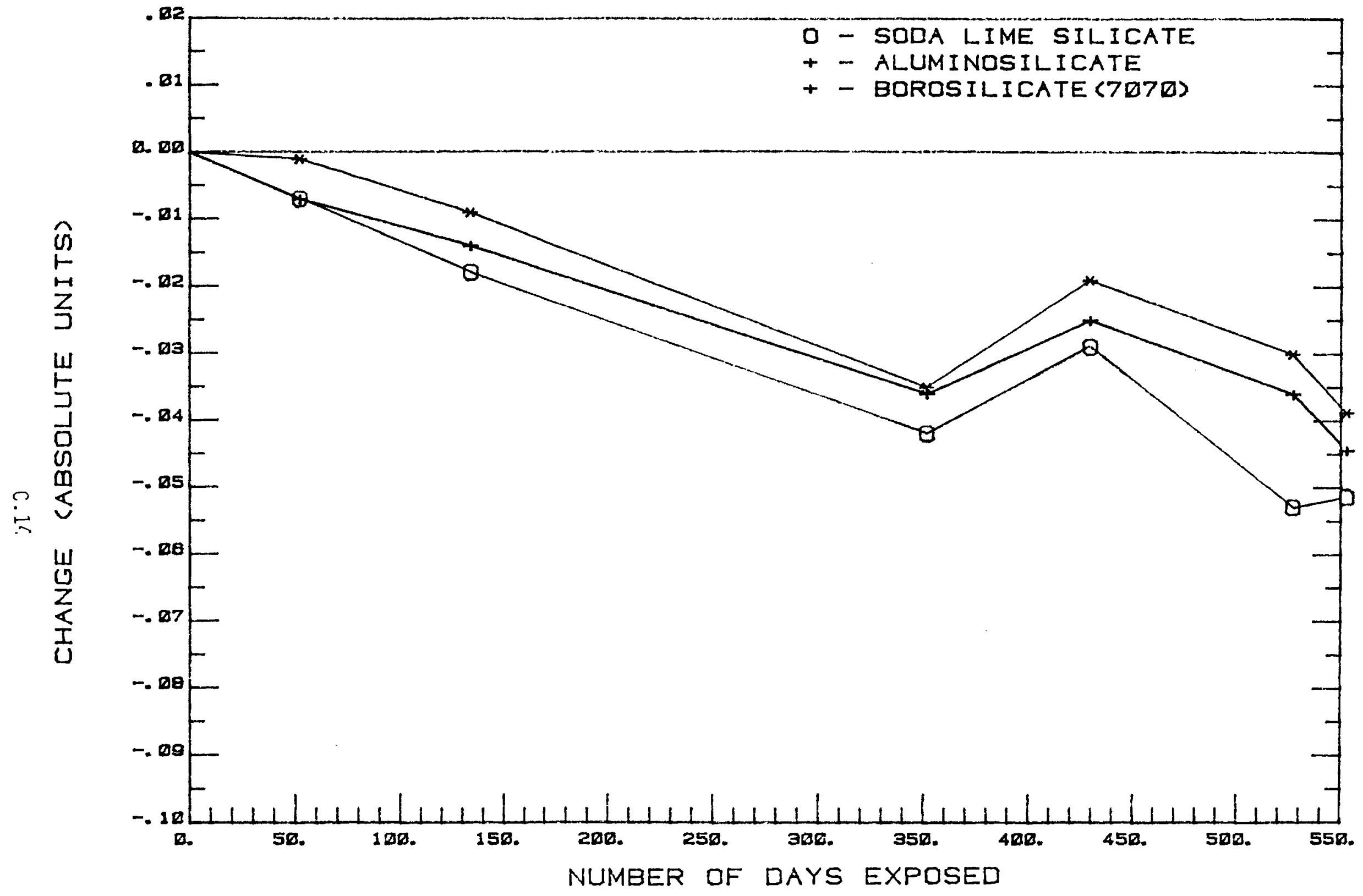

FIGURE C.14. Effects of Atmospheric Contamination on the Solar Weighted Diffuse Reflectance $\left(-\Delta R_{D}\right)$ of Glasses Weathered at the Richland Site, 1980-1981 


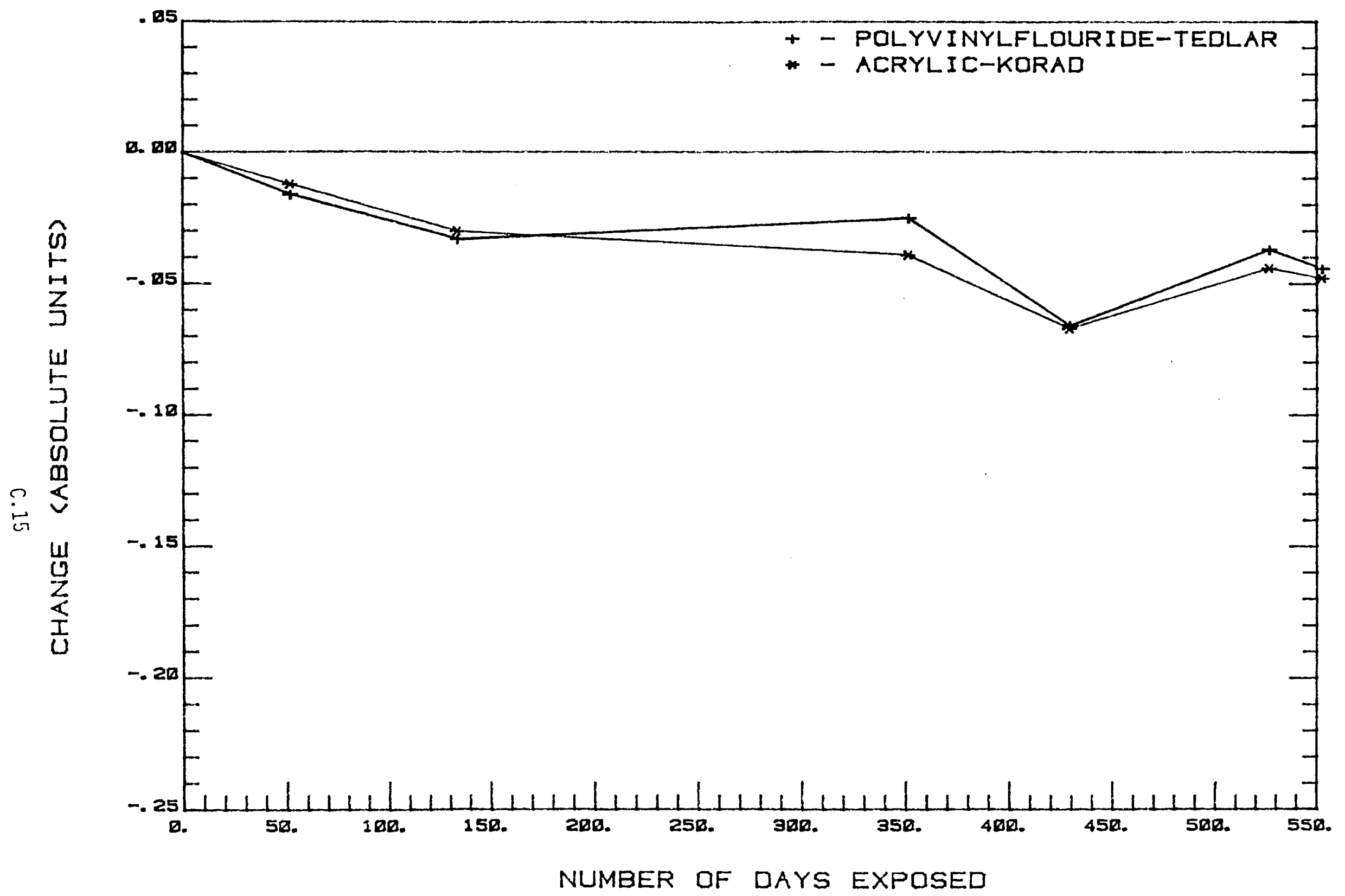

FIGURE C.15. Effects of Atmospheric Contamination on the Solar Weighted Transmittance $\left(\Delta T_{H}\right)$ of Polymers Weathered at the Richland Site, 1980-1981 


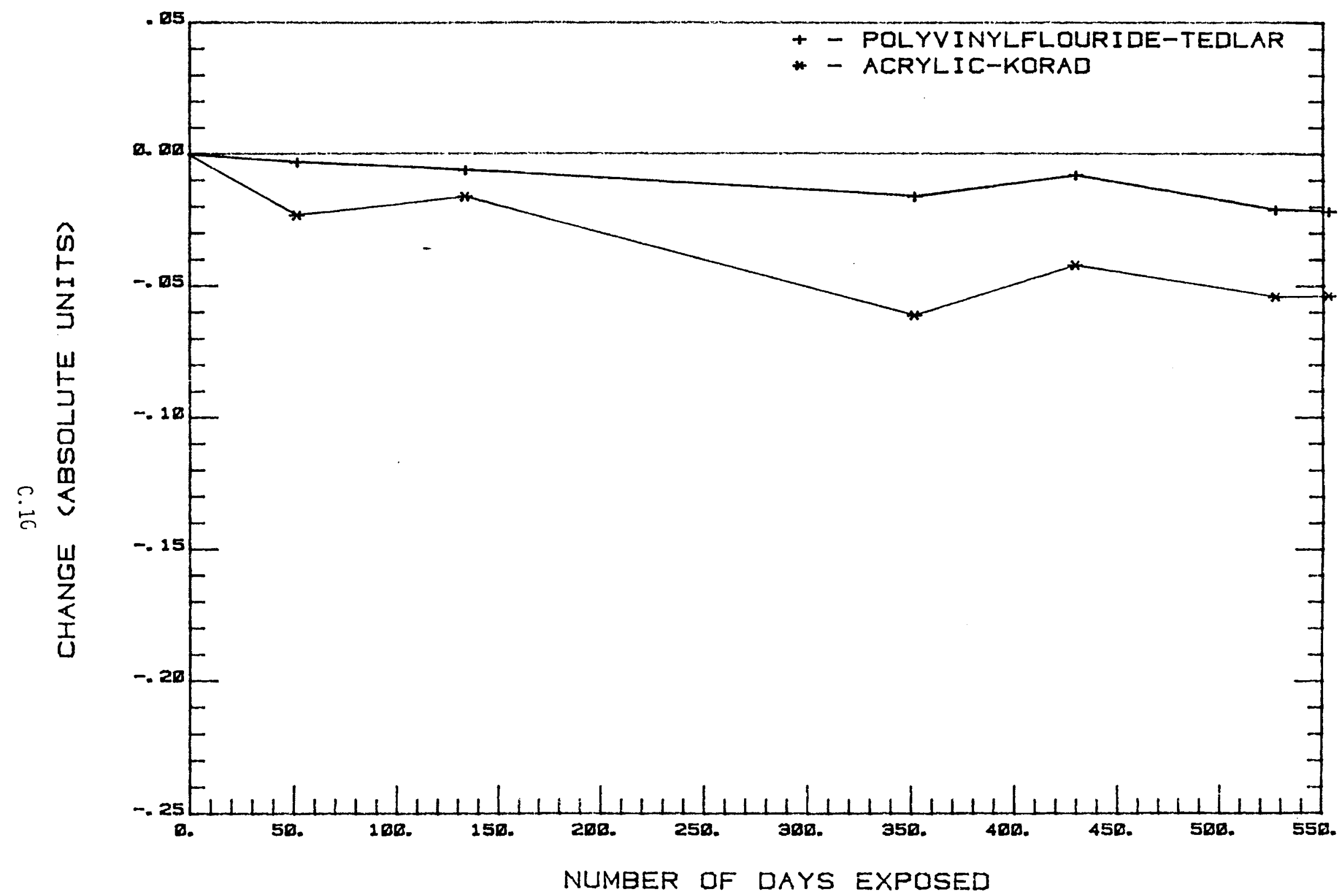

FIGURE C.16. Effects of Atmospheric Contamination on the Solar Weighted Diffuse Reflectance $\left(-\Delta R_{D}\right)$ of Polymers Weathered at the Richland Site, 1980-1981 


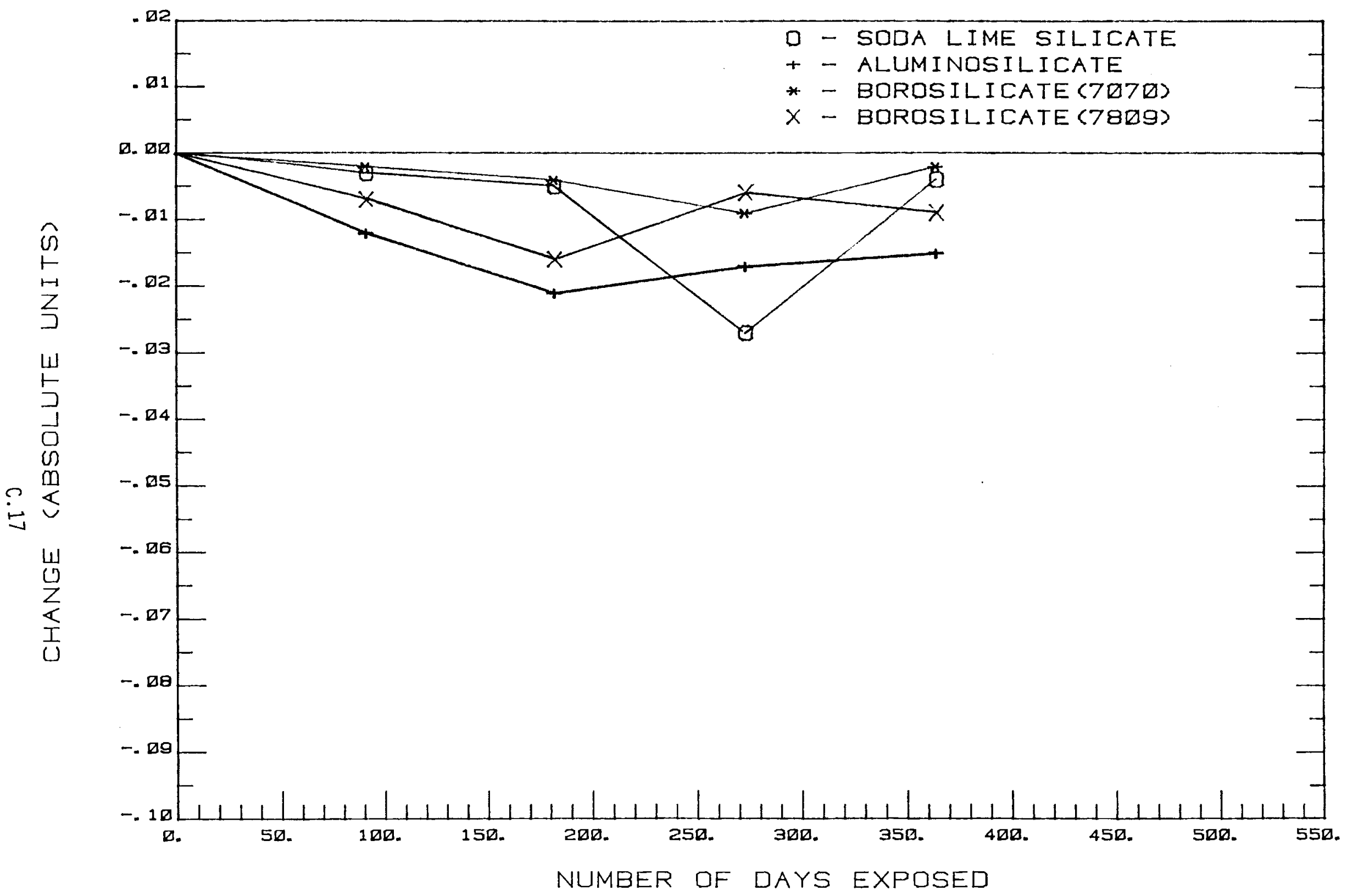
FIGURE C.17. Effects of Atmospheric Contamination on the Solar Weighted Transmittance $\left(\Delta T_{H}\right)$ of Glasses
Weathered at the Goldstone Site, 1980-1981 


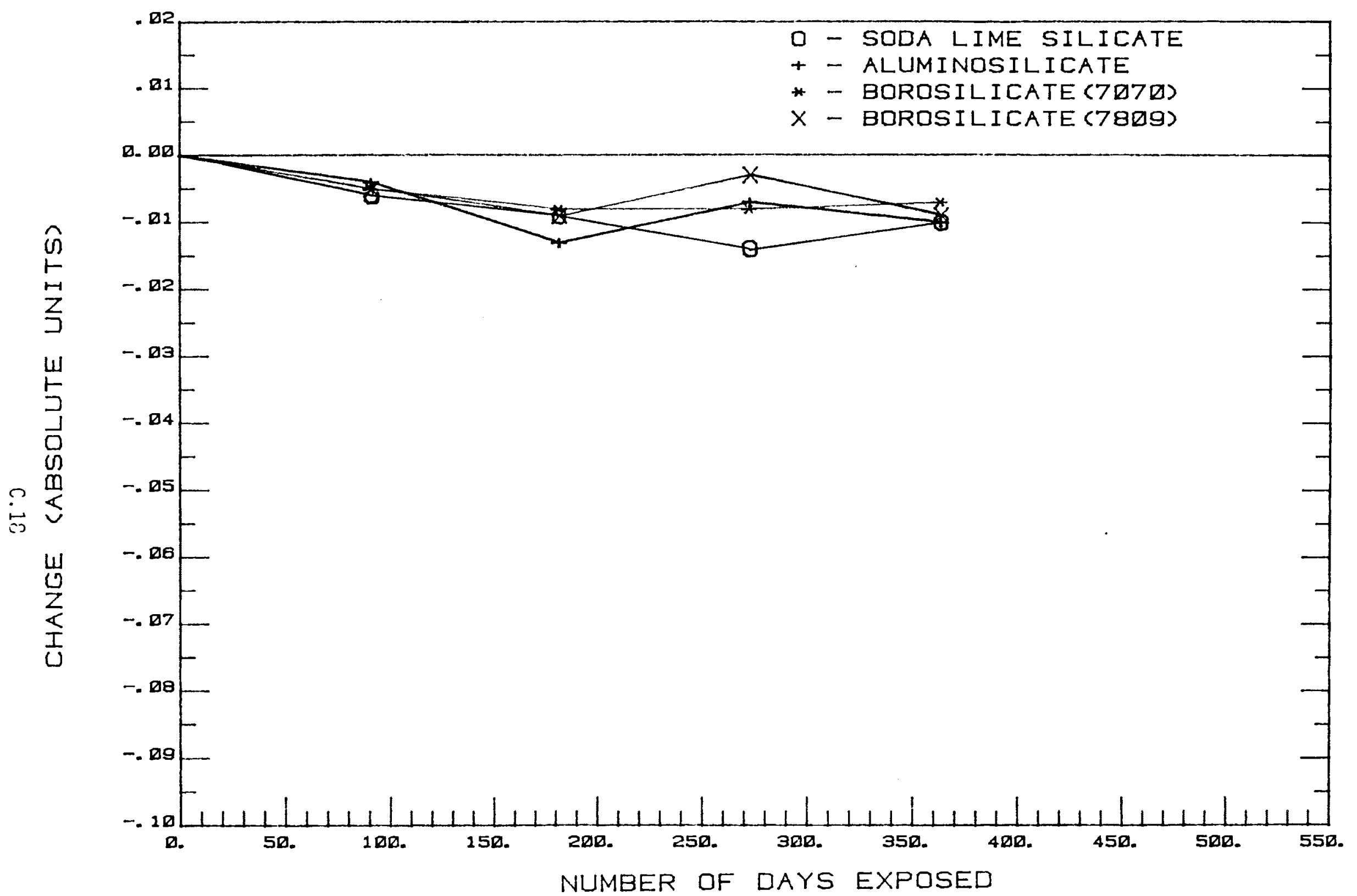
FIGURE C.18. Effects of Atmospheric Contamination on the Solar Weighted Diffuse Reflectance $\left(-\Delta R_{D}\right)$ of GTasses
Weathered at the Goldstone Site, 1980-1981 


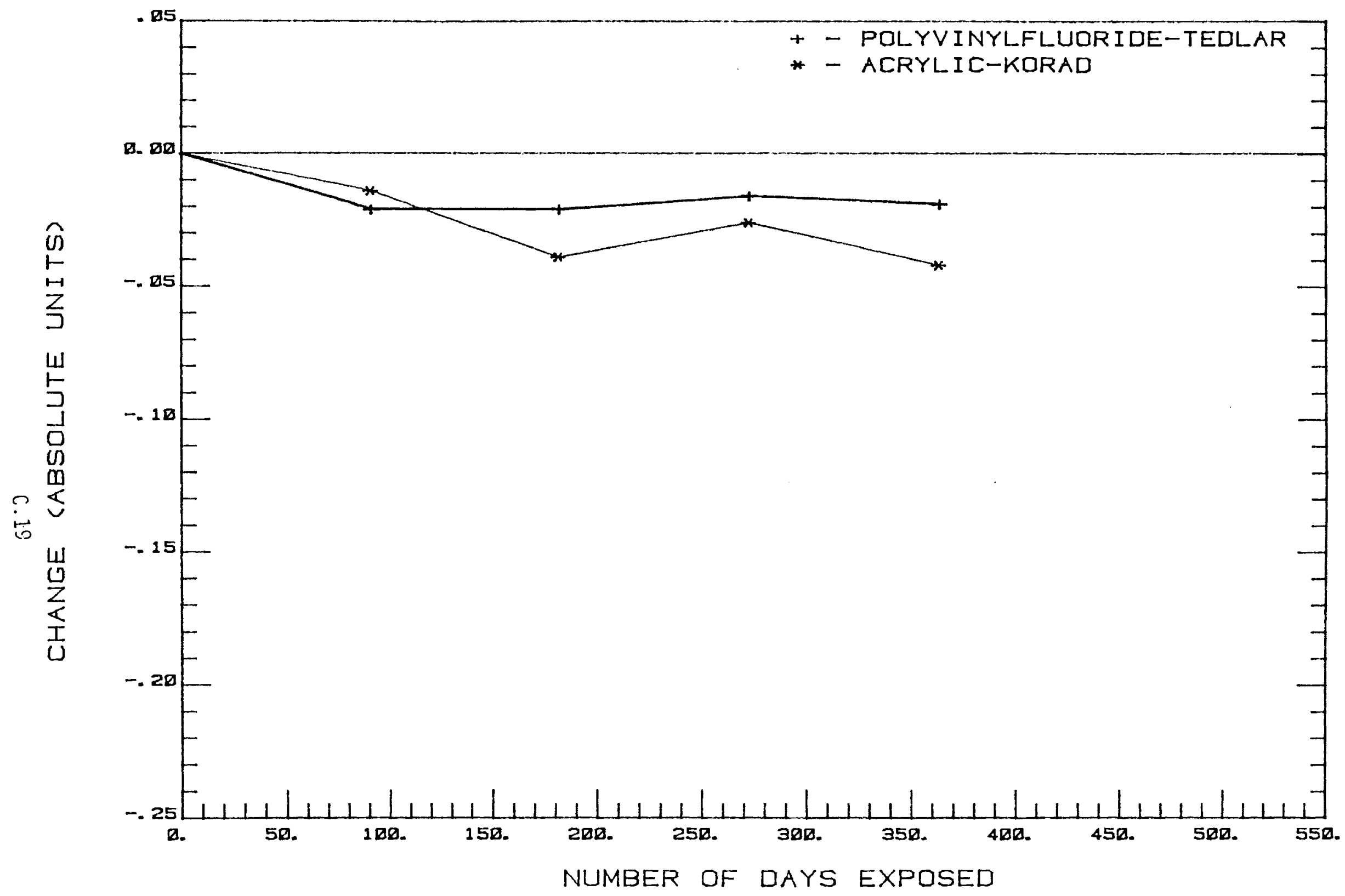

FIGURE C.19. Effects of Atmospheric Contamination on the Solar Weighted Transmittance $\left(\Delta T_{H}\right)$ of Polymers Weathered at the Goldstone Site, 1980-1981 


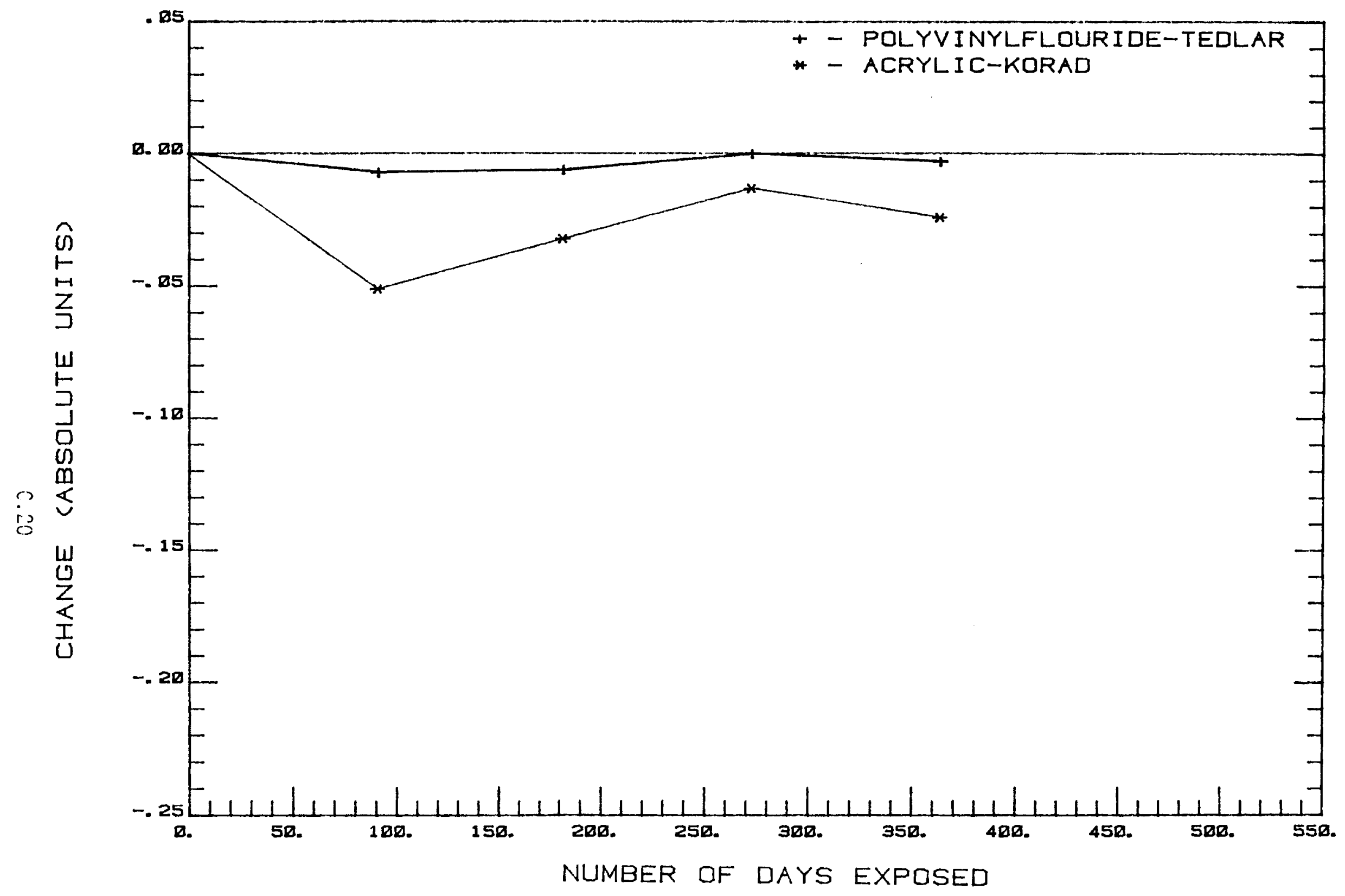
FIGURE C.20. Effects of Atmospheric Contamination on the Solar Weighted Diffuse Reflectance $\left(-\Delta R_{D}\right)$ of
Polymers Weathered at the Goldstone Site, 1980-1981 


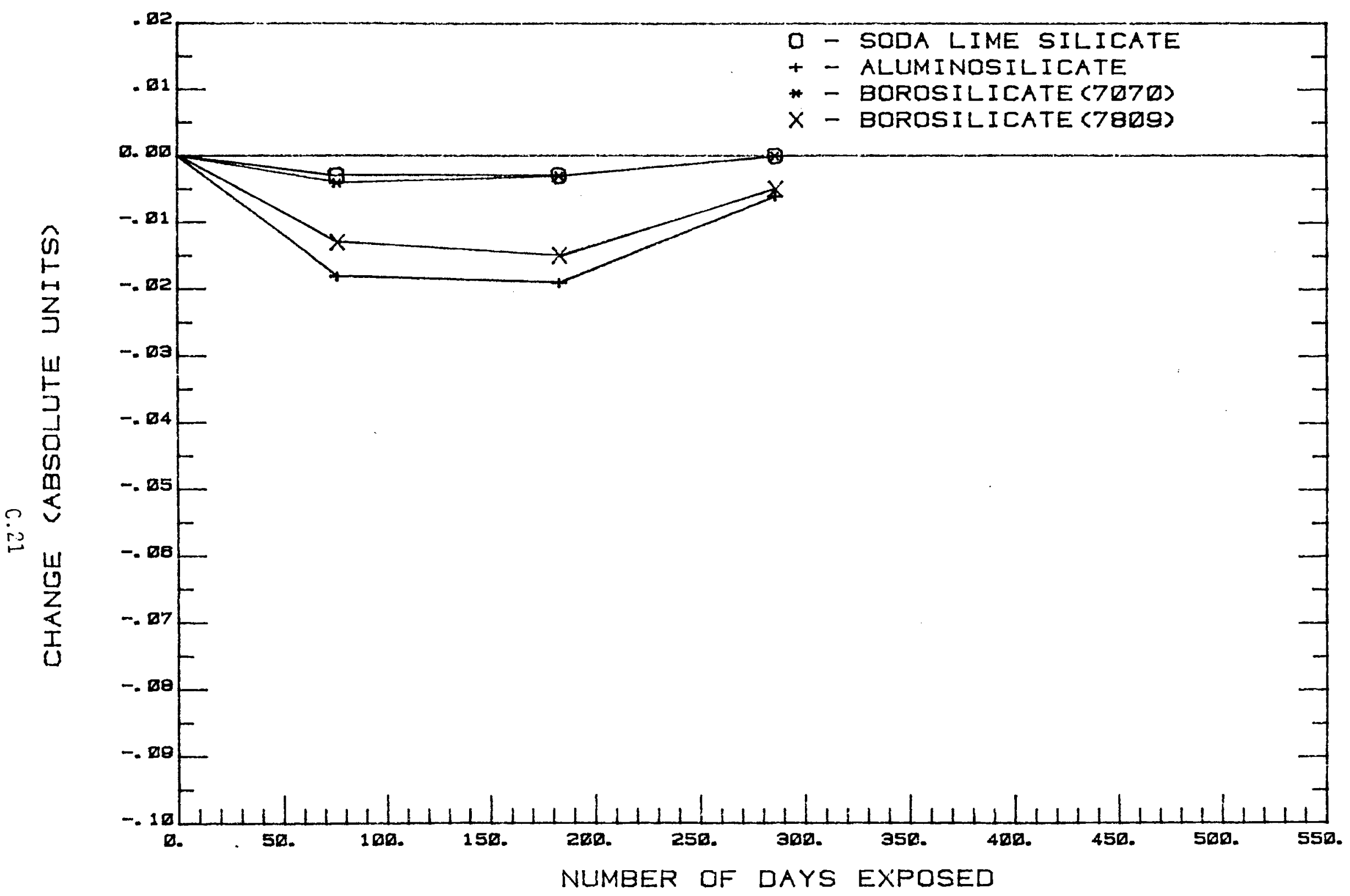
FIGURE C.21. Effects of Atmospheric Contamination on the Solar Weighted Transmittance ( $\triangle \mathrm{T}_{H}$ ) of Glasses
Weathered at the Table Mountain Site, 1980-1981 


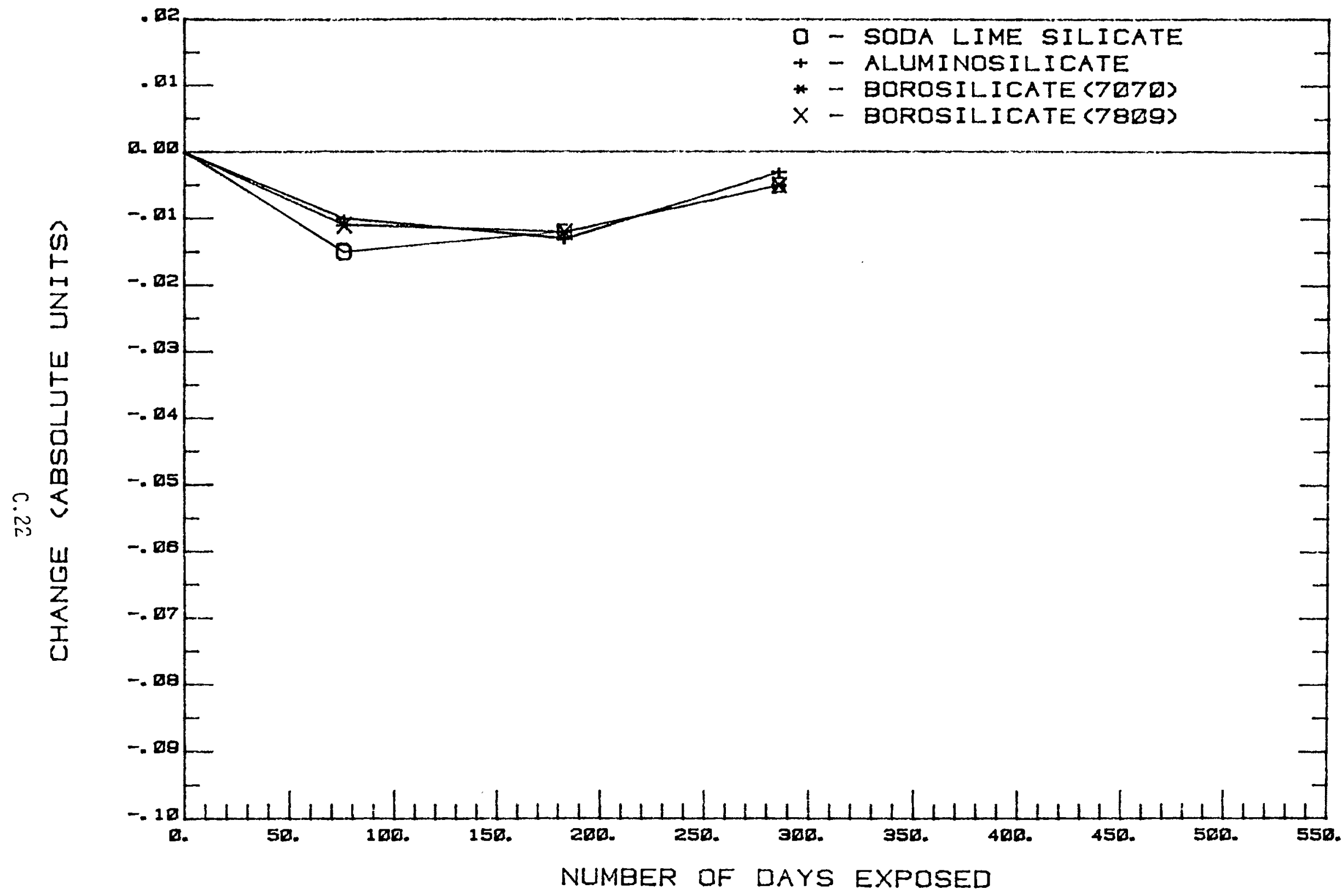
FIGURE C.22. Effects of Atmospheric Contamination on the Solar Weighted Diffuse Reflectance (- $\triangle R_{D}$ ) of Glasses
Weathered at the Table Mountain Site, 1980-1981 


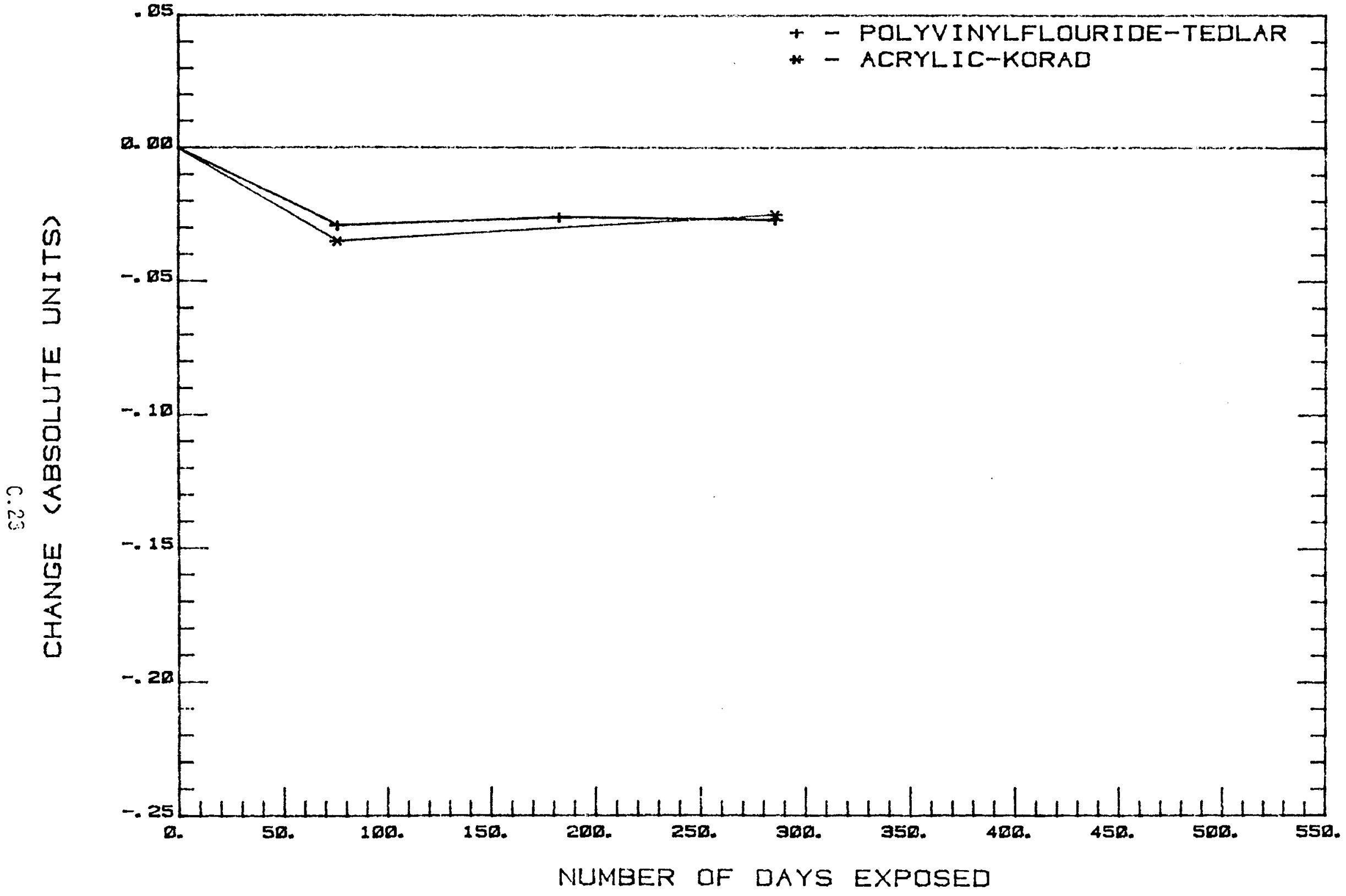

FIGURE C.23. Effects of Atmospheric Contamination on the Solar Weighted Transmittance $\left(\Delta T_{H}\right)$ of Polymers Weathered at the Table Mountain Site, 1980-1981 


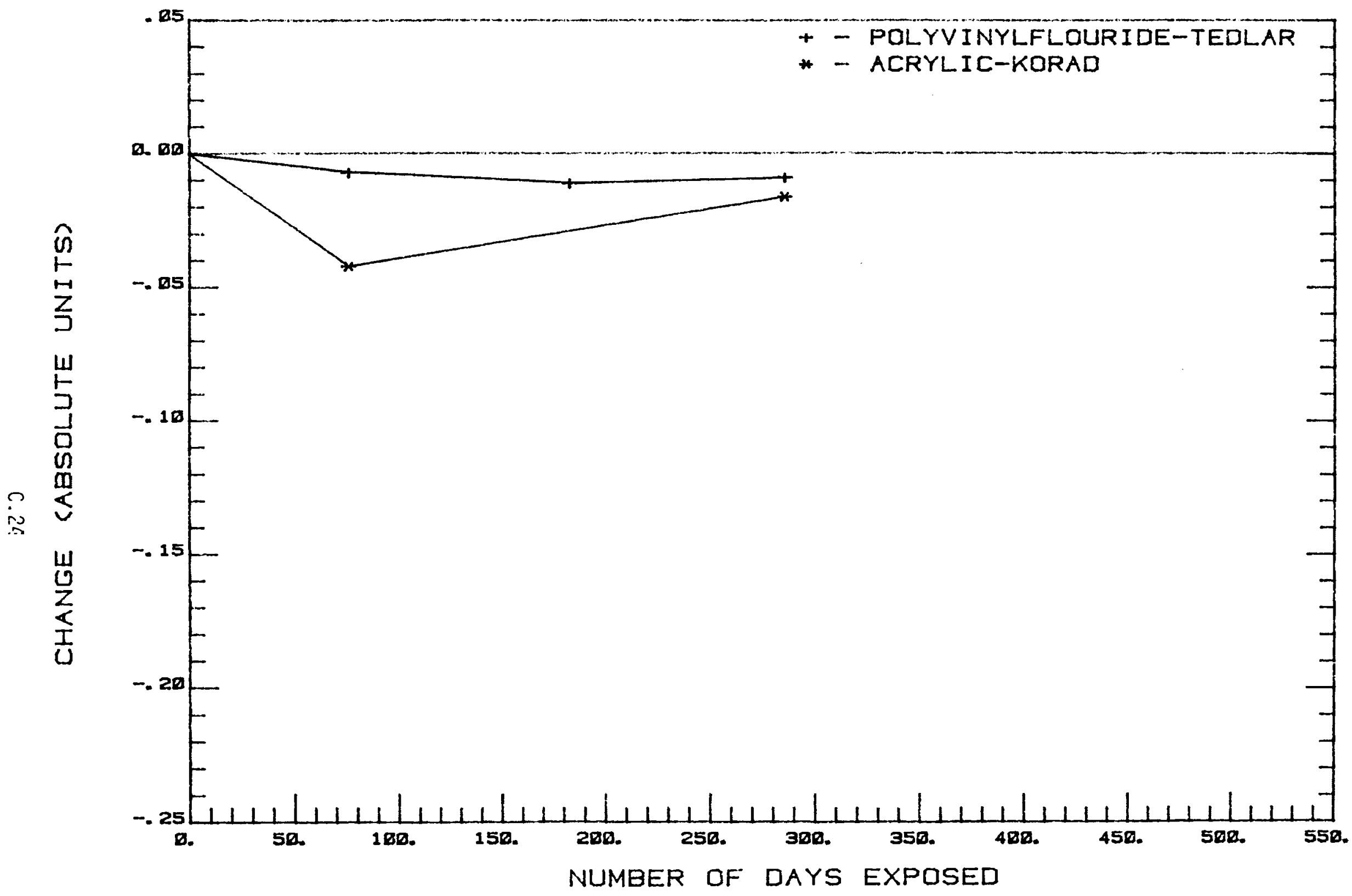

FIGURE C.24. Effects of Atmospheric Contamination on the Solar Weighted Diffuse Reflectance (- $\left.\triangle R_{D}\right)$ of Polymers Weathered at the Table Mountain Site, 1980-1981 
APPENDIX D

GLASS AND POLYMER ENCAPSULANT DATA

FIRST YEAR STUDY 


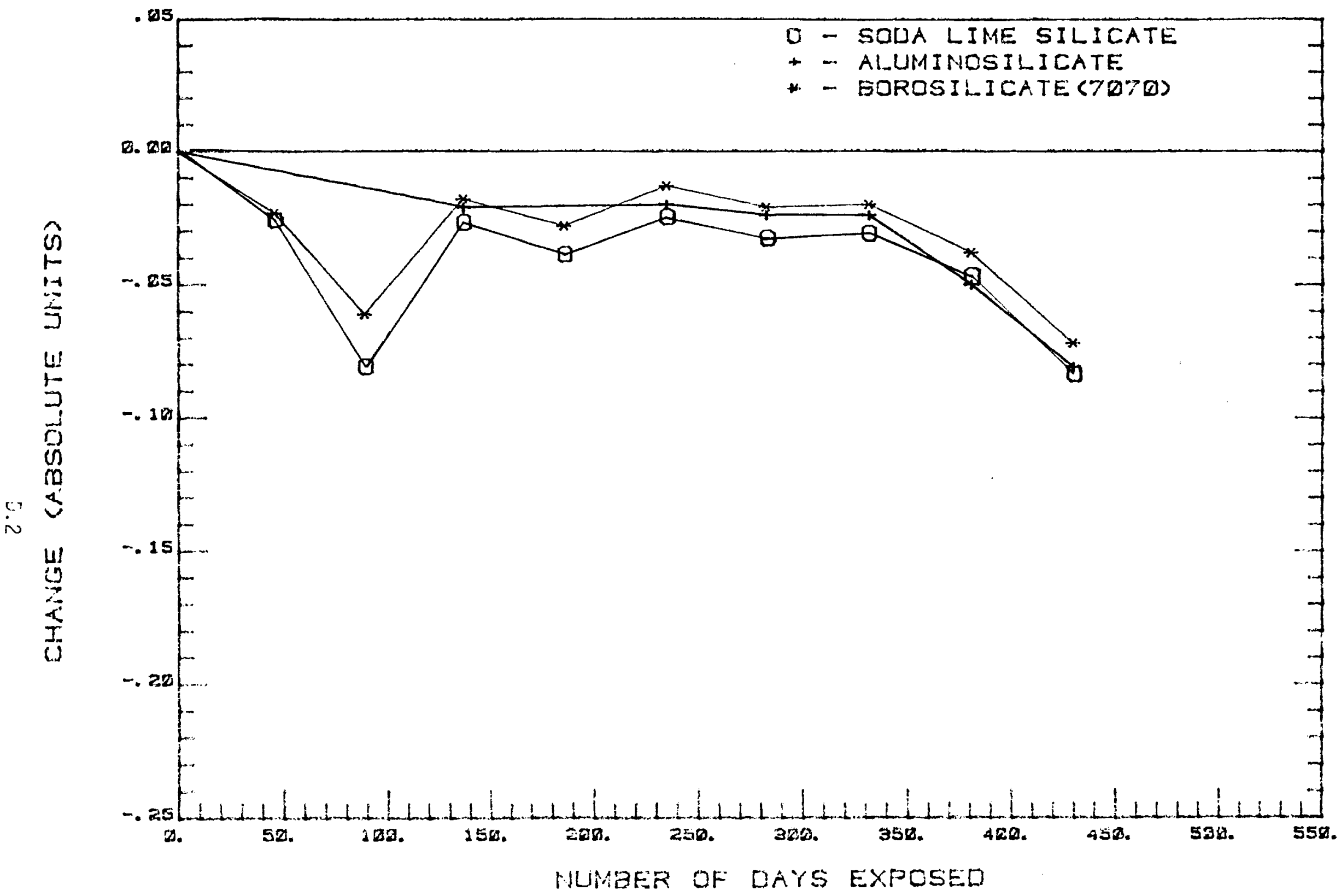

FIGURE D.2. Effects of Atmospheric Contamination on the Solar Weighted Diffuse Reflectance (- $\Delta R_{D}$ ) of Glasses Weathered at the Torrance Site, 1979-1980 


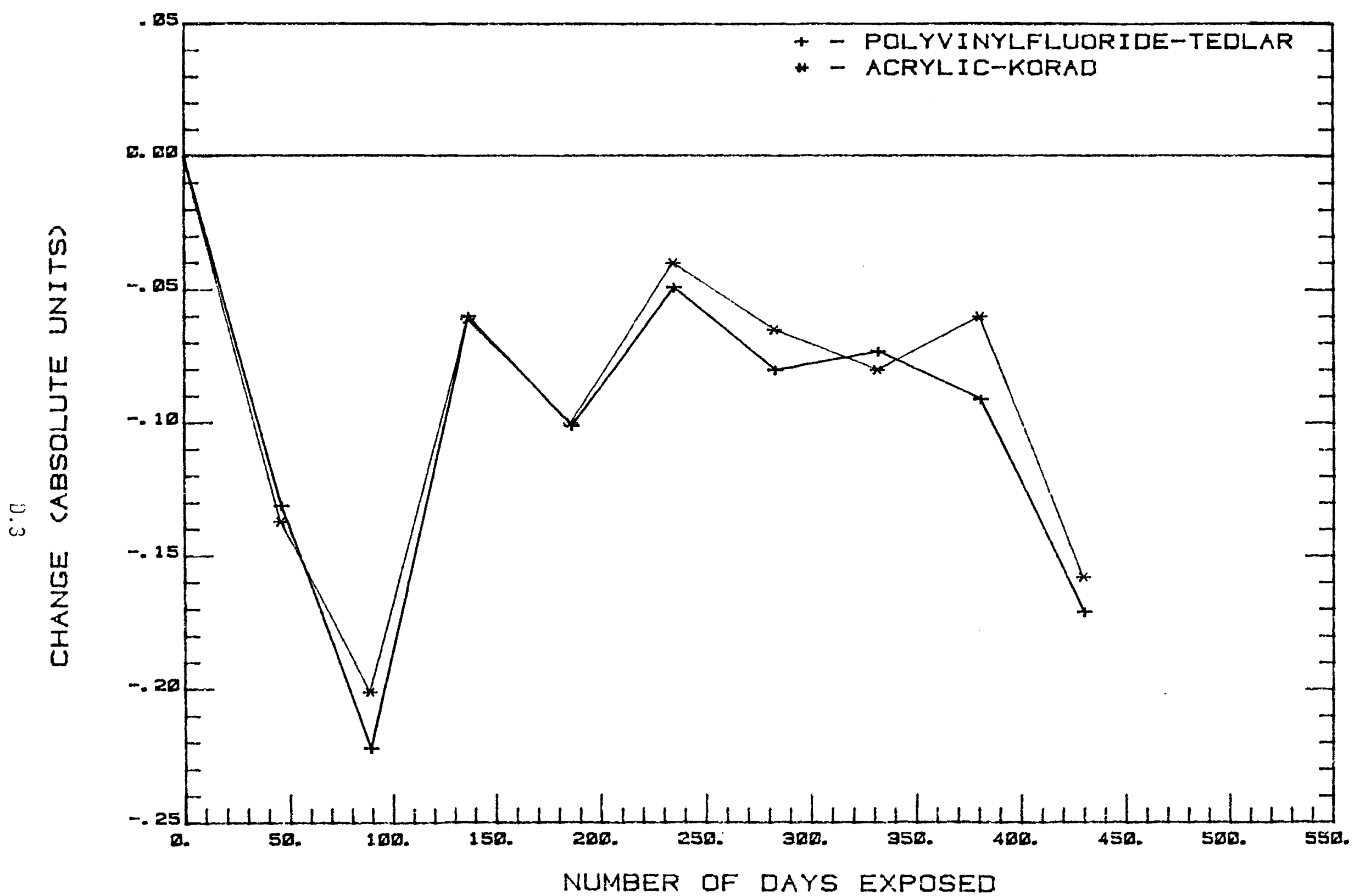

FIGURE D.3. Effects of Atmospheric Contamination on the Solar Weighted Transmittance $\left(\Delta T_{H}\right)$ of Polymers Weathered at the Torrance Site, 1979-1980 


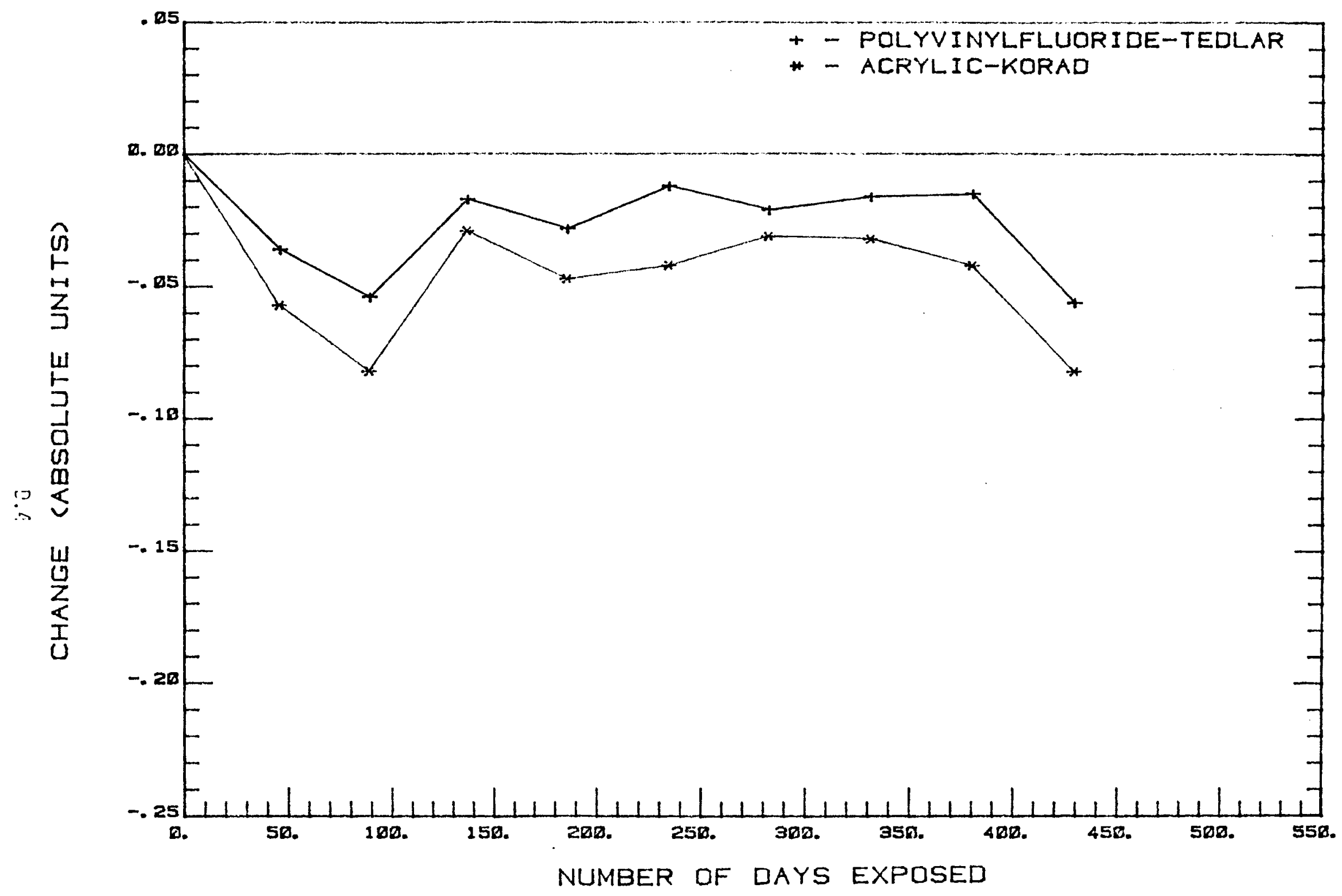
FIGURE D.4. Effects of Atmospheric Contamination on the Solar Weighted Diffuse Reflectance $\left(-\Delta R_{D}\right)$ of
Polymers Weathered at the Torrance Site, 1979-1980 


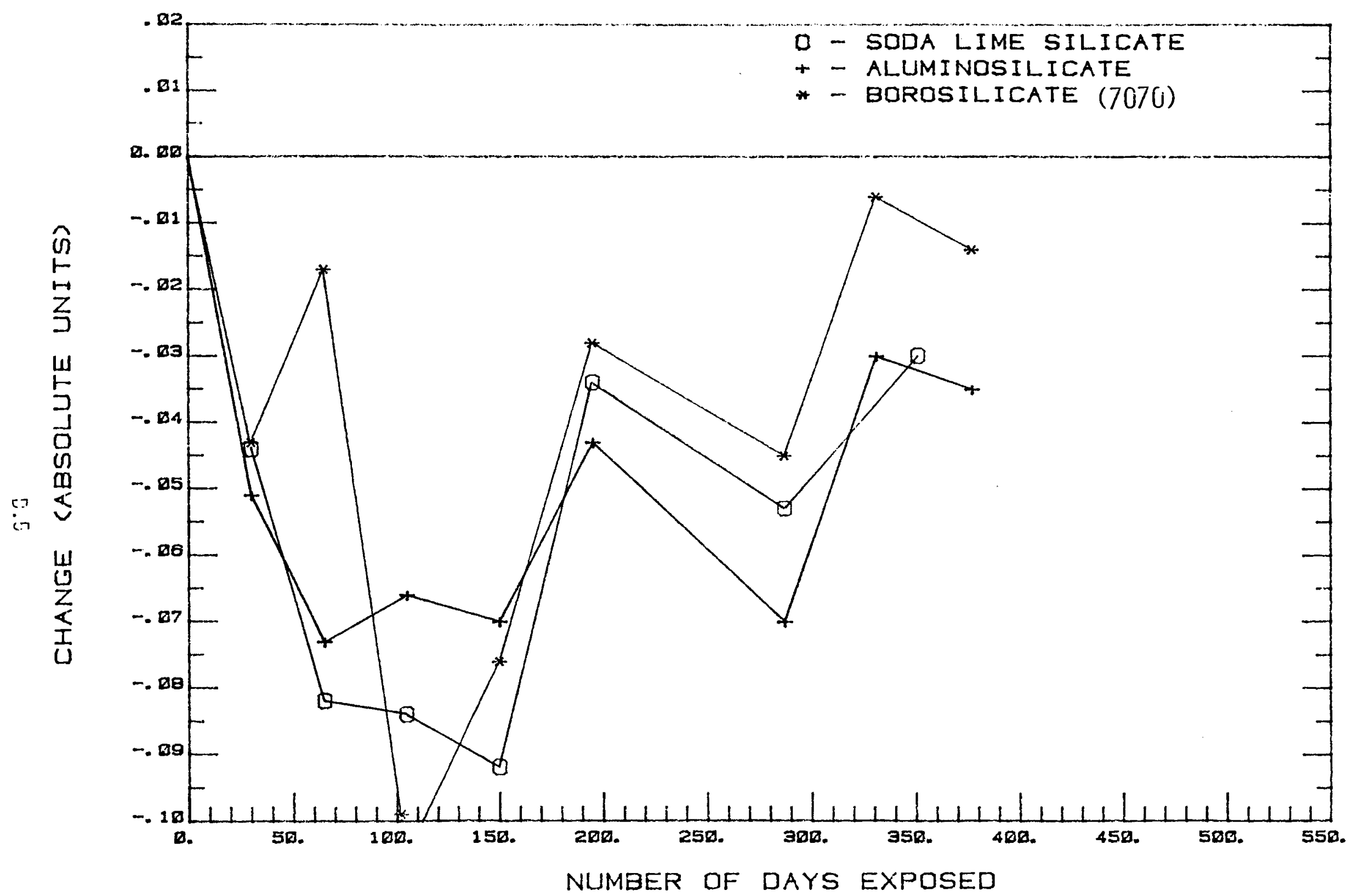

FIGURE D.5. Effects of Atmospheric Contamination on the Solar Weighted Transmittance $\left(\Delta T_{H}\right)$ of Glasses Weathered at the Pasadena Site, 1979-1980 


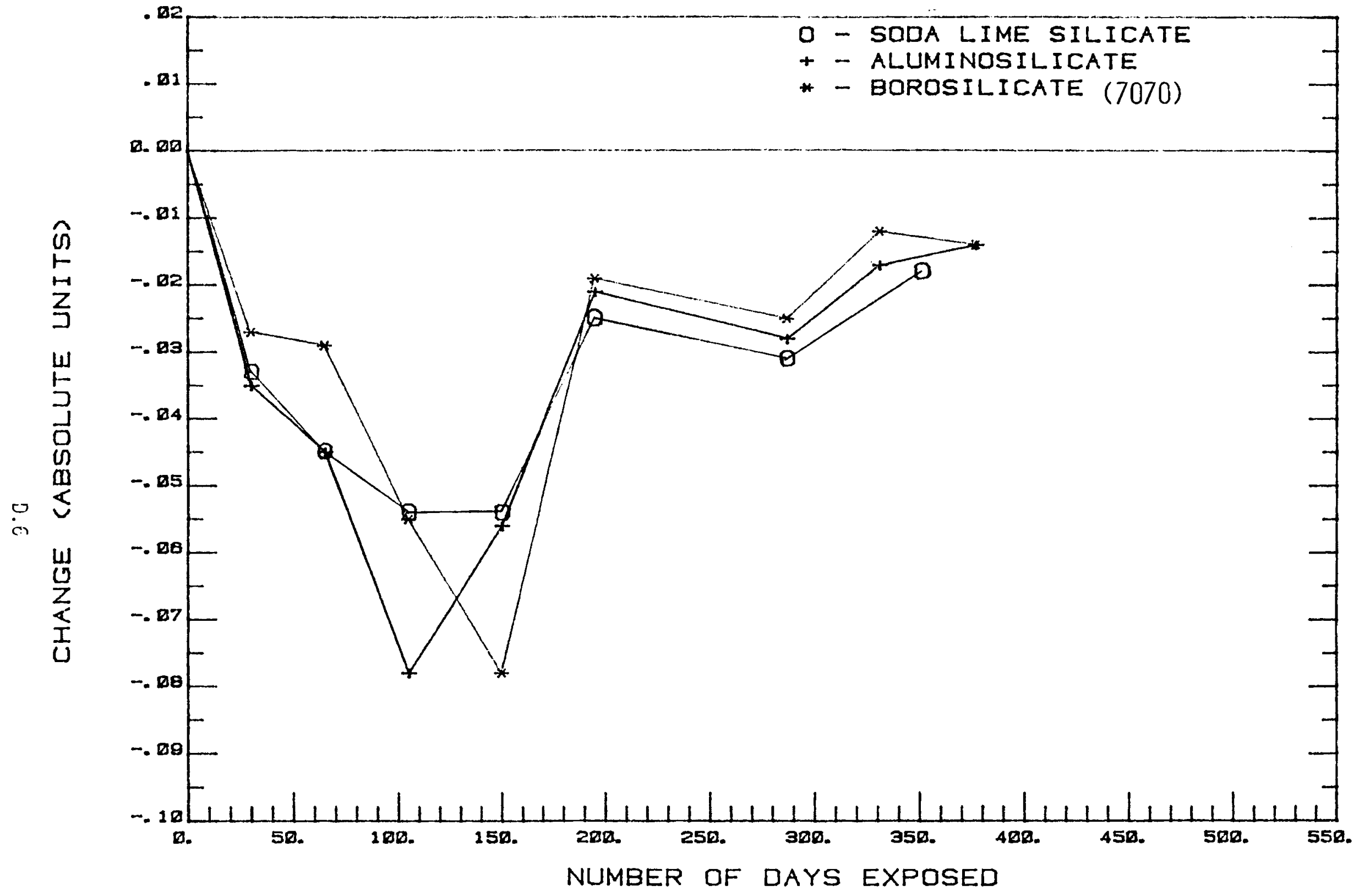

FIGURE D.6. Effects of Atmospheric Contamination on the Solar Weighted Diffuse Reflectance (- $\Delta R_{D}$ ) of Glasses Weathered at the Pasadena Site, 1979-1980 


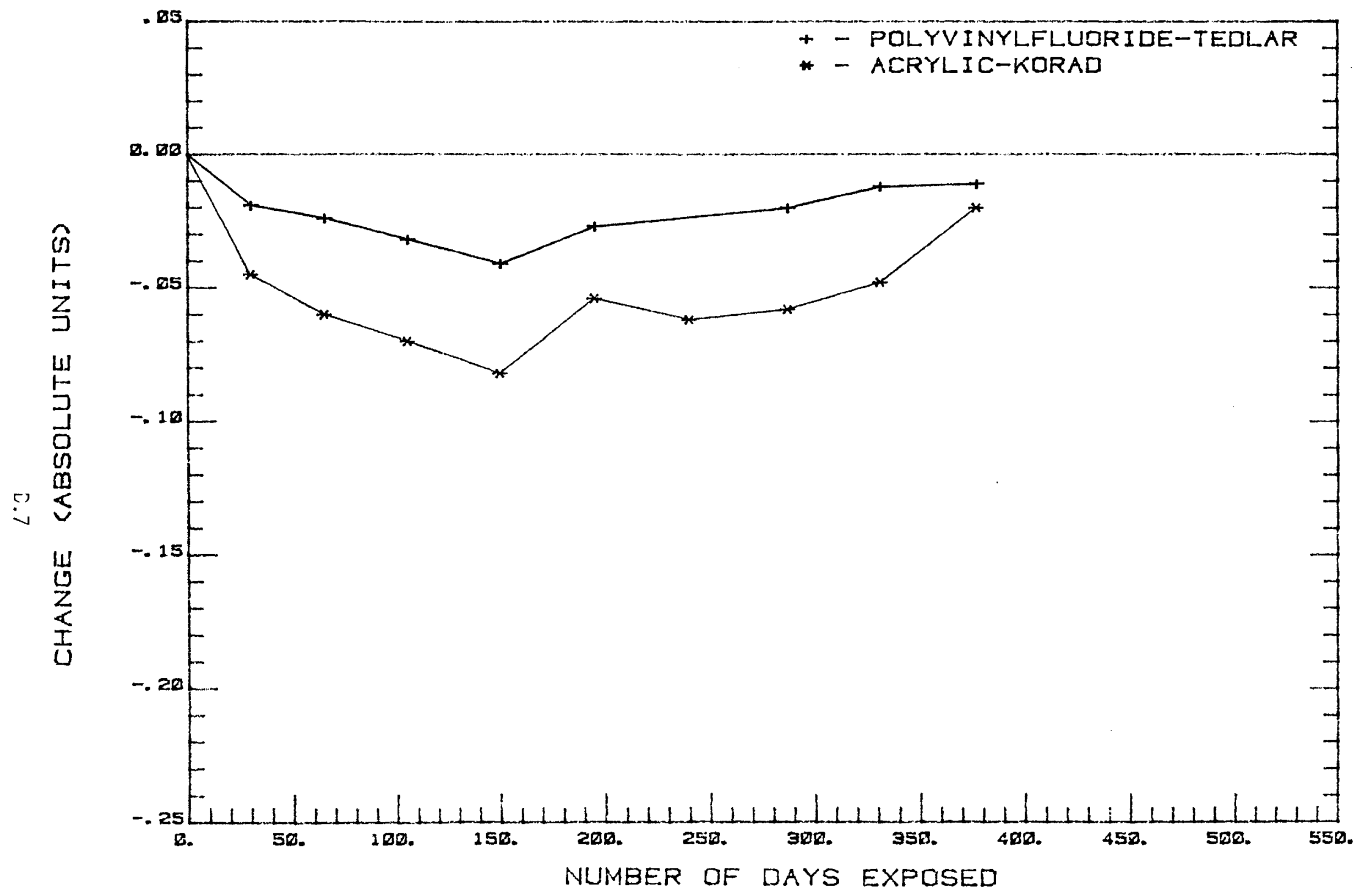
FIGURE D.7. Effects of Atmospheric Contamination on the Solar Weighted Diffuse Reflectance (- $\left.\triangle R_{D}\right)$ of
Polymers Weathered at the Pasadena Site, 1979-1980 


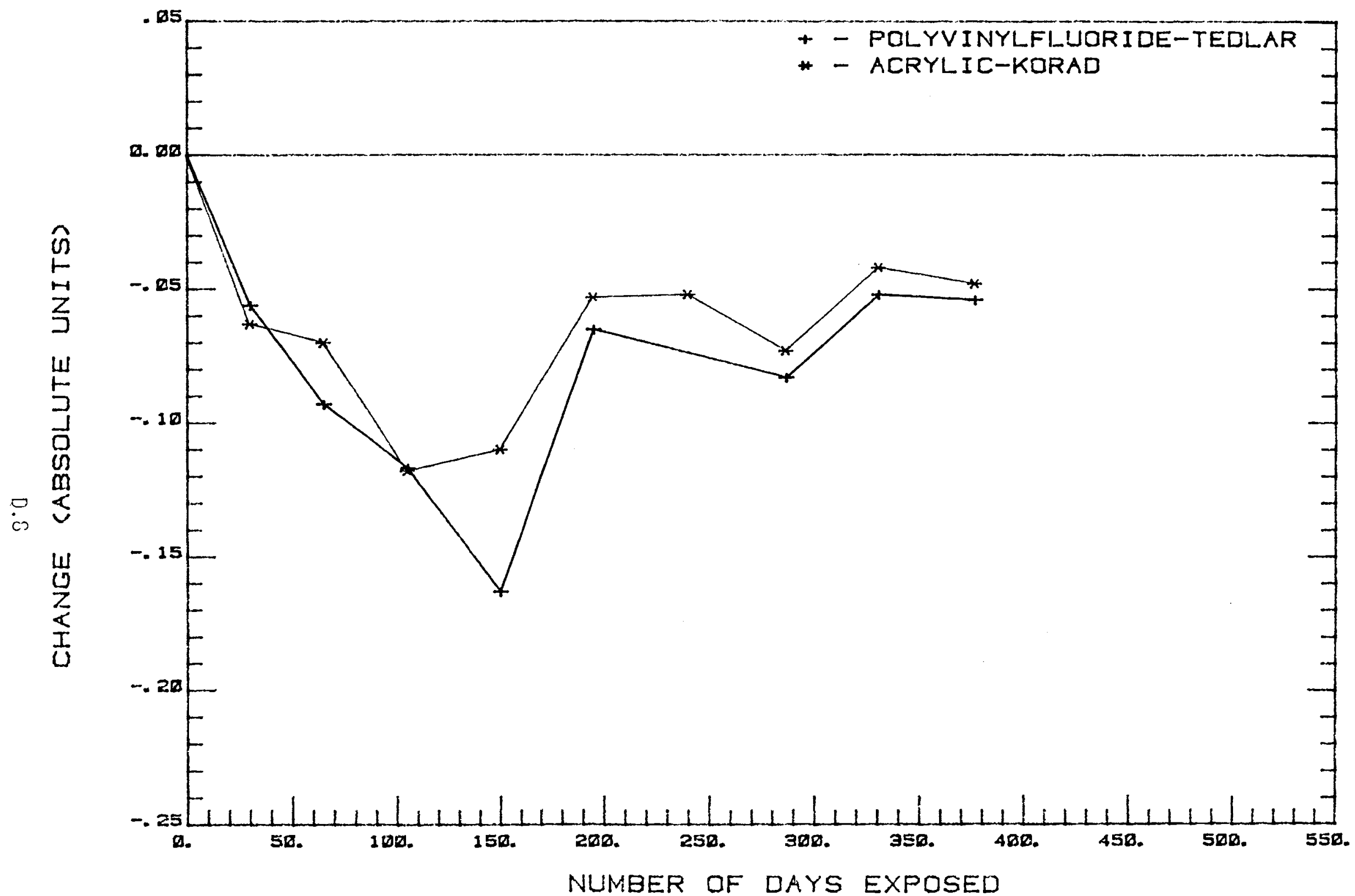

FIGURE D.8. Effects of Atmospheric Contamination on the Solar Weighted Transmittance $\left(\Delta T_{H}\right)$ of Polymers Weathered at the Pasadena Site, 1979-1980 


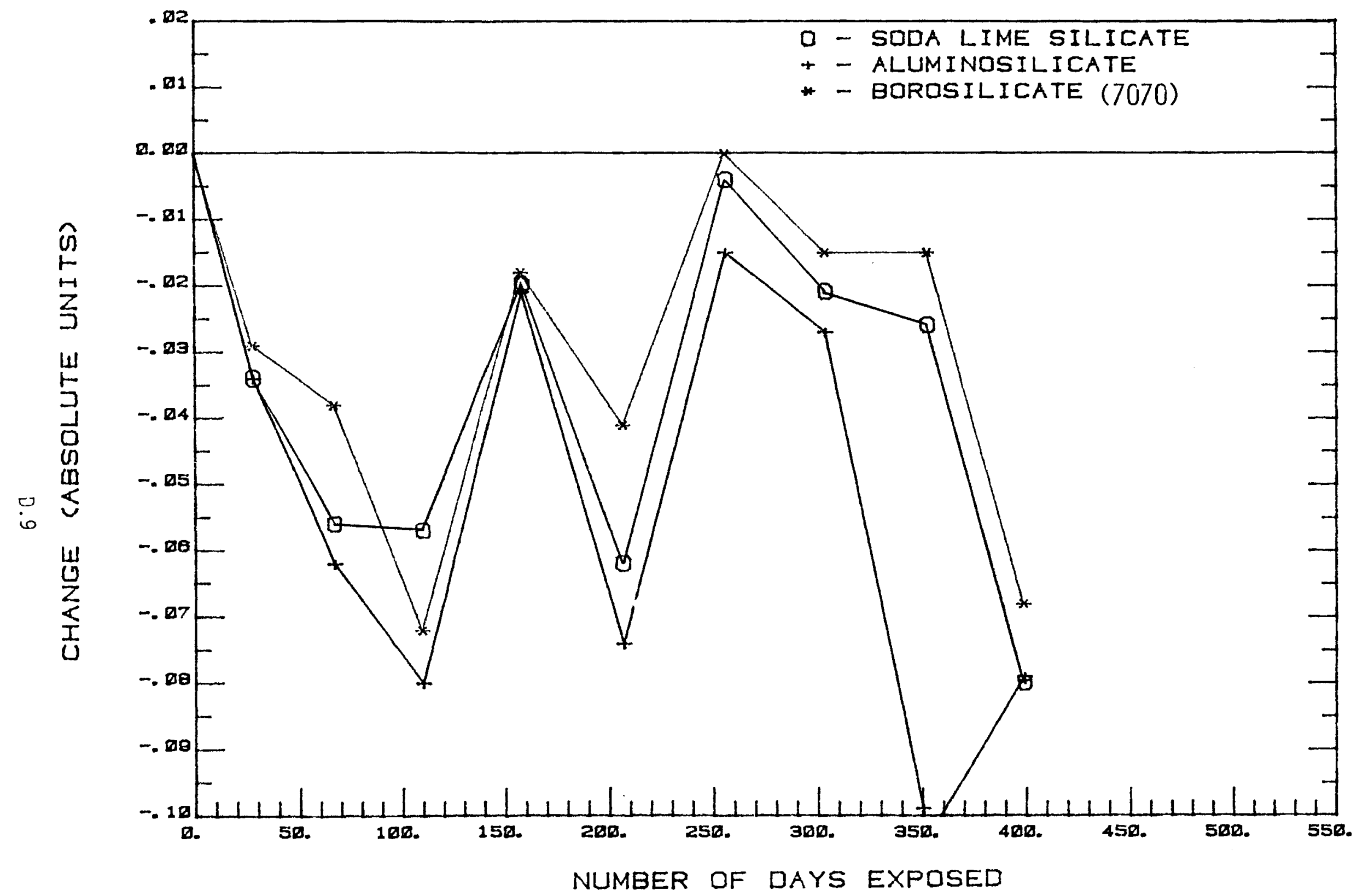

FIGURE D.9. Effects of Atmospheric Contamination on the Solar Weighted Transmittance $\left(\Delta T_{H}\right)$ of Glasses Weathered at the Point Vicente Site, 1979-1980 


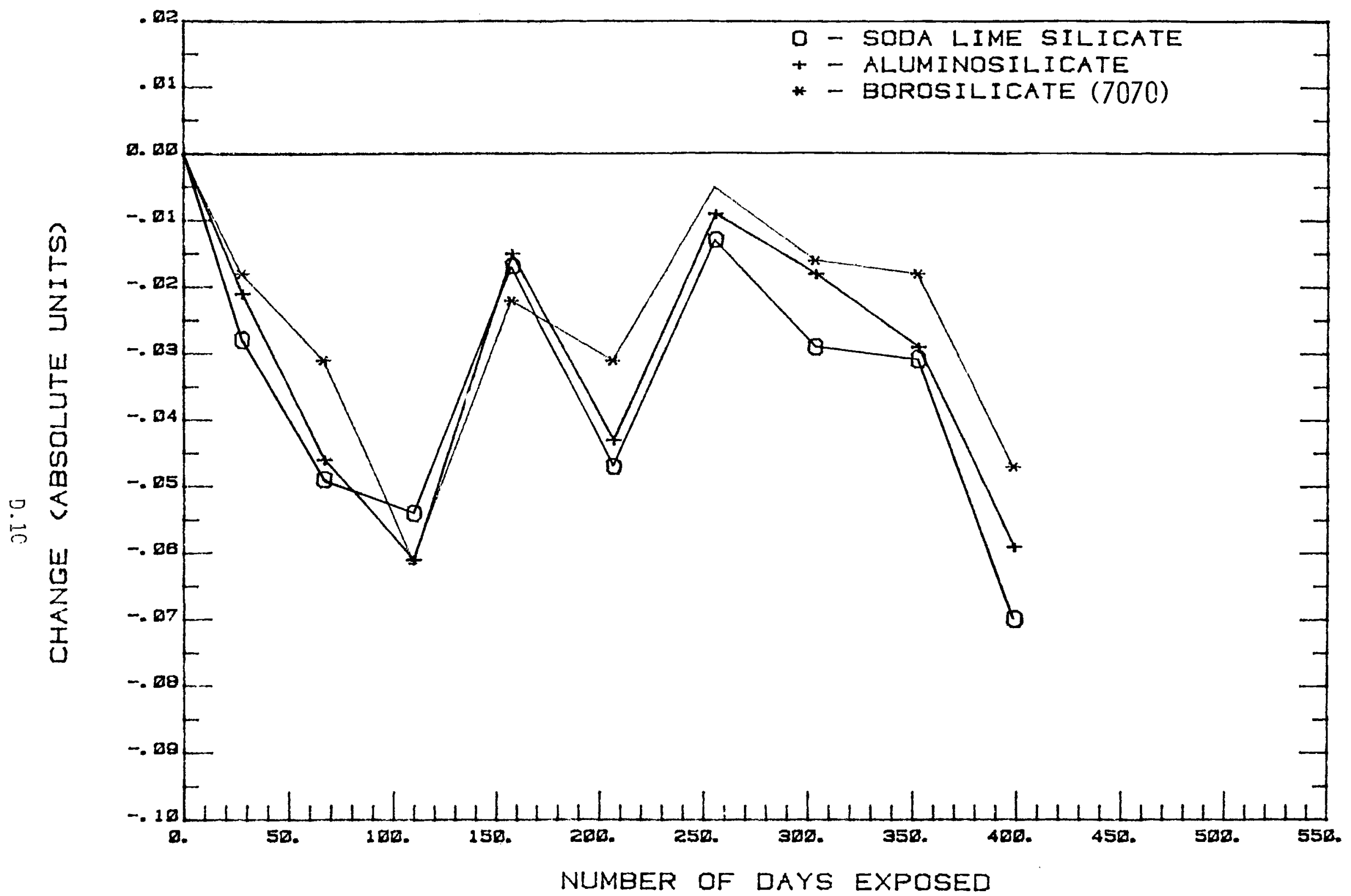
FIGURE D.10. Effects of Atmospheric Contamination on the Solar Weighted Diffuse Reflectance (- $\left.\triangle R_{D}\right)$ of Glasses
Weathered at the Point Vicente Site, 1979-1980 


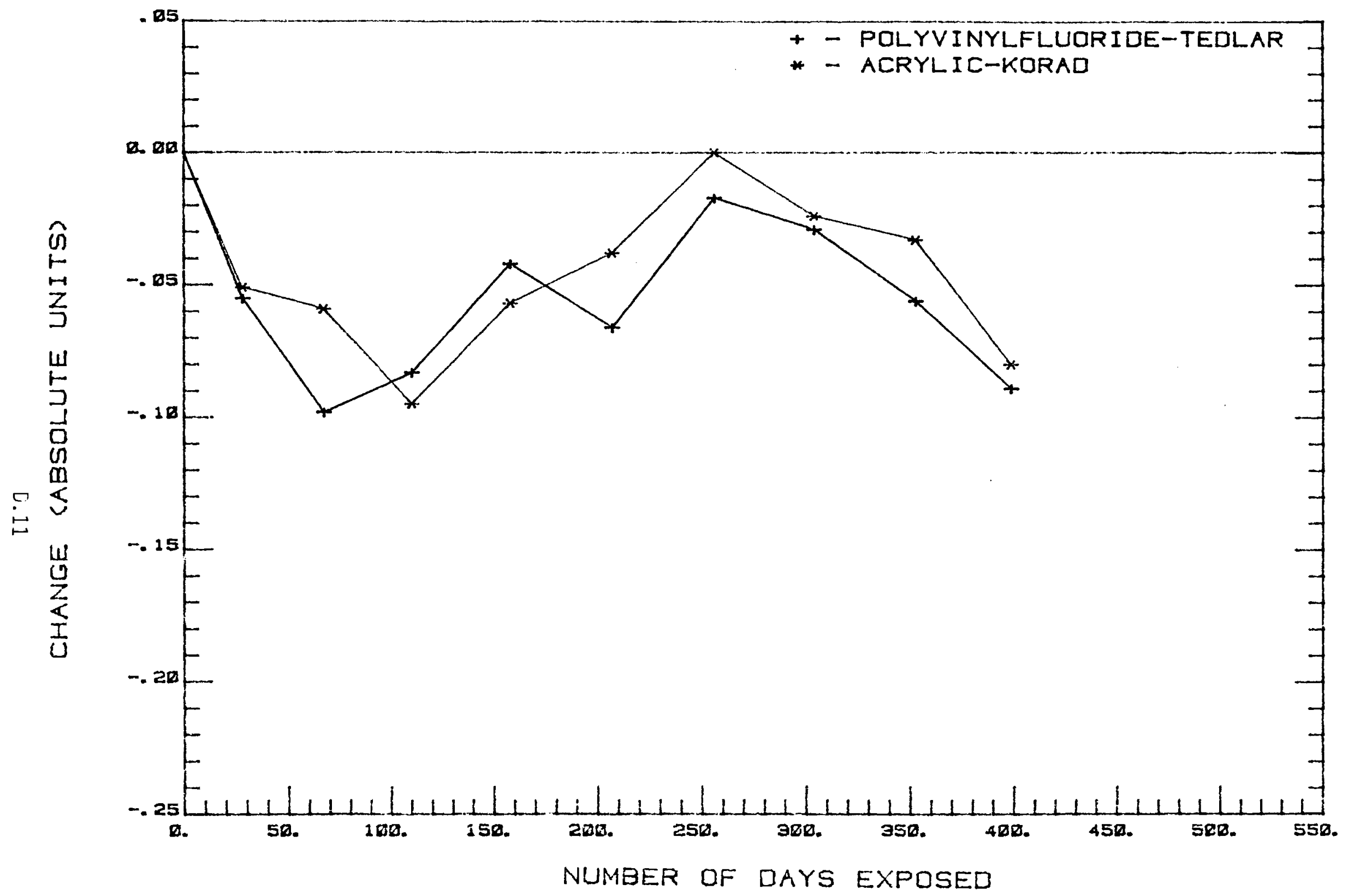

FIGURE D.11. Effects of Atmospheric Contamination on the Solar Weighted Transmittance $\left(\Delta T_{H}\right)$ of Polymers Weathered at the Point Vicente Site, 1979-1980 


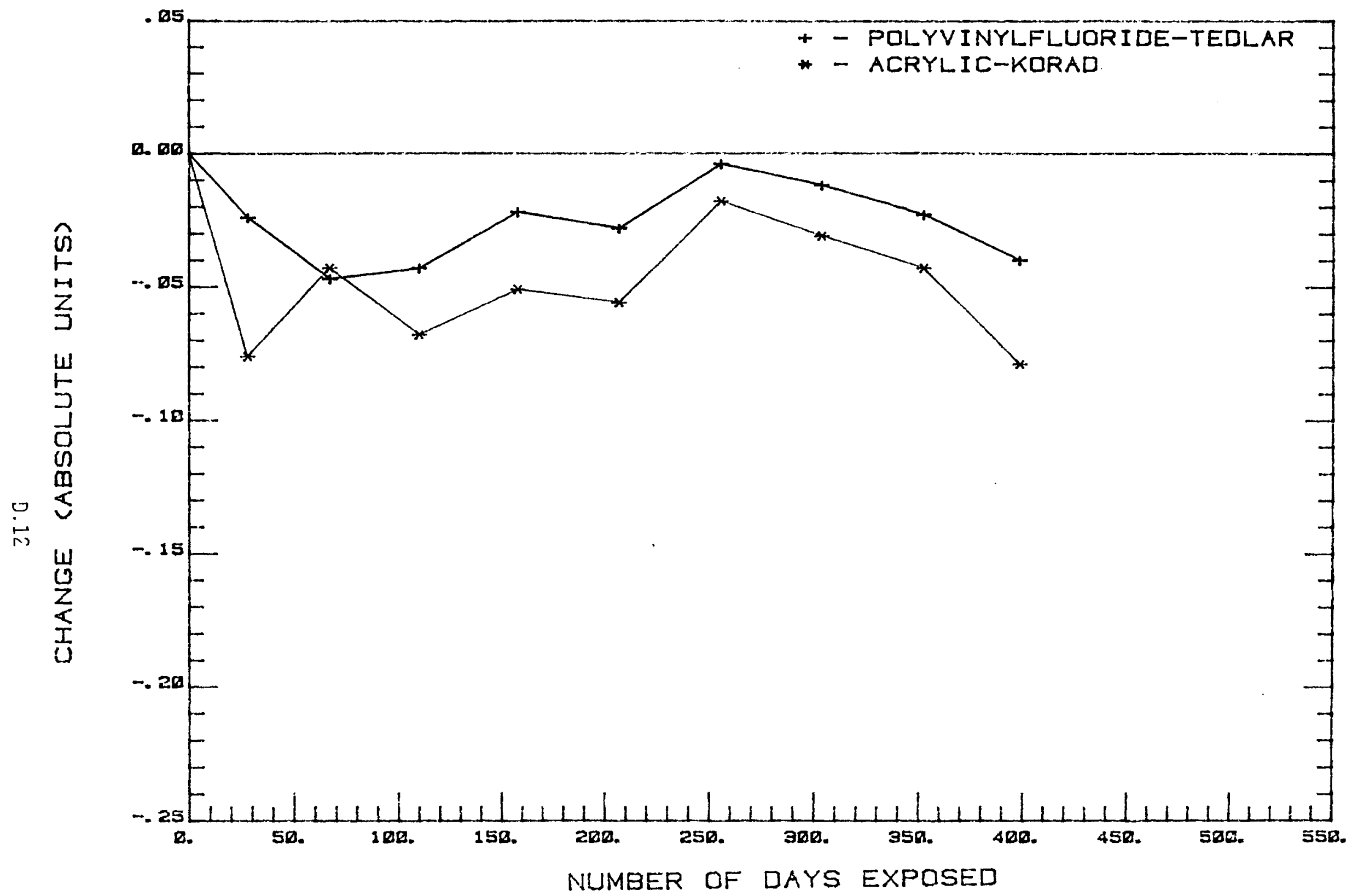

FIGURE D.12. Effects of Atmospheric Contamination on the Solar Weighted Diffuse Reflectance (- $\left.\Delta R_{D}\right)$ of Polymers Weathered at the Point Vicente Site, 1979-1980 


\section{DISTRIBUTION}

No. of

Copies

OFFSITE

27 Technical Information Center

B. Ackerman

Corning Glass Works

Ma in Plant, Bldg. 8-5

Corning, NY 14830

M. Adams

Jet Propulsion Laboratory

4800 Oak Grove Drive

Pasadena, CA 91108

J.F. Banas, 4722

Sandia Laboratories

Box 5800

Albuquerque, NM 87115

M. Berry

Boeing Engr. and Const.

P.0. Box 3707

Seattle, WA 98124

J. Bigger

Electric Power Research Insti.

P.0. Box 10412

Palo Alto, CA 93403

F. Blake

Northrup, Inc., Blake Lab.

Suite 306

7061 S. University Blvd.

Littleton, CO 80122

T. Blaney

Sunpower Systems Corp.

510 So. 52nd Street

Tempe, AR 85281

F.L. Bouquet

Jet Propulsion Laboratory

4800 Oak Grove Drive

Pasadena, CA 91108
No. of

Copies

G. Braun

DOE Division of Solar Technology

Forrestahl Building

Washington, DC 20545

C.J. Brinker, 5845

Sandia Laboratories

Box 5800

Albuquerque, NM 87115

T.D. Brumleve, 8451

Sandia Laboratories

Livermore, CA 94550

V. Burolla

Sandia Laboratories

Livermore, CA 94550

Ken Busche

Busche Energy Systems

7288 Murdy Circle

Huntington Beach, CA 92647

B. Butler

Solar Energy Research Institute 1536 Cole Boulevard

Golden, CO 80401

P. Cal1

Solar Energy Research Institute

1536 Cole Boulevard

Golden, CO 80401

R.E. Cambron

Springborn Laboratories

Water Street

Enfield, CT 06082

W. Carroll

Jet Propulsion Laboratory

4800 0ak Grove Drive

Pasadena, CA 91108

A.A. Churm

DOE Chicago Patent Group

9800 South Cass Avenue

Argonne, I1 60439 
No of

Copies

E. Clark

National Bureau of Standards

Washington, DC 20234

N.H. Clark, 1415

Sandia Laboratories

Box 5800

Albuquerque, NM 87115

G. Cottingham

Brookhaven National Lab.

Upton, NY 11973

T. Coyle

Solar Energy Research Insti.

1536 Cole Boulevard

Golden, CO 80401

E. Cuddihy

Jet Propulsion Laboratory

4800 Oak Grove

Pasadena, CA 91108

D. Culler

Gardner Mirror Corp.

P.0. Box 638, Hwy. 268E.

N. Wilkesboro, NC 28659

A. Czanderna

Solar Energy Research Insti.

1536 Cole Boulevard

Golden, CO 80401

W.R. Delameter, 8451

Sandia Laboratories

Livermore, CA 94550

E.J. Dempsey

London Laboratories Limited

Box 3637

Woodbridge, CT 06525

C.R. Easton

McDonnel1 Douglas

Astronautics Co.

5307 Bolsa Avenue

Huntington Beach, CA 92647
No of

Copies

P.J. Eicker, 8326

Sandia Laboratories

Livermore, CA 94550

S.D. Elliott

DOE San Francisco Operations office

1333 Broadway

Wells Fargo Building

Oakland, CA 94612

R.A. England

Martin Marietta

MS S0403

P.0. Box 179

Denver, CO 80201

H.E. Felix

Solaramics, Inc.

1301 El Segundo Blvd.

El Segundo, CA 90245

C.R. Frownfelter

PPG Industries, Inc.

One Gateway Center

Pittsburg, PA 15222

John Garate

General Electric

1 River Road

Schenectady, IY 12345

R. Gillette

MS 9A-46

Boeing Engr. and Const.

P.0. Box 3707

Seattle, WA 98124

D. Gray

Black \& Veatch

P.5.D. 5

P.0. Box 8405

Kansas City, MC 64114

R.H. Griffin

General Electric

1 River Road

Schenectady, NY 12345 
No. of

Copies

G. Gross

Solar Energy Research Insti.

1536 Cole Boulevard

Golden, CO 80401

B. Gupta

Solar Energy Research Insti.

1536 Cole Boulevard

Golden, C0 80401

M.U. Gutstein

DOE Division of Solar Tech.

Forrestahl Building

Washington, DC 20545

R. Hobbs

General Electric Company

P.0. Box 8661, Room 7310

Philadelphia, PA 19101

P.L. Hofmann

Battelle

505 King Avenue

Columbus, $\mathrm{OH} 43201$

L. Hornberger

Acurex Corporation

485 Clyde MS2-2240

Mountain View, CA 94042

Richard Horton

General Electric

1 River Road

Schenectady, NY 12345

C.G. Howard

Booz, Allen \& Hamilton, Inc.

8801 E. Pleasant Valley Road

Cleveland, $\mathrm{OH} 44131$

W. Jankowski

Engelhard Industries

1 West Central Avenue

E. Newark, NJ 07029

E.L. Katz

Aerospace Corporation

Solar Thermal Projects

Energy Systems Group

P.0. Box 92957

Los Angeles, CA 90009
No. of

Copies

Ernie Lam

Bechtel National Inc.

MS 50/16

P.0. Box 3965

San Francisco, CA 94119

S. Lamensdorf

Binswanger Mirror Co.

1355 Lynnfield Road

Suite 205

P.0. Box 17127

Memphis, TN 38117

C.M. Lampert

Lawrence Berkeley Laboratory

Building 62, Room 235

University of California

Berkeley, CA 94720

J.A. Leonard, 4725

Sandia Laboratories

Box 5800

Albuquerque, NM 87115

I.E. Lewis

Ford Aerospace

3939 Fabian Way

Palo Alto, CA 94303

K. Masterson

Solar Energy Research Institute 1536 Cole Boulevard

Golden, CO 80401

C.L. Mavis

Sandia Laboratories

Livermore, CA 94550

Mrs. McHugh

Sanders Associates

95 Canal Street

MS MER 12-1214

Nashua, NH 03061

J. Megland

PRC 1 EAC

7600 01d Springhouse Road

McClaine, VA 22102

C. R. Maag (5)

4800 Oak Grove Drive

Pasadena, CA 91103 
No. of

Copies

Walter Moore

Veda, Inc.

400 N. Mobi1, B1dg. D

Camaril1o, CA 93010

V. Morris

McDonnel 1 Douglas

5301 Bolsa Avenue

Huntington Beach, CA 92647

E. Nelson

ACUREX Corporation

485 Clyde Avenue

Mountain View, CA 94042

L.P. 01dham

Martin Marietta Corp.

MS S8120

P.0. Box 179

Denver, CO 80201

R. Pettit, 5842

Sandia Laboratories

Box 5800

Albuquerque, INM 87115

J.A. Pietsch

Northrup, Incorporated

302 Nichols Drive

Hutchins, TX 75141

P. Roth

Sandia Laboratories

Box 5800

Albuquerque, NM 87115

J. Schrauth

Jena Glaswerk Schoot

\& Gen., Inc.

11 East 26th Street

New York, NY 10010

J.C. Schumacher

Schumacher \& Associates

2550 Fair Oaks Blvd., Suite 120

Sacramento, CA 95825 ivo of

Copies

R.N. Schweinberg

DOE San Francisco Operations Office

1333 Broadway

Wells Fargo Building

Oakland, CA 94612

J. Shelby

Sandia Laboratories

Livermore, CA 94550

A.F. Shoemaker

Corning Glass Works

Corning, NY 14830

John Thornton

Solar Energy Research Institute

1536 Cold Boulevard

Golden, CO 80401

W. Tomlinson

Environmental Library

758 Eddy Street

University of Montana

Missoula, MT 59812

P. Tremblay

Foster-Miller Associates

135 Second Avenue

Wa] tham, MA 02154

R.R. Walters

E. Systems

Energy Technology Center

P.0. Box 6118

Dallas, TX 75222

J.D. Walton, Jr.

Engineering Experiment Station

Georgia Institute of Technology

Atlanta, GA 30332

R.C. Wayne, 8450

Sandia Laboratories

Livermore, CA 94550 
No of

Copies

L. Weinstein

McDonnel 1 Douglas Astronautics Co. 5301 Bolsa Avenue

Huntington Beach, CA 92647

S. White, 8451

Sandia Laboratories

Livermore, CA 94550

W.G. Wilson

Sandia Laboratories

Livermore, CA 94550
No of

Copies

ONSITE

2 DOE Richland Operations Office

H.E. Ransom

R. Stewart

44 Pacific Northwest Laboratory

L.S. Dake (24)

K. Drumheller

J.S. Hartman

M.A. Lind (10)

A.M. Sutey

Publishing Coordination

Technical Information 
